Felipe Silva Semaan

\title{
Desenvolvimento de estratégias analíticas para determinação do anti-hipertensivo furosemida
}

Tese apresentada ao Instituto de Química de São Carlos, da Universidade de São Paulo, como um dos requisitos para obtenção do título de Doutor em Ciências (Química Analítica)

Orientador: Prof. Dr. Éder Tadeu Gomes Cavalheiro

São Carlos

2007 
Dedicatória

Dedico esta tese aos meus pais William Miguel e Isabel Cristina, ao meu irmão Gustavo Semaan e à minha namorada Francesca Dell'Olio. Tenho em vocês meu alicerce e exemplo de vida a ser seguido. Amo muito todos vocês. 


\section{Agradecimentos}

Agradeço primeiramente a Deus, por me derrubar e erguer, nos momentos necessários.

Agradeço à minha família, em especial aos meus pais e ao meu irmão, por todo o amor, carinho e apoio e compreensão.

Agradeço à minha namorada Frá, que mesmo distante esteve sempre junto de mim. Pelo amor, carinho, incentivo e paciência.

À minha família são-carlense: Alexandre, Sandra, Paulo, Leninha, Dona Laura, Sr. Luiz.

Ao Prof. Dr. Éder T.G. Cavalheiro, primeiramente pela confiança, pela orientação, incentivo, amizade e discussões.

Ao Prof. Dr. Gilberto Chierice pela disponibilidade do laboratório e pela amizade e estímulo.

Aos grandes amigos Álvaro José dos Santos Neto, Ronaldo Spezia Nunes e Rogério Adelino de Sousa, pelas discussões, apoio e amizade.

Ao Prof. Dr. Christopher Michael Ashton Brett, e sua esposa, Prof. Dra. Ana Maria Oliveira-Brett, pela carinhosa acolhida em seus laboratórios, e pela atenciosa supervisão durante estágio na Universidade de Coimbra.

Aos amigos do LATEQS e GQATP: Ana Paula, Marcelo, Naíse, Gabi, Dani Oshita, Luciana (tia Lu), Pri, Milena, Rita, Ivana, Lucinéia, Carol, Amanda, Isabel, Juliana (Bärbie), Luiz (tio Lu), Érika, André, Grazi, Érica, Sandra, Braba, Bruno, Júnia, Erik, Paulo, Rafael, Toninho, Marli, Salvador, Glimaldo, Avaré. Ao colega Tony (CAASO), pelas caricaturas.

Aos amigos da Universidade de Coimbra: Edilson, Madalina, Madi, Carla, João, Adrian, Carlão, Victor, Oanna, Patrícia e Ana Maria.

Aos técnicos da CAQI, pela disponibilidade e auxílio; à Andréia, Silvia, Fátima, Eliana, Bernadete, Regina e demais secretárias e bibliotecárias do IQSC, sempre muito atenciosas e prestativas.

Ao CNPq (Mestrado, 131284/04-5), FAPESP (Doutorado Direto, 04/08550-0) e CAPES (Doutorado Sandwich, 2670/06-2), pelas bolsas concedidas.

E a todos que contribuíram indiretamente... 
"Faça as coisas o mais simples, não as mais simples." Albert Einstein
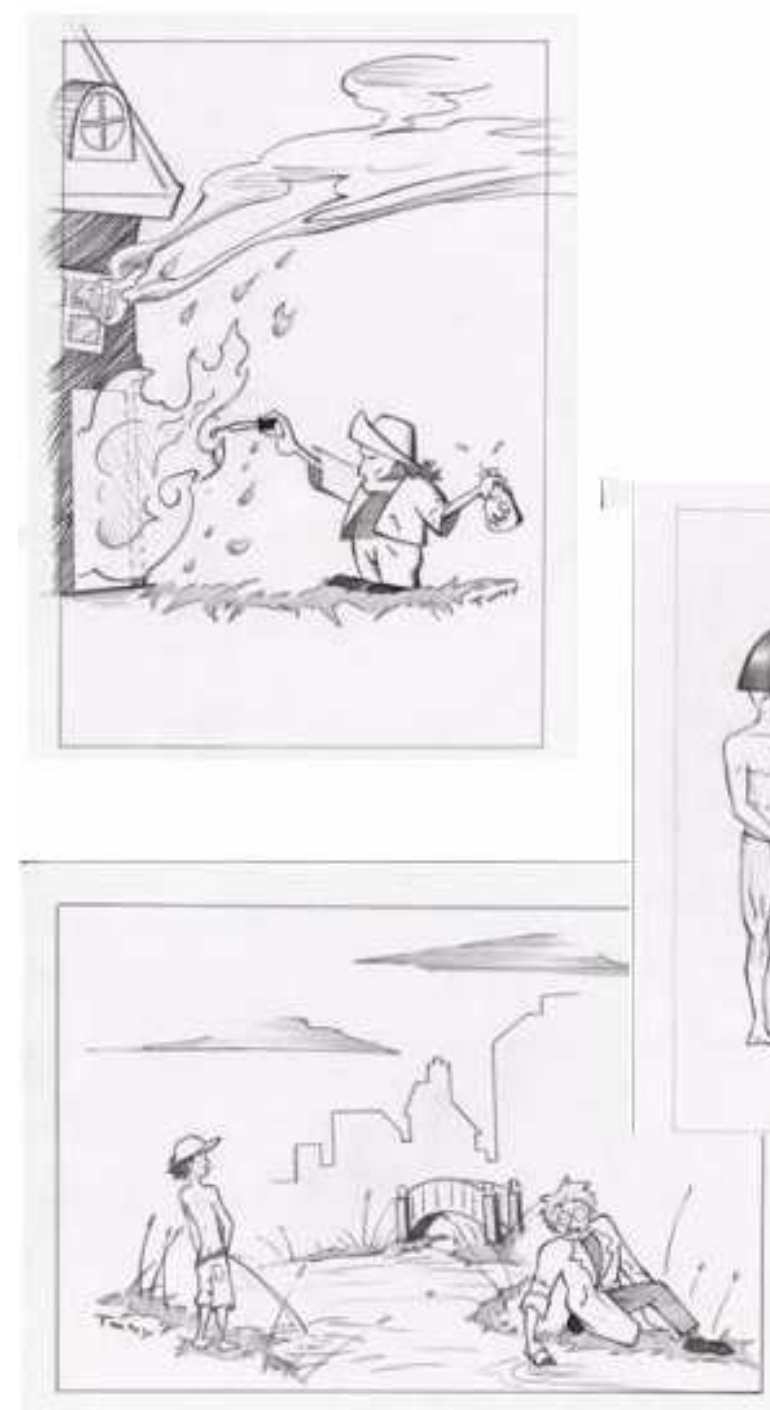
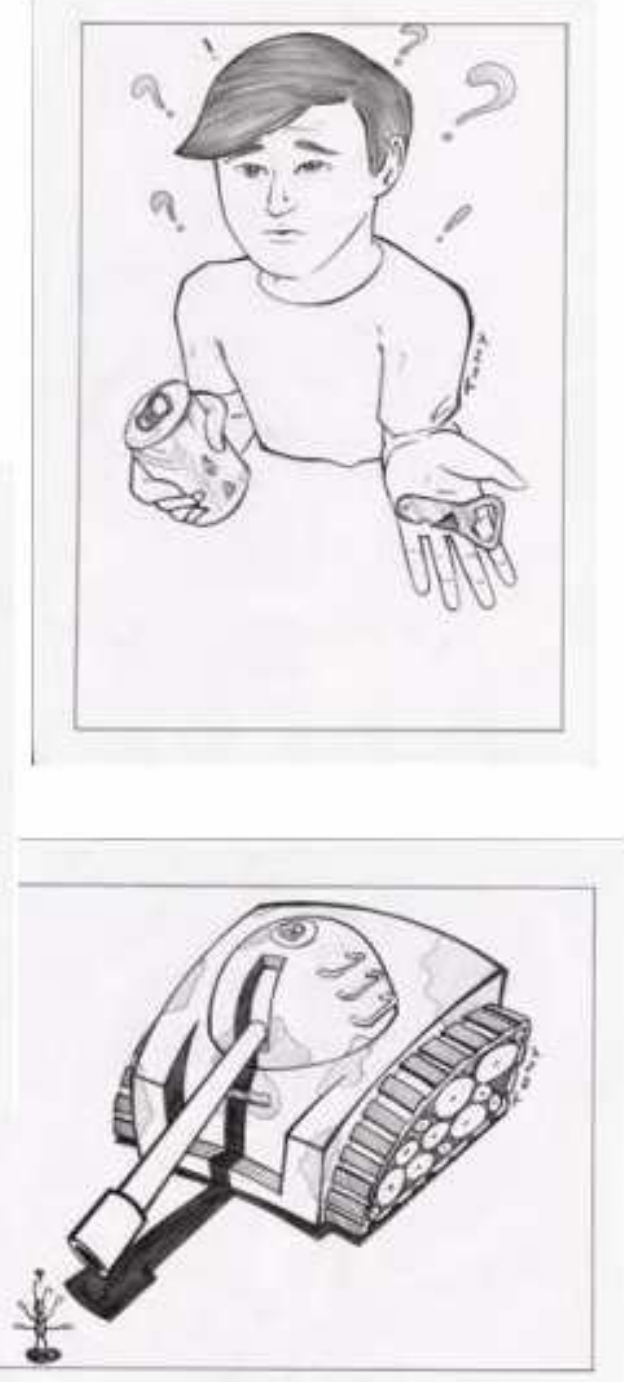

"A simplicidade é o último estágio da sofisticação."

Leonardo da Vinci 


\section{Resumo}

O presente trabalho teve por objetivo o desenvolvimento e aplicação de diferentes procedimentos para quantificação do fármaco furosemida, explorando suas reações e características físicas. Os métodos apresentados podem ser divididos em estáticos e em fluxo. Dentre os procedimentos estáticos utilizou-se a titrimetria de óxido-redução, a qual explorou as reações de hidrólise e oxidação do fármaco; a determinação espectrofotométrica em batelada, que explorou a reação de complexação com íons $\mathrm{Fe}^{3+}$, e a determinação empregando métodos eletroanalíticos, como voltametria cíclica, de pulso diferencial e de onda quadrada, nos quais o comportamento eletroquímico do analito foi explorado. Todos os procedimentos estáticos serviram de base para o desenvolvimento de procedimentos dinâmicos, em fluxo, visando minimizar a manipulação de padrões e amostras, bem como reduzir o consumo de reagentes e soluções, a geração de resíduos e aumentar a freqüência analítica. Com relação aos procedimentos dinâmicos foram realizados experimentos empregando detectores espectrofotométricos com base em reações de óxido-redução e complexação, fluorimétricos, com base na emissão pelo analito quando excitado e no seu aumento em ambientes micelares, e eletroanalíticos, com base na hidrólise e oxidação do fármaco em meios adequados. Observou-se, como previsto, perda de sensibilidade nos métodos dinâmicos quando comparados aos procedimentos estáticos, porém com aumento na freqüência analítica, redução de custos operacionais, minimização na manipulação das soluções. Os resíduos gerados foram reaproveitados na maioria dos casos. Todos os procedimentos descritos foram aplicados a amostras comerciais e/ou material biológico sintético, com 
resultados satisfatórios quando comparados estatisticamente aos obtidos para mesma amostra por meio de método oficial. Ensaios de adição e recuperação demonstraram, também, a aplicabilidade das estratégias apresentadas; não foram observadas interferências dos demais constituintes das formulações farmacêuticas.

Palavras-chave: furosemida, estratégias analíticas, análise por injeção em fluxo. 


\section{Abstract}

The development and application of different procedures for the quantification of the drug furosemide, exploiting its reactions and physical properties are described. The presented methods were based in static and flow injection procedures. Among the static redox procedures titrimetry was applied, which exploited the hydrolysis and oxidation reactions of this drug; batch spectrophotometric determination was carried out applying the complexation between furosemide and ferric ions and, electroanalytical determinations, by cyclic, differential pulse and square wave voltammetry, were developed exploiting the electrochemical behavior of the analyte. All the static procedures were used as base to the development of flow injection methods, aiming to minimize the manipulation of standards and samples, as well as to reduce the reagent and solutions consumes and the waste generation, and to improve the analytical frequency. Based on the flow injection procedures some experiments were developed using spectrophotometric detectors, applying redox and complexation reactions; fluorimetric detectors, based on the fluorescence emission generated by the analyte when excited and exploiting its improvement by micellar media; and electrochemical detectors, based on the hydrolysis and oxidation under suitable conditions. Lost of sensitivity could be observed in the flow injection procedures, on the other hand, improvement on analytical frequency, reduction on operational costs and minimization on solutions handling could also be noted. The waste generated was reused in the majority of the cases. All the procedures described were applied to commercial samples and/or synthetic biological material, with satisfactory results when statistically 
compared to those obtained by a reference method to the same samples. Recovery tests also demonstrated the applicability of the developed strategies. Interference from the constituents of the pharmaceutical formulations was not observed.

Keywords: furosemide, analytical strategies, flow injection analysis. 


\section{Lista de Figuras}

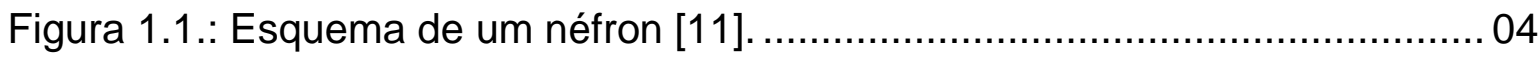

Figura 1.2.: Fórmula estrutural da furosemida....................................... 05

Figura 3.1.: Espectro da furosemida na região do infravermelho em pastilhas de $\mathrm{KBr}$ a $1 \%(m / m)$. 13

Figura 3.2.: Espectro de $\mathrm{RMN}{ }^{1} \mathrm{H}$ da furosemida padrão. 14

Figura 4.1.: Solubilidade estimada para a furosemida em função da concentração de SDS em solução. 25

Figura 5.1.: Espectro de absorção de uma solução de furosemida $10^{-5} \mathrm{~mol} \mathrm{~L}^{-1}$, em etanol. 28

Figura 5.2.: Espectros de absorção do etanol e de soluções contendo apenas furosemida $0,01 \mathrm{~mol} \mathrm{~L}^{-1}, \mathrm{FeCl}_{3} \cdot 6 \mathrm{H}_{2} \mathrm{O} 0,01 \mathrm{~mol} \mathrm{~L}^{-1}$ e $\mathrm{FeCl}_{3} \cdot 6 \mathrm{H}_{2} \mathrm{O} 0,01 \mathrm{~mol} \mathrm{~L}^{-1}$ na presença de Fr 0,01 $\mathrm{mol} \mathrm{L}^{-1}$. 30

Figura 5.3.: Curva analítica para a furosemida usando a reação de complexação com $\mathrm{Fe}^{+3}$, em etanol, com absorbância medida em 513 nm. 31

Figura 5.4.: Curva de adição de padrão para determinação de furosemida em comprimidos da marca Cinfa ${ }^{\circledR}$, como exemplo.

Figura 6.1.: Diagrama esquemático para o sistema em fluxo empregado neste trabalho. $\mathrm{C}$ = fluido carregador $\left(2,2 \mathrm{~mL} \mathrm{~min}^{-1}\right), \mathrm{S}=$ injeção de brancos, padrões ou amostras, I = injetor-comutador, $\mathrm{R}$ = reator termostatizado, Deb. = desborbulhador de vidro em "T", $\mathrm{D}=$ detector e $\mathrm{W}=$ descarte. 36

Figura 6.2.: Variação dos sinais de absorbância em função da temperatura. .... 38 
Figura 6.3.: Intervalo linear para determinação (padrões de furosemida de A a $\mathrm{K}, \mathrm{mol} \mathrm{L}^{-1}: \mathrm{A}=1,5 \times 10^{-4}, \mathrm{~B}=2,9 \times 10^{-4}, \mathrm{C}=5,8 \times 10^{-4}, \mathrm{D}=8,7 \times 10^{-4}$, $E=1,2 \times 10^{-3}, F=1,5 \times 10^{-3}, G=1,7 \times 10^{-3}, H=2,0 \times 10^{-3}, I=2,3 \times 10^{-3}$, $\mathrm{J}=2,9 \times 10^{-3}, \mathrm{~K}=3,0 \times 10^{-3}$, Z é o branco). 39

Figura 6.4.: Variação da absorbância em função da concentração de furosemida 40

Figura 6.5.: Sinais gerados pelo branco $(Z)$, padrões de furosemida $(A-F$, mol L $L^{-1}: A=1,0 \times 10^{-4}, B=2,0 \times 10^{-4}, C=3,1 \times 10^{-4}, D=4,1 \times 10^{-4}$, $E=5,1 \times 10^{-4}$ e, $F=6,1 \times 10^{-4}$ ) e amostras (1: Lasix ${ }^{\circledR}$ ampolas; 2: Lasix $^{\circledR}$

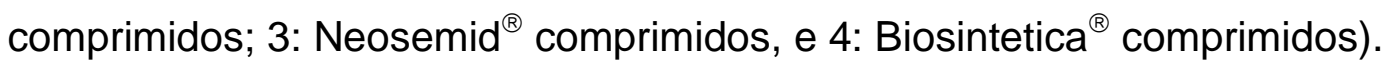
41

Figura 6.6.: Sistema em fluxo empregado: $A=\mathrm{Fe}^{+3} 2,0 \times 10^{-2} \mathrm{~mol} \mathrm{~L}^{-1}$, $B=$ etanol, $D=$ detector $(513 \mathrm{~nm}), I=$ injetor (alça de amostra $=50 \mathrm{~cm}$ ), $\mathrm{P}=$ bomba peristáltica (vazão $\left.1,0 \mathrm{~mL} \mathrm{~min}^{-1}\right), \mathrm{R}=$ reator helicoidal $(50 \mathrm{~cm})$, $\mathrm{S}=$ amostra, $\mathrm{W}=$ descarte 44

Figura 6.7.: Sinais transientes para curva de calibração (concentração, $\mathrm{mol} \mathrm{L}^{-1}$ : $A=10^{-4}, B=3,0 \times 10^{-4}, C=5,0 \times 10^{-4}, D=10^{-3}, E=2,0 \times 10^{-3}, F=6,0 \times 10^{-3}$, $\mathrm{G}=8,0 \times 10^{-3}, \mathrm{H}=10^{-2}$ ), brancos ( $\mathrm{I} ; 10$ medidas) e amostras de comprimidos

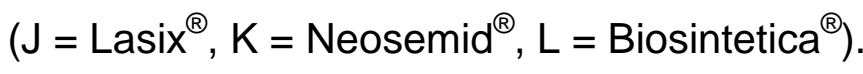

Figura 6.8.: Sinais transientes obtidos na análise de amostra injetável (Lasi ${ }^{\circledR}$ preparada para $1,5 \times 10^{-3} \mathrm{~mol} \mathrm{~L}^{-1}$ ). Adição de padrão de furosemida: $\mathrm{mol} \mathrm{L}{ }^{-1}: A=0, B=10^{-3}, C=2,0 \times 10^{-3}, D=3,0 \times 10^{-3}$. 48

Figura 6.9.: Sinais transientes obtidos para amostra de urina adicionada (preparada para $10^{-3} \mathrm{~mol} \mathrm{~L}^{-1}$ ). Adição de padrão de furosemida: $\mathrm{mol} \mathrm{L}^{-1}: \mathrm{A}=0$, $B=10^{-3}, C=2,0 \times 10^{-3}, D=3,0 \times 10^{-3}$. 49 
Figura 7.1.: Cromatogramas obtidos no estudo de produtos de reação empregando fase móvel 2. $\mathrm{A}$ = furosemida, $\mathrm{B}=$ saluamina, $\mathrm{C}=$ álcool furfurílico, $\mathrm{D}=$ excesso de ácido sulfúrico $\mathrm{E}=$ produto de oxidação da saluamina 52

Figura 7.2.: Curva obtida para DSC da furosemida padrão. 54

Figura 7.3.: Curvas TG e DTG obtidas a $5^{\circ} \mathrm{C} \mathrm{min}^{-1}$, massa de furosemida de 5 $\mathrm{mg}$ em suporte de alumina, atmosfera inerte de nitrogênio a $100 \mathrm{~mL} \mathrm{~min}^{-1}$. 57

Figura 7.4.: Curvas TG e DTA obtidas a $5^{\circ} \mathrm{C} \mathrm{min}^{-1}$, massa de furosemida de 5 $\mathrm{mg}$ em suporte de alumina, atmosfera inerte de nitrogênio a $100 \mathrm{~mL} \mathrm{~min}{ }^{-1}$. 57

Figura 7.5.: Curva Ea vs a, para estudo dos mecanismos de degradação térmica da furosemida. 58

Figura 8.1.: Efeito estático da influência do $\mathrm{pH}$ sobre a intensidade de fluorescência (IF) do analito. 61

Figura 8.2.: Esquema do sistema de análise em fluxo proposto com detecção por fluorescência. $C=$ solução carregadora; $P=$ bomba peristáltica, $S=$ amostra; $I=$ injetor-comutador; $R=$ reator $(40 \mathrm{~cm}), D=$ detector $\mathrm{e}$ $\mathrm{W}=$ descarte. 63

Figura 8.3.: Sinais transientes para curva analítica $\left(1,0 \times 10^{-7}, 5,0 \times 10^{-7}\right.$, $1,0 \times 10^{-6}, 2,5 \times 10^{-6}, 5,0 \times 10^{-6}, 7,5 \times 10^{-6}$ e $1,0 \times 10^{-5} \mathrm{~mol} \mathrm{~L}^{-1}$ ), amostras comerciais (Furosem ${ }^{\circledR}$, Teuto $^{\circledR}$ ) e urina sintética. 65

Figura 8.4.: Sinais transientes para curva analítica $\left(1,0 \times 10^{-7}, 5,0 \times 10^{-7}\right.$, $1,0 \times 10^{-6}, 2,5 \times 10^{-6}, 5,0 \times 10^{-6}, 7,5 \times 10^{-6}$ e $1,0 \times 10^{-5} \mathrm{~mol} \mathrm{~L}^{-1}$ ), amostra (Lasix ${ }^{\circledR}$ Inj,como exemplo), urina sintética adicionada e testes de adição-recuperação....66 Figura 8.5.: Espectros de absorção na região ultra-violeta de soluções aquosas de furosemida, SDS, CTAB e Triton X-100, todos a $5 \times 10^{-5} \mathrm{~mol} \mathrm{~L}^{-1}$. 70 
Figura 8.6.: Espectro de emissão de fluorescência para soluções aquosas de furosemida, SDS, CTAB em concentração de $5 \times 10^{-5} \mathrm{~mol} \mathrm{~L}^{-1}$. Comprimento de excitação em $225 \mathrm{~nm}$.

Figura 8.7.: Espectro de emissão de fluorescência para soluções aquosas de furosemida, SDS, CTAB em concentração de $5 \times 10^{-5} \mathrm{~mol} \mathrm{~L}^{-1}$. Comprimento de excitação em $271 \mathrm{~nm}$.

Figura 8.8.: Espectro de emissão de fluorescência para soluções aquosas de furosemida, SDS, CTAB em concentração de $5 \times 10^{-5} \mathrm{~mol} \mathrm{~L}^{-1}$. Comprimento de excitação em $330 \mathrm{~nm}$.

Figura 8.9.: Sistema em fluxo empregado: $\mathrm{A}$ = tensoativo em concentração igual ao dobro de sua $\mathrm{CMC}, \mathrm{B}=$ solução carregadora de Clark \& Lubbs pH 1,00, $\mathrm{D}=$ detector $\left(\lambda_{\text {excit. }}=271 \mathrm{~nm}, \lambda_{\text {emissão }}=410 \mathrm{~nm}\right.$, fendas de excitação e emissão em 10 e $20 \mathrm{~nm}$, respectivamente), I = injetor (alça de amostra $=80 \mathrm{~cm}$, que corresponde a $400 \mu \mathrm{L}$ ), $\mathrm{P}=$ bomba peristáltica (vazão $1,8 \mathrm{~mL} \mathrm{~min}^{-1}$ para cada solução), $\mathrm{R}=$ reator helicoidal $(40 \mathrm{~cm}), \mathrm{S}=$ amostra, $\mathrm{W}=$ descarte. 74

Figura 8.10a.: Sinais transientes para curva analítica $\left(1,0 \times 10^{-7}, 5,0 \times 10^{-7}\right.$, $1,0 \times 10^{-6}, 2,5 \times 10^{-6}, 5,0 \times 10^{-6}, 7,5 \times 10^{-6}$ e $1,0 \times 10^{-5} \mathrm{~mol} \mathrm{~L}^{-1}$ ), e amostras $\left(\right.$ Teuto $^{\circledR}$ e Pharlab ${ }^{\circledR}$ ), em meio de SDS.

Figura 8.10b.: Sinais transientes para curva analítica $\left(1,0 \times 10^{-7}, 5,0 \times 10^{-7}\right.$, $1,0 \times 10^{-6}, 2,5 \times 10^{-6}, 5,0 \times 10^{-6}, 7,5 \times 10^{-6}$ e $1,0 \times 10^{-5} \mathrm{~mol} \mathrm{~L}^{-1}$ ), e amostras $\left(\right.$ Teuto $^{\circledR}$ e Pharlab $^{\circledR}$ ), em meio de CTAB. 76

Figura 9.1.: Variação da corrente $\left(\bullet, \mu \mathrm{A} \mathrm{cm}^{-2}\right)$ e potencial ( $\square, E$ vs. ECS), de pico anódico da furosemida, em função do $\mathrm{pH}$, usando-se voltametria cíclica, $v=100 \mathrm{mV} \mathrm{s}^{-1}$ e o eletrodo compósito. 
Figura 9.2.: Mecanismo proposto para hidrólise seguida de oxidação da furosemida, envolvendo dois elétrons por próton. 82

Figura 9.3.: Voltamogramas cíclicos para análise de Neosemid $^{\circledR}$, por adições sucessivas de padrão, sob condições otimizadas. Concentrações, em $\mu \mathrm{mol} \mathrm{L}^{-1}$ : (a) branco, (b) amostra, (c) 8, (d) 16, (e) 20. 83

Figura 9.4a: Espectros de impedância eletroquímica para branco e adições em $+0.5 \vee v s$. ECS 84

Figura 9.4b: Espectros de impedância eletroquímica para branco e adições em $+0.75 \vee v s$. ECS. 85

Figura 9.4c: Espectros de impedância eletroquímica para branco e adições em $+1,0$ V vs. ECS. 85

Figura 9.4d: Espectros de impedância eletroquímica para branco e adições em $+1,1 \mathrm{~V}$ vs. ECS. 86

Figura 9.5.: Circuito modificado de Randles proposto ara o sistema em estudo.. 86 Figura 9.6.: Voltamogramas de pulso diferencial para análise de Furosix ${ }^{\circledR}$,sob condições otimizadas. Concentrações, em $\mu \mathrm{mol} \mathrm{L}^{-1}$ : (a) branco, (b) amostra, (c) 2,2, (d) 3,7, (e) 5,1, (f) 6,5 . 89

Figura 9.7.: Voltamogramas de onda quadrada para análise de Pharlab $^{\circledR}$, sob condições otimizadas. Concentrações, em $\mu \mathrm{mol} \mathrm{L}^{-1}$ : (a) branco, (b) amostra, (c) $0,8,(d) 2,2,(e) 4,4,(f) 6,5$. 90

Figura 9.8.: diagrama ilustrativo do sistema em fluxo explorado. $\mathrm{C}=$ carregador

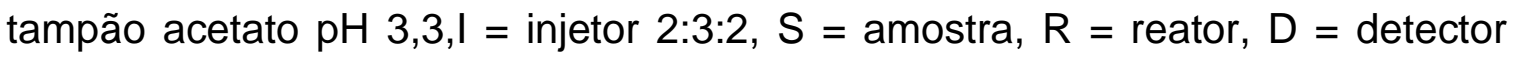
amperometrico (três eletrodos), $\mathrm{W}=$ descarte. 91 Figura 9.9.: Otimização da alça de amostragem a ser empregada no sistema em fluxo. 
Figura 9.10.: Sinais transientes para curva analítica $\left(A=10^{-5}, B=2,5 \times 10^{-5}\right.$, $C=5,0 \times 10^{-5}, \mathrm{D}=7,5 \times 10^{-5}$ e $\mathrm{E}=10^{-4}, \mathrm{~mol} \mathrm{~L}^{-1}$ ) e exemplos de amostras reais ( 1 = Pharlab, 2 = Teuto $)$. .92

Figura 9.11.: Curva de calibração obtida a partir do registro anterior. 93 
Lista de Tabelas

Tabela 3.1.: Resultados obtidos por análise elementar

Tabela 3.2.: Bandas de absorção e modos vibracionais na região do infravermelho

Tabela 3.3.: Parâmetros de deslocamentos químicos previamente descritos [38]

e experimentais de ${ }^{1} \mathrm{H}$ para furosemida 14

Tabela 4.1.: Resultados obtidos por titulometria 23

Tabela 4.2.: Resultados obtidos por titulometria em meio micelar 25

Tabela 5.1.: Resultados obtidos por espectrofotometria 32

Tabela 6.1.: Valores encontrados e rotulados. 42

Tabela 6.2.: Composição da urina sintética empregada 45

Tabela 6.3.: Resultados obtidos na análise de formas farmacêuticas comerciais. 48

Tabela 6.4.: Resultados obtidos para furosemida na urina sintética 49

Tabela 7.1.: Parâmetros cinéticos obtidos em diferentes razões de conversão....56

Tabela 8.1.: Resultados obtidos para amostras comerciais de furosemida 66

Tabela 8.2.: Resultados obtidos para urina sintética adicionada. 66

Tabela 8.3.: Características dos tensoativos empregados em solução aquosa....69

Tabela 8.4.: Resultados obtidos para amostras comerciais de furosemida 77

Tabela 8.5.: Resultados obtidos para urina sintética adicionada.

Tabela 8.6.: Comparação entre figuras de mérito obtidas 77

Tabela 9.1.: Composição das soluções tampão empregadas 79

Tabela 9.2.: Resultados obtidos após ajuste dos espectros de impedância eletroquímica empregando modelo selecionado..... 87

Tabela 9.3.: Resultados obtidos pelas diferentes técnicas para comprimidos contendo $40 \mathrm{mg}$ de analito, segundo valor rotulado. 
Tabela 10.1.: Comparação entre resultados obtidos pelos diversos procedimentos instrumentais desenvolvidos ............................................ 99 


\section{Glossário de símbolos e abreviaturas}

$v$ - velocidade de varredura

Abs - absorbância

$\mathrm{APCl}$ - ionização química a pressão atmosférica

AVC - acidente vascular cerebral

CL - solução de Clark \& Lubbs

CMC - concentração micelar crítica

CPE - elemento constante de fase

CTAB - brometo de cetil trimetil amônio

CV - voltametria cíclica

DAD - detector por arranjo de fotodiodos

DPV - voltametria de pulso diferencial

DSC - calorimetria exploratória diferencial

DTA - análise térmica diferencial

E - potencial

EA - análise elementar

Ea - energia de ativação

ECA - enzima conversora de angiotensina

ECS - eletrodo de calomelano saturado

EI - "electronspray ionization"

EIS - espectroscopia de impedância eletroquímica

FIA - análise por injeção em fluxo

IV - espectrometria na região do infravermelho com transformada de Fourier

HA - hipertensão arterial

HPLC - cromatografia líquida de alta eficiência

IF - intensidade de fluorescência

Ipa - corrente de pico anódica

LC-MS - cromatografia a líquido acoplada a espectrometria de massas

LD - limite de detecção

LQ - limite de quantificação 
PA - pró análise, grau analítico

$\mathrm{PU}$ - poliuretana

$R$ - coeficiente de correlação linear

$\mathrm{RMN}-{ }^{1} \mathrm{H}$ - ressonância magnética nuclear de próton

SDS - dodecil sulfato de sódio

SUS - sistema único de saúde

SWV - voltametria de onda quadrada

TG - termogravimetria 


\section{SUMÁRIO}

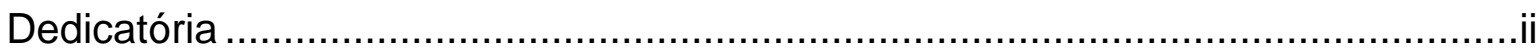

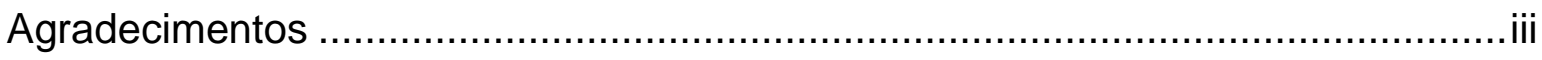

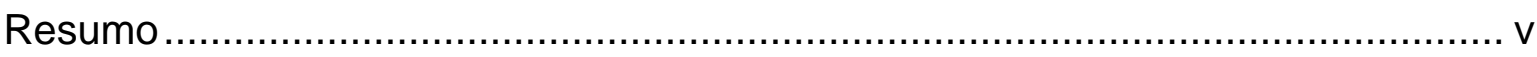

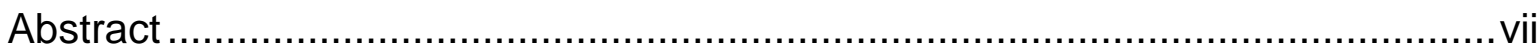

Lista de Figuras ........................................................................................

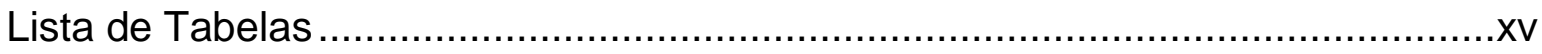

Glossário de símbolos e abreviaturas ……………..................................... xvii

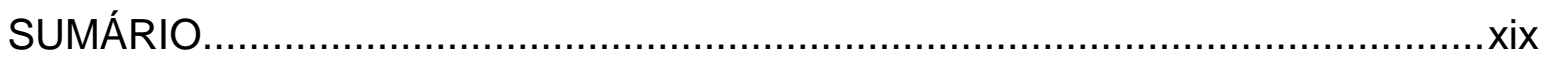

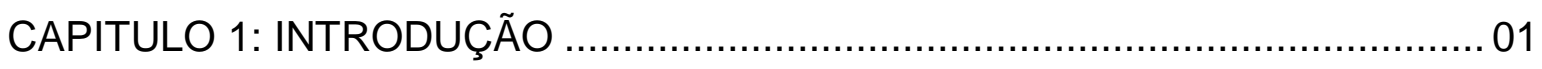

1.1. Hipertensão arterial (HA): etiologia e controle .................................... 01

1.2. Fármacos empregados no controle da HA ........................................ 03

1.3. Diuréticos de alça ............................................................................. 04

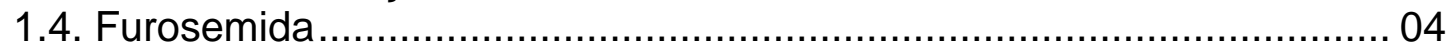

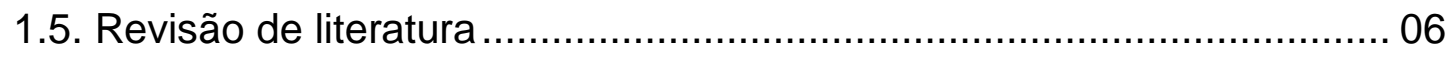

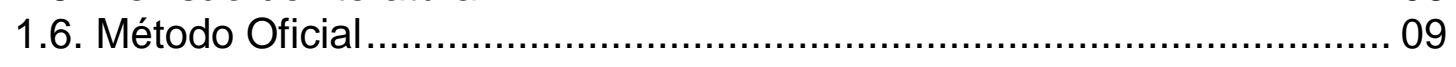

CAPITULO 2: JUSTIFICATIVA E OBJETIVOS ..................................................... 11

CAPITULO 3: MATÉRIA-PRIMA E FORMAS FARMACÊUTICAS ......................... 12

3.1. Caracterização da furosemida utilizada ................................................ 12

3.1.1. Análise elementar (EA) ....................................................... 12

3.1.2. Análise por espectrometris na região do infravermelho (IV)............ 13

3.1.3. Espectrometria de ressonância magnética nuclear de hidrogênio

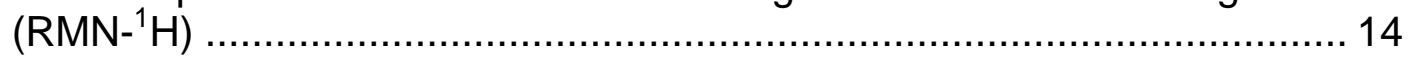

3.2. Análise farmacotécnica das amostras ................................................. 15

3.2.1. Definição tecnológica de comprimidos [39] ..................................... 15

3.2.2. Conceito e emprego dos excipientes .......................................... 16

3.2.3. Estudo dos excipientes presentes............................................... 17

CAPITULO 4: DETERMINACÕES TITRIMÉTRICAS .......................................... 20

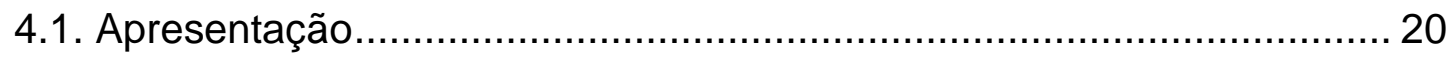

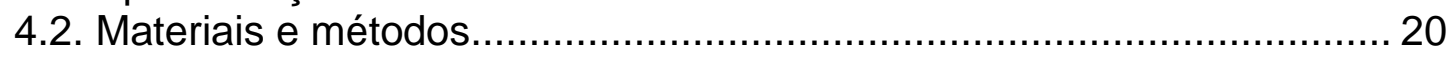

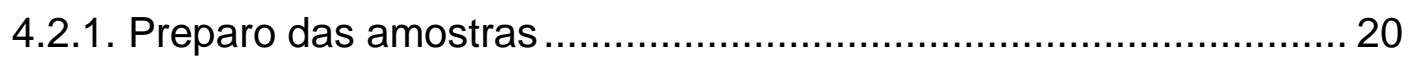

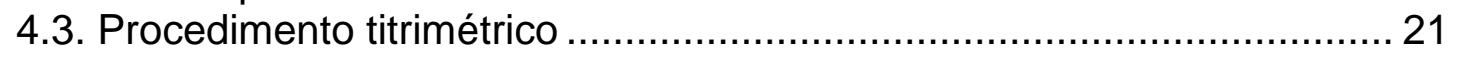

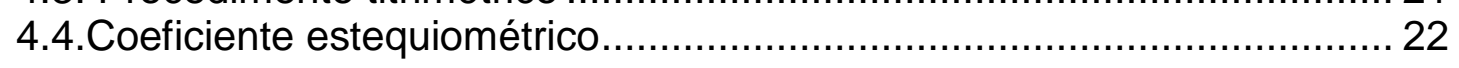




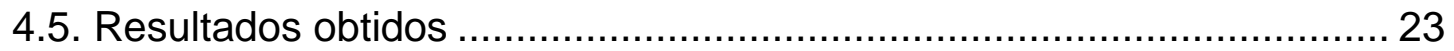

4.6. Exploração de meios micelares ....................................................... 24

CAPITULO 5: DETERMINACÕES ESPECTROFOTOMÉTRICAS ESTÁTICAS .. 27

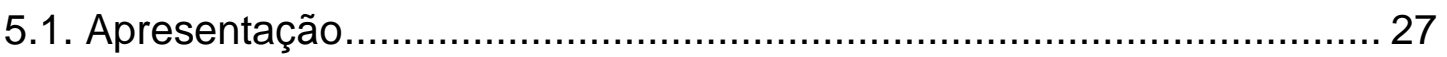

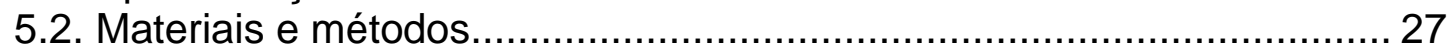

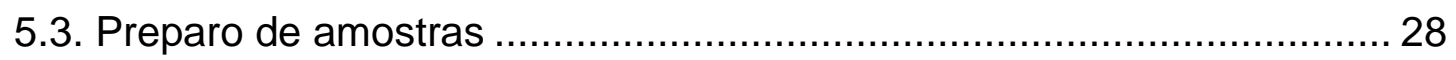

5.4. Procedimentos espectrofotométricos ................................................. 29

5.4.1. Espectro de absorção e determinação do comprimento de onda

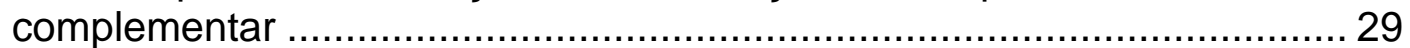

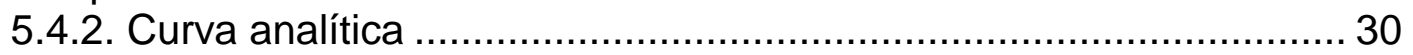

5.4.3. Adição de padrão ................................................................... 31

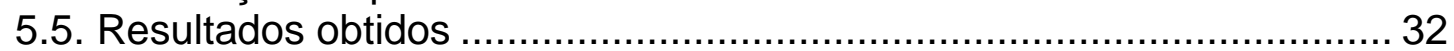

CAPITULO 6: DETERMINACÕES ESPECTOFOTOMÉTRICAS DE

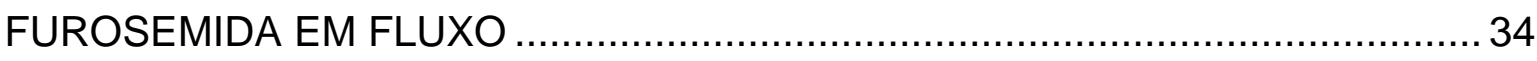

6.1. Apresentação: análise por injeção em fluxo (FIA) …………............... 34

6.2. Determinação espectrofotométrica em fluxo por meio da reação com

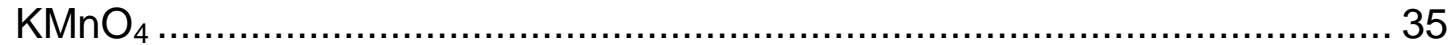

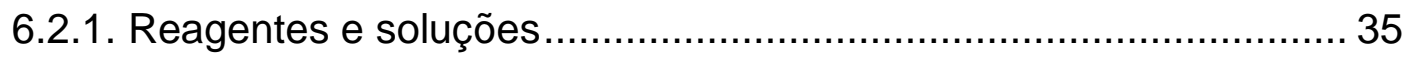

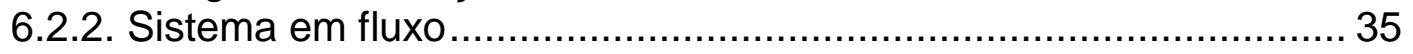

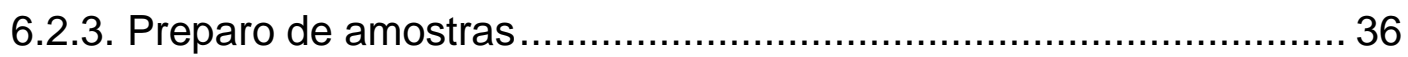

6.2.4. Otimização de parâmetros do sistema em fluxo ............................. 37

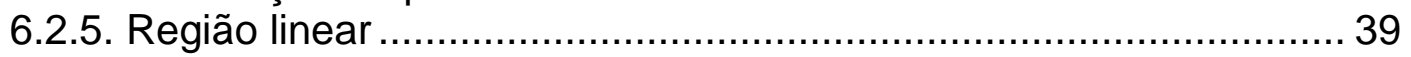

6.2.6. Aplicações analíticas ................................................................. 40

6.3. Determinação em fluxo por meio da reação $\mathrm{com} \mathrm{Fe}^{+3} \mathrm{em}$ meio etanólico com detecção espectrofotométrica ........................................................ 42

6.3.1. Reagentes e soluções......................................................... 42

6.3.2. Sistema em fluxo ............................................................... 43

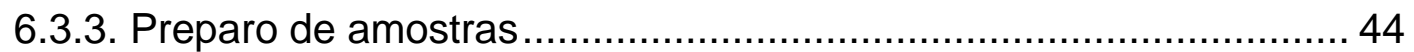

6.3.4. Otimização de parâmetros do sistema em fluxo ............................ 46

6.3.5. Figuras de mérito ................................................................ 46

6.3.6. Aplicações analíticas ............................................................ 47

CAPÍTULO 7: ESTUDOS DOS PRODUTOS DE REAÇÂO ...................................51

7.1. Estudos por cromatografia líquida de alto desempenho (HPLC) ...........5 51

7.1.1. Materiais e métodos ................................................................ 51

7.1.2. Resultados e discussão .......................................................... 51

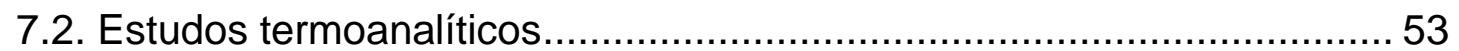

7.2.1. Materiais e métodos................................................................... 53

CAPÍTULO 8: DETERMINAÇÕES COM BASE EM ESPECTROSCOPIA DE

FLUORESCÊNCIA 
8.1. Determinação de furosemida por espectroscopia de fluorescência.......59 59

8.1.1. Soluções de calibração e reagentes ............................................ 59

8.1.2. Equipamentos, ajustes na detecção e sistema em fluxo.................60 60

8.1.3. Otimização dos parâmetros da determinação ............................6 60

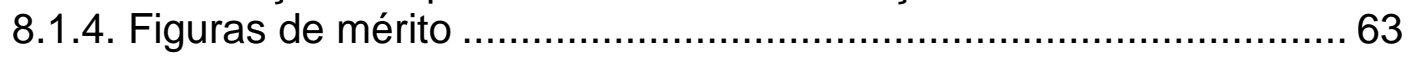

8.1.5. Preparo de amostras ......................................................... 64

8.1.6. Aplicações analíticas .......................................................... 65

8.2. Emprego de ambientes micelares na determinação de furosemida por espetroscopia de fluorescência ............................................................ 67

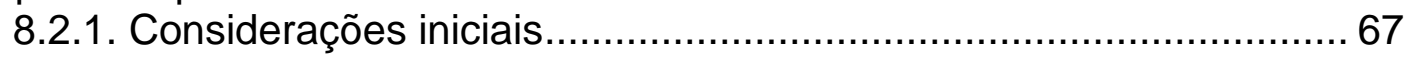

8.2.2. Reagentes e soluções ....................................................... 68

8.2.3. Equipamentos, ajustes na detecção e sistema em fluxo................. 69

8.2.4. Figuras de mérito .................................................................... 74

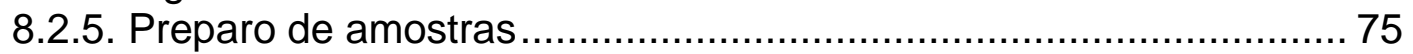

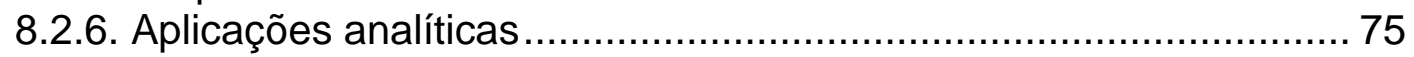

CAPITULO 9: DETERMINAÇÕES ELETROANALÍTICAS USANDO

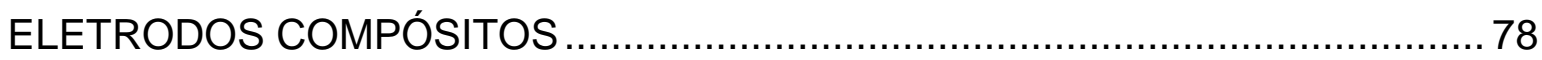

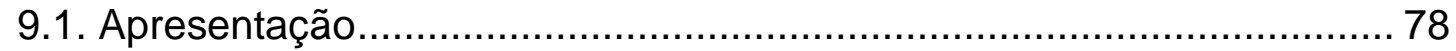

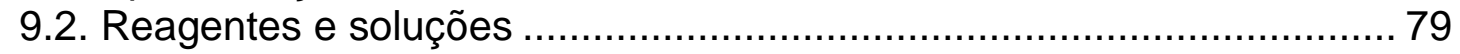

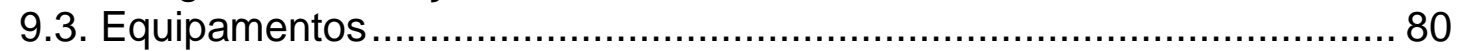

9.4. Eletrodos compósitos............................................................ 80

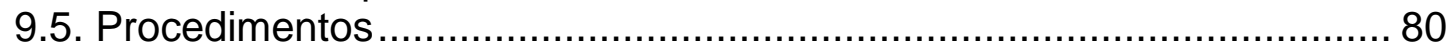

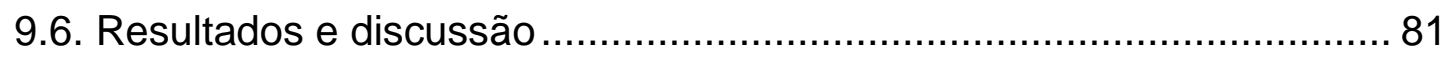

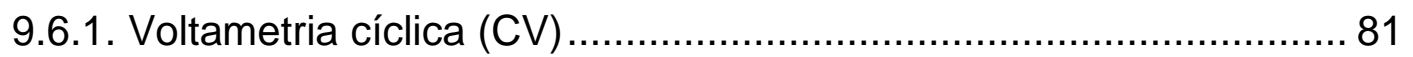

9.6.2. Espectroscopia de impedância eletroquímica (EIS) ...................... 84

9.6.3. Voltametria de pulso diferencial (DPV) .................................... 88

9.6.4. Voltametria de onda quadrada (SWV) ..................................... 89

9.6.5. Análises por injeção em fluxo (FIA) ............................................ 90

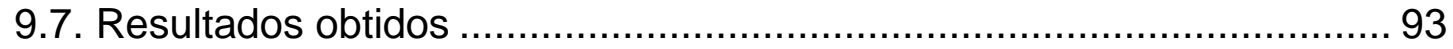

CAPITULO 10: CONSIDERAÇÕES FINAIS E COMPARAÇÕES ...................... 95

CAPITULO 11: REFERÊNCIAS BIBLIOGRÁFICAS .................................. 101

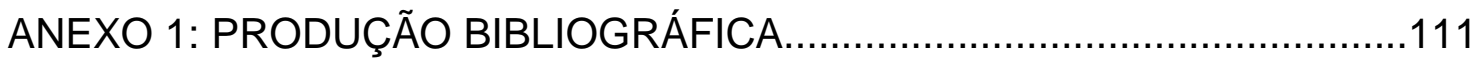




\section{CAPITULO 1: INTRODUÇÃO}

\subsection{Hipertensão arterial (HA): etiologia e controle}

A pressão arterial pode ser definida como a razão entre a força exercida pelo bombeamento do sangue pelo ventrículo esquerdo e a área das paredes dos vasos que comportarão o sangue circulante; tratando-se de um fenômeno pulsátil, ocorrendo em ciclos de pressões máximas (sistólicas) e mínimas (diastólicas), cujos valores médios considerados comuns são próximos a 120 e $80 \mathrm{mmHg}$, respectivamente, correspondendo ao ritmo dos batimentos cardíacos [1]. Alterações nestas pressões podem apresentar etiopatogenia multifatorial, sendo, na maioria dos casos, vinculadas a fatores genéticohereditários e ambientais, tais como alimentação, sedentarismo, tabagismo e uso de álcool, entre outros [1].

Segundo Riera [1] a hipertensão arterial (HA) atinge cerca de $20 \%$ da população adulta do Brasil, e representa o principal fator de risco para doenças cerebrovasculares, sendo responsável por $65 \%$ das mortes por acidente vascular cerebral (AVC). Tal quadro apresenta, ainda, uma incidência de 7\% entre crianças e adolescentes, e por volta de $65 \%$ entre idosos, podendo chegar a $80 \%$ em pessoas acima de 75 anos. A hipertensão arterial apresenta prevalência aumentada em até quatro vezes, quando se estuda uma população negra [1].

Cerca de $50 \%$ dos hipertensos desconhecem sua condição e, dos $50 \%$ restantes, metade não faz tratamento e, dos que o fazem, apenas 55\% conseguem controlar de suas pressões arteriais adequadamente, o que resulta 
numa parcela de $15 \%$ de hipertensos com controle efetivo de pressão arterial $[1]$.

Dentre as medidas de controle da hipertensão pode-se destacar a reeducação alimentar através de uma dieta com baixo consumo de sódio e outros nutrientes, a prática de esportes, abstenção ao álcool e tabaco, uso racional de medicação, combate ao "stress" e controle de diabetes, sendo ideal a associação de todos estes fatores para um controle eficaz [2].

Outras informações clínicas, classificações de hipertensos, tratamentos, cuidados e medicamentos podem ser encontrados em literatura especializada [3-7]. A discussão detalhada destes aspectos estenderia demasiadamente esta introdução.

Em suma, os autores consideram que, modernamente, a HA não pode ser considerada uma condição clínica, na qual valores tensionais estão acima de valores pré-estabelecidos, mas sim um contexto sindrômico, que envolve alterações hemodinâmicas, tróficas e metabólicas. Tais fatores provocam a elevação da pressão arterial, dislipidemias, resistência insulínica, obesidade, aumento da atividade dos fatores de coagulação e hipertrofia da função diastólica do ventrículo esquerdo [3-7].

Uma vez que a HA resulta de uma série de fatores, o seu controle pode ser feito por mudanças no estilo de vida do indivíduo, ou quando isto não surte efeito, usando-se medicamentos [3,4], contendo fármacos indicados em cada caso. Há várias classes de fármacos, usados no controle da HA, como se descreve a seguir. 


\subsection{Fármacos empregados no controle da HA}

Diversos fármacos são empregados no controle da hipertensão arterial, os quais são classificados como $[1,8,9]$ :
a) inibidores da enzima conversora de angiotensina (inibidores da ECA),
b) antagonistas da angiotensina II (ARAII),
c) antagonistas dos canais de cálcio,
d) diuréticos,
e) $\beta$-bloqueadores,
f) bloqueadores $\alpha 1$ e $\beta$-adrenérgicos,
g) outros.

Os fármacos diuréticos são drogas que exercem sua ação nos rins ao nível dos néfrons, na alça ascendente de Henle (Figura 1.1), sobre a parte inicial do túbulo distal e túbulos e ductos coletores, resultando em maior excreção de sódio e água do corpo. Até 1920 eram utilizados diuréticos osmóticos (exemplo uréia) e xantinas (exemplos teofilina e cafeína), sendo introduzidos, em seqüência, os inibidores da anidrase carbônica.

Atualmente, esta categoria de fármacos pode ser subdividida, principalmente, em diuréticos de alça ou diuréticos de alto limiar, tiazidas, e diuréticos poupadores de potássio $[8,9]$. 


\subsection{Diuréticos de alça}

São os mais poderosos entre os diuréticos; agindo primariamente sobre o segmento espesso da alça ascendente de Henle, inibindo o transporte de cloreto de sódio para fora do túbulo e para o interior do tecido intersticial, provocando a excreção de $15-25 \%$ do sódio existente nos fluidos biológicos.

Representados pela furosemida, bumetanida, piretanida, torasemida e ácido etacrínico, os diuréticos de alça são empregados clinicamente em pacientes com edema pulmonar agudo, insuficiência cardíaca crônica, cirrose hepática complicada por ascite, síndrome nefrótica e insuficiência renal [10].

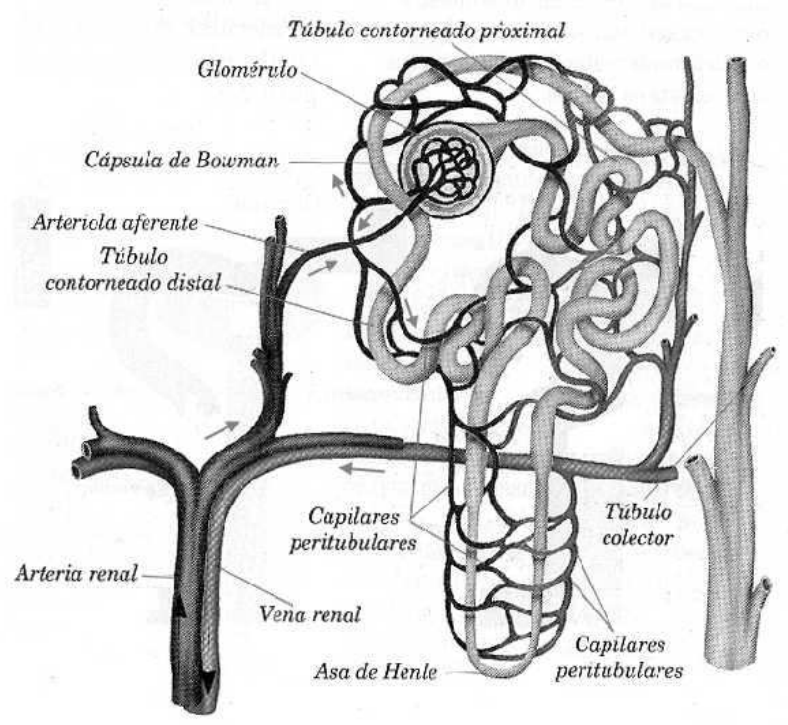

Figura 1.1.: Esquema de um néfron [11].

\subsection{Furosemida}

A furosemida, denominada ácido 4-cloro-N-furfuril-sulfamilantranilico, é um pó cristalino, branco e inodoro, praticamente insolúvel em água e soluções ácidas diluídas, ligeiramente solúvel em solventes orgânicos como álcool e 
acetona, solúvel em soluções alcalinas diluídas [12]. A fórmula estrutural da furosemida é apresentada na Figura 1.2.<smiles>NS(=O)(=O)c1cc(C(=O)O)c(NCc2ccco2)cc1Cl</smiles>

Figura 1.2.: Fórmula estrutural da furosemida.

Derivada do ácido antranílico, a furosemida representa um potente diurético que, se administrado em excesso, pode gerar depleção excessiva de água e eletrólitos, devendo, portanto, ser utilizada com cuidadosa supervisão médica, havendo necessidade de ajuste de dosagem de acordo com a necessidade do paciente $[2,10,13]$.

Apresentações comerciais disponíveis deste fármaco variam entre comprimidos $\left(20,40\right.$ e $80 \mathrm{mg}$ ) e soluções injetáveis $\left(10 \mathrm{mg} \mathrm{mL} \mathrm{m}^{-1}\right)$, sendo fabricadas e vendidas por diversas indústrias farmacêuticas. Comprimidos de $40 \mathrm{mg}$ podem ser obtidos gratuitamente através do Sistema Único de Saúde (SUS).

A posologia para adultos varia entre 20 e $80 \mathrm{mg}$, em dose única pela manhã, podendo ser aumentada gradativamente, evitando-se ultrapassar 600 $\mathrm{mg} \mathrm{dia}{ }^{-1}$. Em crianças, utiliza-se dose única de $2 \mathrm{mg} \mathrm{kg}^{-1}$ de peso, podendo ser ajustada entre 1 e $2 \mathrm{mg}$, tendo-se como dosagem máxima $6 \mathrm{mg} \mathrm{kg}^{-1}$ [9].

O medicamento de referência é o Lasix $^{\circledR}$ (Aventis), de ampla utilização como diurético. Com o advento dos medicamentos genéricos, aumentou-se o 
número de formas farmacêuticas disponíveis, exigindo maior controle da qualidade do medicamento produzido e disponibilizado ao usuário, quer seja no controle microbiológico, físico-químico ou de princípios ativos, tornando necessárias metodologias rápidas e confiáveis para aplicação nestas situações.

Por outro lado, observa-se, também, a necessidade de controle rigoroso de princípios ativos, visto ser seu excesso - ou falta - gerador de danos à saúde do paciente. Dentre às reações adversas mais comuns, associadas ao uso excessivo da furosemida, pode-se citar a depleção excessiva de água e eletrólitos, como dito acima [10], principalmente potássio (hipocalemia), alcalose metabólica (em função da excreção de $\mathrm{H}^{+}$), hipovolemia e hipotensão, podendo ser observados efeitos mais severos como náuseas, reações alérgicas, ou ainda, surdez $[1,2,10]$.

Em tratamentos contínuos de crianças e adultos observa-se, ainda, a possibilidade de surgimento de tolerância e resistência ao diurético, o que pode ser superado com a administração da furosemida em associação a outros fármacos como as tiazidas [1,2].

\subsection{Revisão de literatura}

A grande maioria dos métodos para determinação da furosemida é baseada em procedimentos cromatográficos, dentre os quais pode-se destacar as referências 14 a 22. Entretanto, a maioria necessita de preparo de amostra e envolve os volumes elevados de solventes dispendiosos, normalmente envolvidos neste tipo de procedimento, tal fato pode ser minimizado pelo 
emprego de micro cromatografia. Isto torna tais metodologias caras e geradoras de grandes volumes de resíduos a serem descartados ou tratados.

Nesta revisão procurou-se descrever metodologias alternativas, que pudessem colaborar evitando tais inconvenientes, em concordância com os objetivos deste trabalho.

Conhecendo-se a alta incidência da patologia em questão, pode-se concluir que o uso amplo de fármacos capazes de controlar a pressão arterial implica na necessidade de estratégias de análise de princípios ativos e produtos acabados a serem disponibilizados aos usuários, assim como 0 conhecimento de sua farmacocinética.

Para determinações da furosemida em meio aquoso deve-se considerar que a mesma só apresenta solubilidade adequada em meio básico [23,24], ou na presença de tensoativos. Sob tais condições, a determinação da furosemida em diferentes amostras foi feita conforme se descreve a seguir.

Agatonovic-Kustrin et al. [23] e Garcia et al. [24], determinaram a furosemida por meio da reação entre esta e o paládio (II), sendo padrões e amostras do fármaco preparados em soluções com $\mathrm{pH}$ 9, usando procedimentos estático e injeção em fluxo, respectivamente. A reação ocorre gerando uma coloração avermelhada com máximo de absorbância em 527 nm, sendo o cloreto de paládio adicionado em excesso ao sistema. O complexo é formado em pH entre 9 e 13. A absorbância aumenta gradualmente quando se aumenta $\circ \mathrm{pH}$ de 9 para 11, fixando-se $0 \mathrm{pH}$ de trabalho em 10 [23]. A detecção espectrofométrica apresentou uma relação linear entre 0,25 e $3,5 \times 10^{-3} \mathrm{~mol} \mathrm{~L}^{-1}$, com limite de detecção de $2,5 \times 10^{-5} \mathrm{~mol} \mathrm{~L}^{-1}$ [23]. Em fluxo, a 
faixa linear foi de 2 a $40 \times 10^{-5} \mathrm{~mol} \mathrm{~L}^{-1}$, com limite de detecção de $5,5 \times 10^{-6} \mathrm{~mol}$ $\mathrm{L}^{-1}[24]$

Determinações simultâneas diretas em amostras contendo furosemida e amilorida foram realizadas usando-se espectrofotometria derivada, entre 240 e $340 \mathrm{~nm}$. Observou-se boa reprodutibilidade e nenhuma interferência com limites de detecção $2,0 \times 10^{-8} \mathrm{~mol} \mathrm{~L}^{-1}$ e resposta linear entre $6,8 \times 10^{-8} \mathrm{e}$ $8,0 \times 10^{-5} \mathrm{~mol} \mathrm{~L}^{-1}[25]$.

Kulichencko e Shevchencko [26], valendo-se das propriedades dos ambientes micelares organizados por tensoativos, determinaram a furosemida

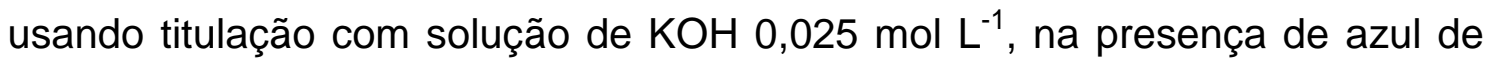
bromofenol, sendo o ponto de viragem observado quando a coloração se altera de amarelo para azul. Neste caso, a furosemida foi dissolvida em 0,25 g de óleo e a solução resultante, emulsificada com $25 \mathrm{~mL}$ de uma solução 2,5\% Triton X-100.

Também empregando agentes tensoativos, Kulichencko e Fesenko [27] determinaram, por titulação ácido-base potenciométrica, furosemida em comprimidos.

Visando determinações de furosemida por voltametria de pulso diferencial (DPV) e de onda quadrada (SWV), usando eletrodos de carbono vítreo em metanol-água 10:90 ( $/ / v$ ) e na presença de tampão Britton-Robinson os autores descrevem picos irreversíveis de oxidação dependentes da acidez do meio. Limites de detecção da ordem de $1,51 \times 10^{-7} \mathrm{~mol} \mathrm{~L}^{-1}$ foram descritos, para ambas as técnicas [28].

Dias et al. [29] desenvolveram eletrodos íon-seletivos à furosemida visando sua determinação potenciométrica, tais sensores utilizam pares iônicos 
como a ortofenantrolina, cloreto de metilrosanilina, tricaprilmetilamônio, azul de metileno, entre outros. Segundo os autores, os melhores resultados foram observados usando-se tricaprilmetilamônio, sendo as leituras realizadas em tampão borato $0,1 \mathrm{~mol} \mathrm{~L}^{-1}, \mathrm{pH}$ 9,6, em força iônica ajustada com $\mathrm{KCl}$.

Trabalhos publicados têm demonstrado aplicabilidade dos lantanídeos na determinação de derivados do ácido antranílico, como a furosemida, usando-se de complexação e exploração das propriedades de luminescência dos complexos, com sensibilidade relativamente elevada. Dentre os lantanídeos empregados reportam-se o cério [30], európio [31], térbio [32,33], entre outros.

Neste caso, limites de detecção da ordem de $10^{-10} \mathrm{~mol} \mathrm{~L}^{-1}$ puderam ser observados, com intervalos lineares de $10^{-9}$ a $10^{-5} \mathrm{~mol} \mathrm{~L}^{-1}$, usando térbio [33].

A presente tese abordará diferentes técnicas e métodos, apresentando estratégias analíticas desenvolvidas para determinação do fármaco em estudo em diversas matrizes; sendo assim, optou-se por detalhar melhor a revisão por ocasião de cada capítulo no qual se discute uma técnica em especial.

\subsection{Método Oficial}

Visando avaliar comparativamente os resultados obtidos no decorrer do desenvolvimento dos métodos descritos na presente tese, mesmas amostras foram submetidas a um método espectrofotométrico de calibração por ponto único, o qual emprega $\mathrm{NaOH}$ como solução extratora, sendo as medidas realizadas em $271 \mathrm{~nm}$. Este procedimento é descrito pela Farmacopéia Americana [34]. Atualmente tal farmacopéia preconiza o uso de cromatografia 
[35], porém, em função da disponibilidade de instrumentação, simplicidade e precisão da técnica, optou-se por empregar UV-vis. 


\section{CAPITULO 2: JUSTIFICATIVA E OBJETIVOS}

Tendo em vista o amplo uso da furosemida na terapêutica da hipertensão arterial, a facilidade de obtenção de suas formas farmacêuticas, quer seja por meio de comércio, quer seja por obtenção pelo SUS e conseqüências de seu uso inadequado, torna-se de grande valia o desenvolvimento de métodos rápidos, práticos e de baixo consumo de reagentes para a determinação do analito, o que facilita sobremaneira a execução de um controle do principio ativo. Tal controle poderia ser feito nas formulações ou até mesmo em fluidos biológicos.

O presente trabalho pretendeu desenvolver e comparar diferentes metodologias não cromatográficas para determinação de furosemida em amostras comerciais nas formas de comprimidos e soluções injetáveis, e/ou em fluidos biológicos sintéticos. Tais procedimentos representam opções ao controle de qualidade, tanto para indústrias quanto para manipulações farmacêuticas, de forma rápida, simplificada e pouco dispendiosa.

Com o objetivo de facilitar a leitura a presente tese se apresenta dividida em capítulos, cada um abordando diferentes técnicas, desde a caracterização do material de partida, até as descrições dos procedimentos propostos, atingindo então as comparações e considerações finais. 


\section{CAPITULO 3: MATÉRIA-PRIMA E FORMAS FARMACÊUTICAS}

\subsection{Caracterização da furosemida utilizada}

Visando aumentar a confiabilidade de posteriores resultados, foram realizados estudos de caracterização da furosemida (matéria-prima, Natural Pharma, Brasil) disponível.

Foram realizados estudos de seu espectro na região do infravermelho, análise elementar, testes de solubilidade, estudos de comportamento térmico usando calorimetria exploratória diferencial, bem como espectrometria de ressonância magnética nuclear de ${ }^{1} \mathrm{H}$.

\subsubsection{Análise elementar (EA)}

Tendo por base informações relacionadas à sua massa molar de $330,75 \mathrm{~g} \mathrm{~mol}^{-1}$ [12] foi realizada a análise elementar, obtendo-se:

Tabela 3.1.: Resultados obtidos por análise elementar

\begin{tabular}{lcc}
\hline Elemento & \% calculado & \% experimental \\
\hline Carbono & 43,6 & 43,0 \\
Hidrogênio & 3,36 & 3,50 \\
Nitrogênio & 8,47 & 8,45 \\
\hline
\end{tabular}

De acordo com os resultados, observa-se concordância entre os valores calculados e obtidos, o que pode ser relacionado à pureza da substância. Para tal estudo foi empregado um analisador elementar CHNS-O da marca CE Instruments, modelo EA 1110. 


\subsubsection{Análise por espectrometria na região do infravermelho (IV)}

Pastilhas do fármaco em $\mathrm{KBr}$, em proporção de 1:100 $(\mathrm{m} / \mathrm{m})$ foram preparadas e usadas para obtenção dos espectros de IV. O espectro de absorção na região do infravermelho da matéria-prima empregada foi obtido empregando um espectrômetro de infravermelho com transformada de Fourier (FTIR) da marca Bomem, modelo MB-102.

Foram observadas bandas características no espectro da furosemida (Figura 3.1.), sendo as principais listadas na Tabela 3.2.

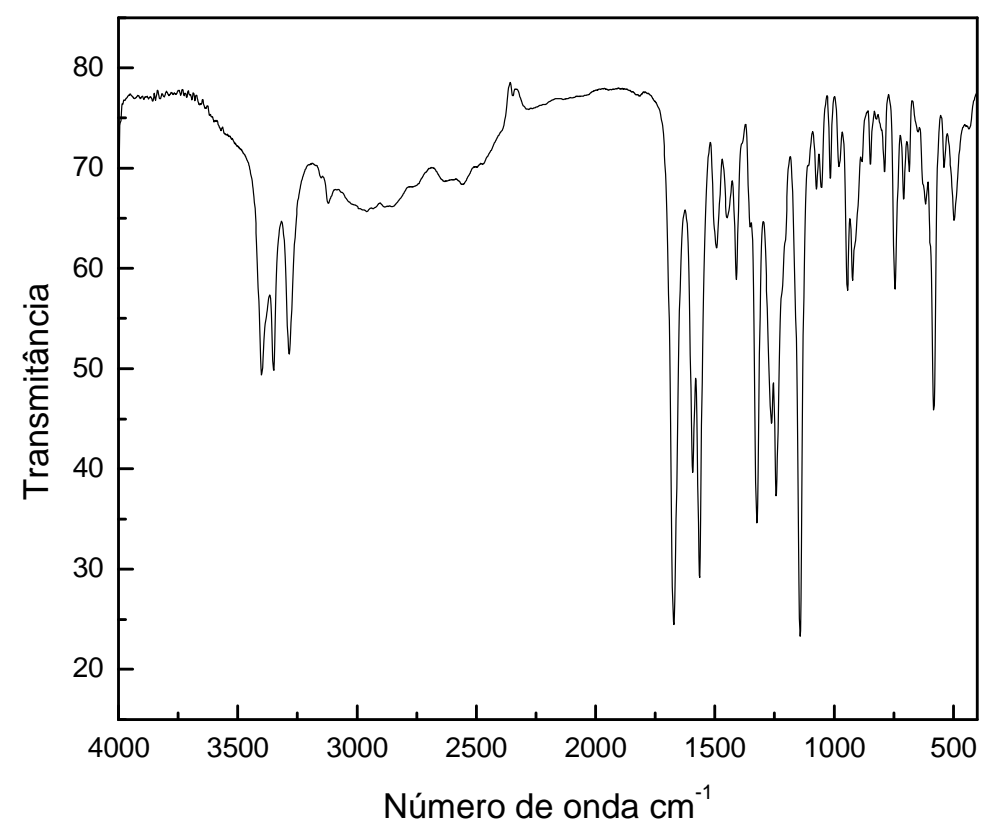

Figura 3.1.: Espectro da furosemida na região do infravermelho em pastilhas de $\mathrm{KBr}$ a $1 \%(\mathrm{~m} / \mathrm{m})$.

Tabela 3.2.: Bandas de absorção e modos vibracionais na região do infravermelho

\begin{tabular}{lccc}
\hline $\begin{array}{l}\text { Grupo } \\
\text { Funcional }\end{array}$ & $\begin{array}{c}\text { Tipo de } \\
\text { Deformação }\end{array}$ & $\begin{array}{c}\text { Absorção Característica } \\
\left(\mathrm{cm}^{-1}\right)[36,37]\end{array}$ & $\begin{array}{c}\text { Absorção } \\
\text { Experimental }\left(\mathrm{cm}^{-1}\right)\end{array}$ \\
\hline$-\mathrm{NH}_{2}$ & Estiramento & 3340 & 3351 \\
$-\mathrm{SO}_{2} \mathrm{NH}_{2}$ & Estiramento & 3260 & 3285 \\
$-\mathrm{COOH}$ & Estiramento & 1560 & 1565 \\
Sulfonil & Estiramento & 1318 & 1324 \\
\hline
\end{tabular}


3.1.3. Espectrometria de ressonância magnética nuclear de hidrogênio (RMN- $\left.{ }^{-1} \mathrm{H}\right)$

Foi empregado um espectrômetro Bruker, modelo AC-200 para obter os espectros de por RMN - ${ }^{1} \mathrm{H}$,; usando-se acetona deuterada como solvente e tetrametil silano (TMS), como referência.

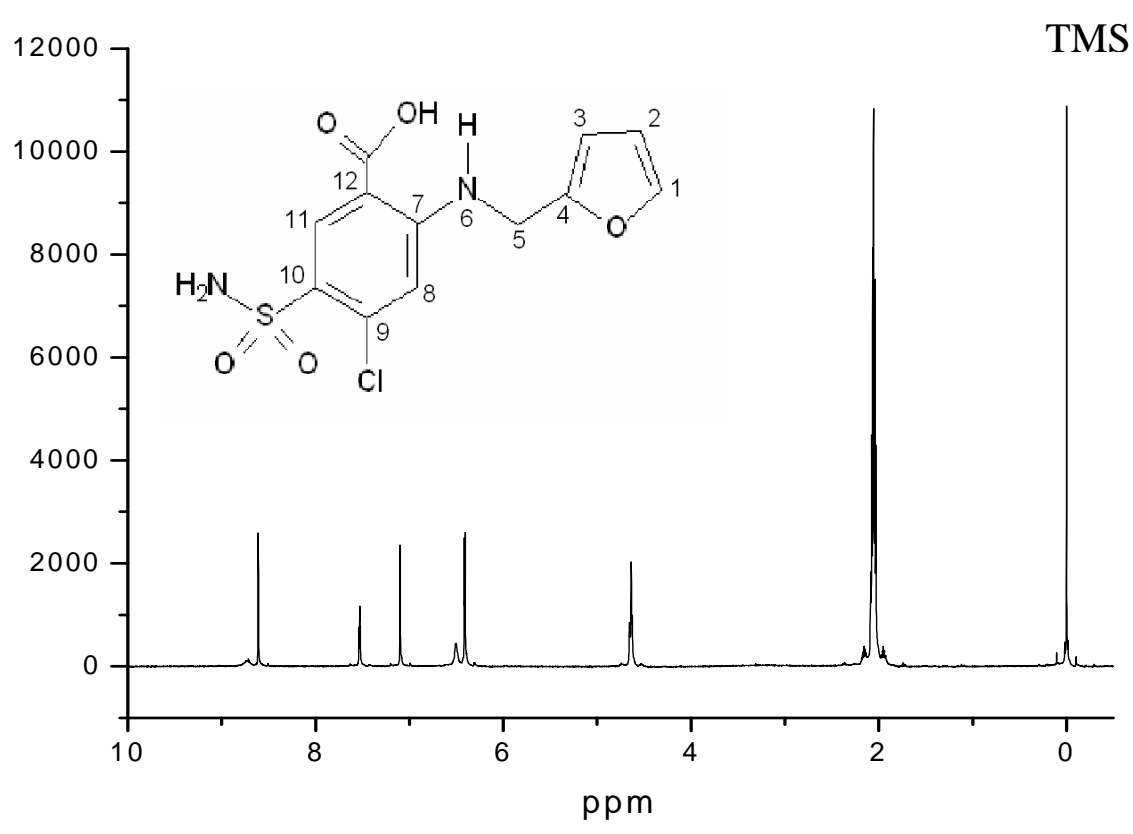

Figura 3.2.: Espectro de $\mathrm{RMN}{ }^{1} \mathrm{H}$ da furosemida padrão.

Tabela 3.3.: Parâmetros de deslocamentos químicos previamente descritos [38] e experimentais de ${ }^{1} \mathrm{H}$ para furosemida

\begin{tabular}{cccc}
\hline Próton & $\delta$ esperado & $\delta$ experimental & Multiplicidade \\
\hline 1 & 7,604 & 7,533 & Dublete \\
2 & 6,406 & 6,409 & Triplete \\
3 & 6,356 & 6,503 & Dublete \\
5 & 4,571 & 4,632 & Dublete \\
8 & 7,050 & 7,097 & Singlete \\
11 & 8,391 & 8,611 & Singlete \\
$-\mathrm{NH}-$ & 8,606 & 8,716 & Singlete \\
$-\mathrm{NH}_{2}$ & 7,300 & 7,523 & Singlete \\
\hline
\end{tabular}

$\delta$ indica deslocamento químico, ppm. 
Os resultados obtidos pelas diversas técnicas espectroscópicas empregadas sugerem um grau de pureza na ordem de $99 \%$ para a furosemida disponível, a qual foi tomada como material de partida para as análises posteriores.

O fabricante sugere uma pureza entre 98,5 e 101\%, de acordo com método oficial (descrito aqui como método Oficial).

\subsection{Análise farmacotécnica das amostras}

\subsubsection{Definição tecnológica de comprimidos [39]}

Em 1943, com o surgimento da primeira prensa, passam a ser produzidos os comprimidos.

Comprimidos são formas farmacêuticas sólidas, de formato variado; obtidas por agregação e compressão de substâncias secas na forma de pó. Seus componentes são misturados em equipamentos especiais como misturadores de pá ou em espiral, visando homogeneização.

Depois de homogeneizada, tal mistura é levada a uma etapa de granulação, nem sempre obrigatória, submetendo-se a um processo de secagem a baixas temperaturas.

Finalmente a massa produzida é levada à compressão em máquinas rotativas ou alternativas.

Nas máquinas alternativas as punções são fixas e o alimentador, móvel, enquanto nas máquinas rotativas, com maior rendimento, o alimentador permanece fixo, enquanto ocorre rotação das punções e matrizes. 
As punções e matrizes são de aço temperado, sendo responsáveis pela forma do comprimido, enquanto a câmara de compressão determina o peso.

Durante a fabricação de comprimidos alguns requisitos terapêuticos, estético-gustativos e tecnológicos devem ser observados. Os comprimidos são compostos pelas substâncias medicamentosas e adjuvantes.

Os adjuvantes apresentam diversas funções, podendo atuar como diluentes, aglutinantes, absorventes, desintegrantes, lubrificantes, edulcorantes, corantes, aromatizantes, entre outras.

Tais adjuvantes devem ser, preferencialmente, inócuos, inodoros, e inertes.

\subsubsection{Conceito e emprego dos excipientes}

Historicamente, os excipientes vêm sendo considerados elementos ou aditivos inertes dentro de uma formulação farmacêutica, porém, com o avanço na tecnologia de controle e liberação programada de fármacos, tal conceito não mais apresenta validade, sendo hoje, considerados excipientes aqueles componentes, que não o fármaco ou pró-fármaco, com segurança avaliada, capazes de facilitar o processo de fabricação, proteger, aumentar a estabilidade ou melhorar a aceitabilidade do fármaco pelo paciente, facilitar a identificação do produto ou, ainda, aumentar a segurança no transporte ou armazenamento [39-42].

Novos excipientes têm sido estudados com vários propósitos como: reduzir incompatibilidades entre componentes de uma fórmula, aumentar a compressibilidade dos pós e superar dificuldades terapêuticas ou mesmo 
farmacotécnicas já encontradas, através de novas formulações capazes de, até mesmo, regular a liberação do princípio ativo no organismo [39-43].

\subsubsection{Estudo dos excipientes presentes}

Nas amostras comerciais analisadas são encontrados vários excipientes, em quantidades variadas, apresentando funções diversas do ponto de vista farmacotécnico. O presente trabalho avaliará diferentes amostras comerciais diferentes, sendo:

a-) medicamento de referência: Lasix.

b-) medicamentos similares: Neosemid, Furosen, Furosix.

c-) medicamentos genéricos: Biosintética genérico, Teuto genérico, Cinfa genérico.

Tais amostras contém excipientes, cujas principais funções tecnológicas são listados a seguir:

a-) amido de milho: desintegrante, aglutinante, adsorvente, deslizante, antiaderente, diluente; permite boa desintegração em função da entrada de água por seus poros. Presente em Lasix, Teuto genérico, e Cinfa genérico. 
b-) estearato de magnésio: antiaderente, lubrificante e desmodelador. Encontrado em Lasix, Neosemid, Biosintética genérico, Furosen, Teuto genérico, Furosix, Cinfa genérico.

c-) lactose: ligante e diluente. Encontrada em Lasix, Neosemid, Biosintetica genérico, Furosen, Furosix.

d-) talco: antiaderente, diluente e deslizante. Encontrado em Lasix, Furosen, Teuto genérico, Furosix.

e-) celulose microcristalina: antiaderente, ligante, diluente e desintegrante. Encontrada em Neosemid, Biosinética genérico, Furosen, Teuto genérico, Furosix.

f-) polivinilpirrolidona (PVP): aglutinante. Encontrada em Neosemid, Biosintética genérico, Furosen.

g-) glicolato amido sódico: desintegrante. Encontrado em Neosemid, Biosintética genérico, Furosen.

h-) sílica anidra coloidal: antiaderente, diluente e deslizante. Encontrada apenas em Biosintética genérico.

i-) álcool etílico: aglutinante. Encontrado apenas em Teuto genérico. 
j-) croscarmelose sódica: desagregante. Presente em Teuto genérico e Furosix.

k-) manitol: diluente. Presente apenas no Teuto genérico.

I-) lauril sulfato de sódio: tensoativo, solubilizante e umectante. Presente apenas em Cinfa genérico.

m-) carbonato de magnésio: protetor básico, ao reagir com meios ácidos, impede a decomposição de princípios ativos que devem ser dissolvidos em ambientes alcalinos. Presente apenas no Cinfa genérico. 


\section{CAPITULO 4: DETERMINACÕES TITULOMÉTRICAS}

\subsection{Apresentação}

A titulometria vem sendo empregada há mais de 200 anos na realização de análises quantitativas, sendo considerada um método primário muito empregado inclusive na validação de outros métodos. Tal processo consiste na adição de quantidades discretas de um dos reagentes no meio reacional, com objetivo de quantificar o analito por meio de reações quantitativas entre este e componentes do meio [44].

\subsection{Materiais e métodos}

Visando determinação titulométrica da furosemida em comprimidos foram utilizadas soluções aquosas de $\mathrm{KMnO}_{4}$ (Merck, Alemanha), com concentrações na ordem de $2,0 \times 10^{-3} \mathrm{~mol} \mathrm{~L}^{-1}$, preparadas por dissolução simples em água destilada e posteriormente padronizadas frente a uma solução padrão primário de ácido oxálico, conforme descrito em [45].

Todos os reagentes empregados apresentavam grau de pureza analítico P.A. As soluções foram preparadas em água destilada ou acetona (Mallinckrodt, EUA), no momento de abertura das amostras comerciais.

\subsubsection{Preparo das amostras}

Três apresentações comerciais contendo furosemida foram analisadas: Lasix $^{\circledR} 40$ mg, Neosemid ${ }^{\circledR} 40$ mg e Furosemida Genérica 40 mg Cinfa ${ }^{\circledR}$, dos 
laboratórios Cinfa ${ }^{\circledR}$, Aventis $^{\circledR}$ e Neoquímica ${ }^{\circledR}$, respectivamente; tais amostras foram adquiridas em drogarias locais.

Dez comprimidos foram triturados com auxílio de almofariz e pistilo até a obtenção de um pó fino e homogêneo, do qual se retirou o equivalente à massa média de um comprimido, com precisão de 0,1 mg.

Tal massa foi transferida a um béquer de $50 \mathrm{~mL}$, sendo dissolvida em 25,0 $\mathrm{mL}$ de acetona sob ultrassom por 10 minutos. A solução obtida foi filtrada e transferida para balão volumétrico de 50,0 mL, completando-o com água destilada.

Amostras da Cinfa ${ }^{\circledR}$ apresentaram ligeira efervescência após adição de água, motivo pelo qual foram deixadas em repouso por 10 minutos antes de se completar o volume.

No caso dos estudos em ambientes micelares, conforme será descrito a seguir, o preparo de amostras consistiu de uma extração prévia, em que o analito foi extraído da matriz com de acetona, sendo este solvente removido do sistema por corrente de ar comprimido. O analito foi re-suspenso em solução de 3\% SDS.

\subsection{Procedimento titrimétrico}

Alíquotas de $10,0 \mathrm{~mL}$ da solução padronizada de $\mathrm{KMnO}_{4}$ foram transferidas para erlenmeyer de $125 \mathrm{~mL}$, adicionando-se ao sistema $3 \mathrm{~mL}$ de $\mathrm{H}_{2} \mathrm{SO}_{4} 4 \mathrm{~mol} \mathrm{~L} \mathrm{~L}^{-1}$, visando acidificação do meio. A padronização foi feita seguindo procedimento oficial baseado na Equação 4.1.[45]:

$$
2 \mathrm{MnO}_{4}^{-}+5 \mathrm{C}_{2} \mathrm{O}_{4}^{-2} \rightarrow 10 \mathrm{CO}_{2} \uparrow+2 \mathrm{Mn}^{+2}+8 \mathrm{H}_{2} \mathrm{O}
$$


A solução obtida foi titulada com a solução de amostra e o ponto final determinado pela mudança de coloração de violeta para incolor sendo o permanganato um auto-indicador.

As titulações foram realizadas sob forte agitação, sob temperatura controlada em $10^{\circ} \mathrm{C}$, visando minimizar perdas de acetona por volatilização. Ensaios em branco foram realizados visando avaliar possíveis reações com o solvente empregado, observando-se necessidade de alto grau de pureza dos mesmos.

\subsection{Coeficiente estequiométrico}

O analito em estudo, em meio ácido, apresenta hidrólise [46], que ocorre inicialmente com protonação no nitrogênio da posição 6 e posterior fragmentação da molécula em saluamina (I) e álcool furfurílico (II), conforme apresentado da Equação 4.2. Tendo em vista a presença dos grupos amina e sulfamida na estrutura da saluamina, espera-se explorar as possíveis reações de óxido-redução entre tais grupos e o $\mathrm{MnO}_{4}{ }^{-}$.<smiles>N#CS(=O)(=O)c1cc(C(=O)O)c(NCc2ccco2)cc1Cl</smiles><smiles>C[C+]P(=O)(O)c1cc(C(=O)O)c(N)cc1Cl</smiles>

(1)

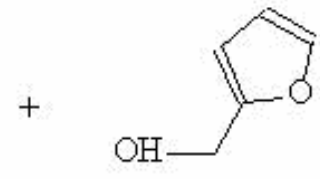

(II) 
Reações com íon permanganato apresentam cinética irregular e, em geral, são auto-catalíticas, o que pode dificultar a elucidação dos processos envolvidos.

Visando minimizar este problema, o coeficiente estequiométrico foi determinado por meio de titulação de uma solução de furosemida de concentração conhecida, sob as condições anteriormente descritas, antes de se iniciar as determinações das amostras, o coeficiente encontrado indica proporção de 5:3 $\left(\mathrm{MnO}_{4}{ }^{-}\right.$: furosemida).

\subsection{Resultados obtidos}

Amostras comerciais foram submetidas ao preparo de amostra e titulação, apresentando como resultados os valores apresentados na Tabela 4.1.

Tabela 4.1.: Resultados obtidos por titulometria

\begin{tabular}{lccc}
\hline Amostra & $\begin{array}{c}\text { Valor } \\
\text { Rotulado }^{\text {a }}\end{array}$ & $\begin{array}{c}\text { Método } \\
\text { Proposto }^{\text {b }}\end{array}$ & Método Oficial $^{\mathrm{b}}$ \\
\hline Lasix $^{\circledR}$ comprimido $_{\text {Neosemid }}^{\circledR}$ comprimido & 40 & $37,4 \pm 0,5$ & $39,5 \pm 0,9$ \\
Cinfa $^{\circledR}$ comprimido $^{\mathrm{a}}$ & 40 & $37,1 \pm 0,6$ & $39,1 \pm 0,6$ \\
\hline
\end{tabular}

${ }^{\mathrm{a}} \mathrm{mg}$ por comprimido;

${ }^{b}$ valores médios e desvios, $n=3$.

Apesar dos valores obtidos com o método proposto serem sistematicamente inferiores aos rotulados, os mesmos concordam com os obtidos pelo método Oficial com 95\% de confiança, segundo teste $t$ - Student. 


\subsection{Exploração de meios micelares}

Visando melhorar a solubilidade do analito e minimização dos resíduos gerados, foram realizados experimentos titrimétricos em ambientes micelares, nos quais a furosemida é solúvel. Neste caso, inicialmente foi necessário um estudo de solubilidade da furosemida no tensoativo a ser empregado.

Ambientes micelares vêm sendo amplamente utilizados em química analítica com diversos objetivos, dentre os quais destacam-se o aumento de sensibilidade de sistemas espectrofotométricos, aumento de solubilidade de analitos pouco solúveis, possibilidade de extrações por ponto nuvem ("CloudPoint'), entre outros [47].

No procedimento titrimétrico em estudo, o tensoativo a ser empregado deve ser cuidadosamente escolhido, visando evitar reações paralelas entre analito e tensoativo ou $\mathrm{KMnO}_{4}$ e tensoativo, pois tais interações inviabilizariam as determinações. Tendo este cuidado, foi escolhido o surfactante dodecil sulfato de sódio, popularmente conhecido por lauril sulfato de sódio; tal agente apresenta massa molar de 288,4 $\mathrm{g} \mathrm{mol}^{-1}$, e caráter aniônico. Este agente tensoativo apresenta amplo emprego em formulações farmacêuticas (inclusive em amostras analisadas) e cosméticas, sendo de fácil obtenção e uso.

Visando avaliar a solubilidade do fármaco em soluções de dodecil sulfato de sódio (SDS), foram realizados testes de solubilidade semelhantes aos realizados por Shihab et al. [48]. Soluções de SDS foram preparadas em concentrações iguais a $1,2,3$ e $4 \%(m / v)$, sendo tais soluções transferidas para erlenmeyers de $125 \mathrm{~mL}$, nos quais foram adicionadas cerca de $200 \mathrm{mg}$ de furosemida, pesadas com precisão de $\pm 0,1 \mathrm{mg}$. Tais frascos foram submetidos a agitação por 30 minutos em mesa agitadora e posteriormente as soluções 
obtidas foram filtradas com o intuito de se eliminar a furosemida em excesso, não solubilizada. Os resultados são apresentados na Figura 4.1.

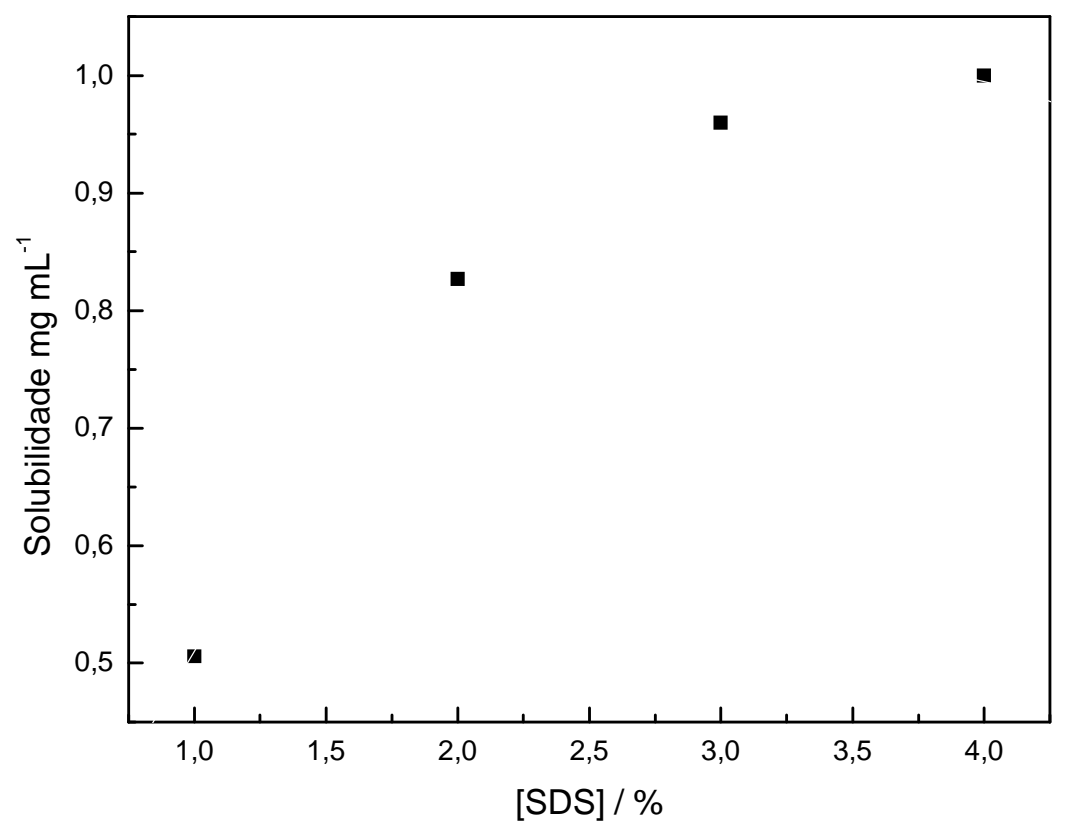

Figura 4.1.: Solubilidade estimada para a furosemida em função da concentração de SDS em solução.

Tendo sido avaliada a solubilidade do analito em ambiente micelar, fixou-se os experimentos titrimétricos em meio de SDS 3\%, por já ser uma concentração suficiente para solubilizar o analito contido na tomada de amostra.

Os procedimentos titrimétricos seguiram as mesmas orientações descritas anteriormente. Os resultados alcançados são demonstrados a seguir.

Tabela 4.2.: Resultados obtidos por titulometria em meio micelar

\begin{tabular}{lccc}
\hline Amostra & $\begin{array}{c}\text { Valor } \\
\text { Rotulado }^{\text {a }}\end{array}$ & $\begin{array}{c}\text { Método } \\
\text { Proposto }^{\text {b }}\end{array}$ & Método Oficial $^{\text {b }}$ \\
\hline Lasix $^{\circledR}$ comprimido $^{\circledR}$ & 40 & $43,0 \pm 0,4$ & $39,5 \pm 0,9$ \\
Neosemid $^{\circledR}$ comprimido & 40 & $39,1 \pm 0,7$ & $39,1 \pm 0,6$ \\
Cinfa $^{\circledR}$ comprimido $^{2}$ & 40 & $41,1 \pm 0,4$ & $41 \pm 2$ \\
\hline
\end{tabular}

\footnotetext{
a mg por comprimido;

${ }^{\mathrm{b}}$ valores médios e desvios, $\mathrm{n}=3$.
} 
Os resultados obtidos pelo método proposto e pelo método Oficial para as amostras comerciais das marcas Neosemid ${ }^{\circledR}$ e Cinfa $^{\circledR}$ apresentam concordância em um nível de confiança de $95 \%$, já os resultados relativos ao Lasix ${ }^{\circledR}$ concordam entre si em um nível de $99 \%$, segundo teste $t$ - Student pareado. 


\section{CAPITULO 5: DETERMINACÕES ESPECTROFOTOMÉTRICAS ESTÁTICAS}

\subsection{Apresentação}

Visando a determinação espectrofotométrica da furosemida nas amostras comerciais, foi utilizada uma reação de complexação entre o analito e íons $\mathrm{Fe}^{+3}$. Tal reação foi descrita por Zivanovic et al. [49], e consiste na formação de um complexo instável entre a furosemida e os íons $\mathrm{Fe}^{+3}$, em meio ácido, com força iônica ajustada em $0,1 \mathrm{~mol} \mathrm{~L}^{-1}$, numa proporção de 2:1. A reação química não é descrita pois não foi possível isolar e caracterizar o complexo formado.

\subsection{Materiais e métodos}

Nestes estudos foi utilizado um espectrofotômetro Spectronic 20 Genesys, as medidas foram realizadas empregando-se cubeta quartzo com 1 cm de caminho analítico.

Todos os reagentes utilizados foram de grau analítico, PA, e a água, usada no preparo das soluções, foi tratada em sistema Milli-Q (Millipore, EUA).

Foram preparadas soluções aquosas de KCl (Synth, Brasil), HCl (Merck, Alemanha) e $\mathrm{FeCl}_{3} \cdot 6 \mathrm{H}_{2} \mathrm{O}$ (Mallinckrodt, EUA) nas concentrações 1,0 mol L-1, $0,10 \mathrm{~mol} \mathrm{~L}^{-1}$ e $1,0 \times 10^{-2} \mathrm{~mol} \mathrm{~L}^{-1}$, respectivamente. Todas as soluções foram preparadas em água destilada.

Soluções de trabalho de furosemida com concentração entre $4,0 \times 10^{-3} \mathrm{~mol} \mathrm{~L}^{-1}$ e $1,2 \times 10^{-2} \mathrm{~mol} \mathrm{~L}^{-1}$ foram preparados em etanol absoluto (Mallinckrodt, EUA) por diluição a partir de uma solução de estoque padrão de concentração $2,0 \times 10^{-2} \mathrm{~mol} \mathrm{~L}^{-1}$. 
Soluções etanólicas de furosemida apresentam absorção intensa na região do ultravioleta, o que pode ser observado por meio de seu espectro, conforme Figura 5.1 que concordam com informações descritas na literatura [50].

A solução estoque de furosemida, em função de sua fotolabilidade [50,51], era preferencialmente preparada no momento do uso, podendo ser, em alguns casos, estocada em frasco âmbar, ao abrigo da luz, por período de tempo de quatro dias.

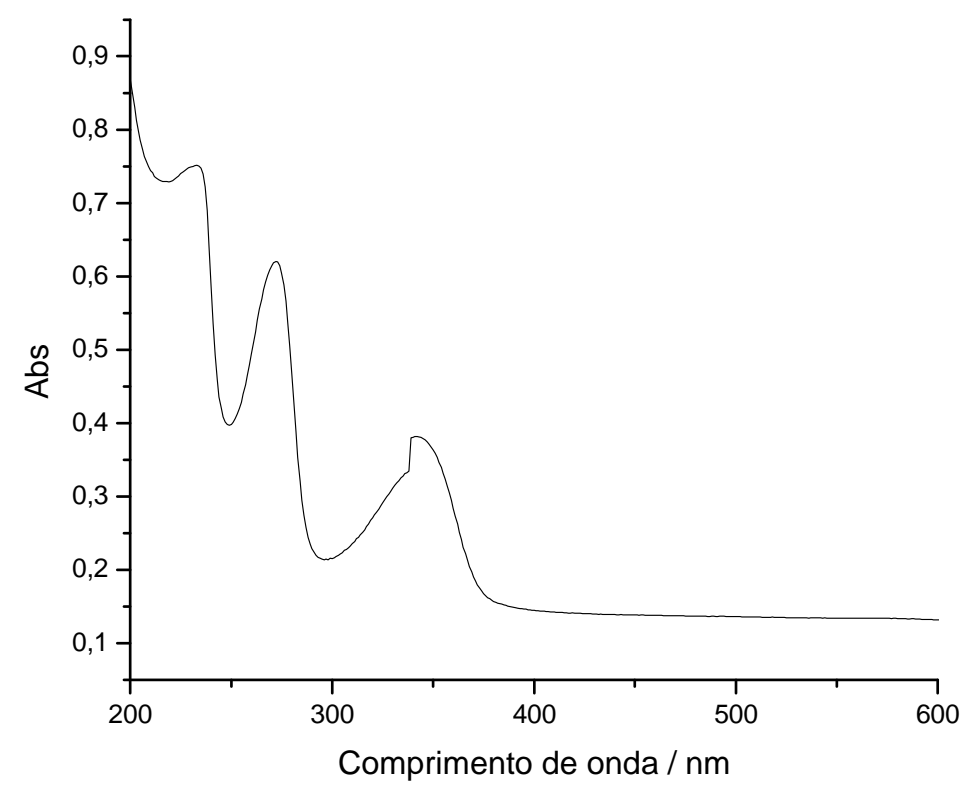

Figura 5.1.: Espectro de absorção de uma solução de furosemida $10^{-5} \mathrm{~mol} \mathrm{~L}^{-1}$, em etanol.

\subsection{Preparo de amostras}

Dez comprimidos foram triturados e homogeneizados em massas equivalentes ao dobro do peso médio de uma unidade foram solubilizadas em etanol, em béquer e submetidas a ultrassom durante 10 minutos. A solução 
obtida foi filtrada e transferida para balão de $50 \mathrm{~mL}$, completando-se o volume com etanol absoluto.

\subsection{Procedimentos espectrofotométricos}

\subsubsection{Espectro de absorção e determinação do comprimento de onda complementar}

Visando determinar o comprimento de onda a ser utilizado nas medidas espectrofotométricas foram obtidos espectros de soluções de $\mathrm{FeCl}_{3} \cdot 6 \mathrm{H}_{2} \mathrm{O}$ e 0 complexo gerado da reação entre $\mathrm{Fe}^{+3}$ e furosemida, observando os espectros ilustrados n Figura 5.2.

O estudo na região do ultravioleta, não mostrou diferenças significativas entre a furosemida pura e o produto de sua complexação com $\mathrm{Fe}^{+3}$. Entretanto é possível observar que a solução de furosemida, na presença de $\mathrm{Fe}^{+3}$ apresenta uma coloração vermelha. Na região do visível foi possível observar o surgimento de uma banda, como pode ser observado na Figura 5.2. Assim, o comprimento de onda de $513 \mathrm{~nm}$ foi escolhido para as determinações no visível, o que concorda com a literatura [49]. Tal escolha se deveu ao emprego da região visível do espectro na qual se julgou mais adequada a diferença entre sinal de branco e sinal das soluções a serem analisadas. 


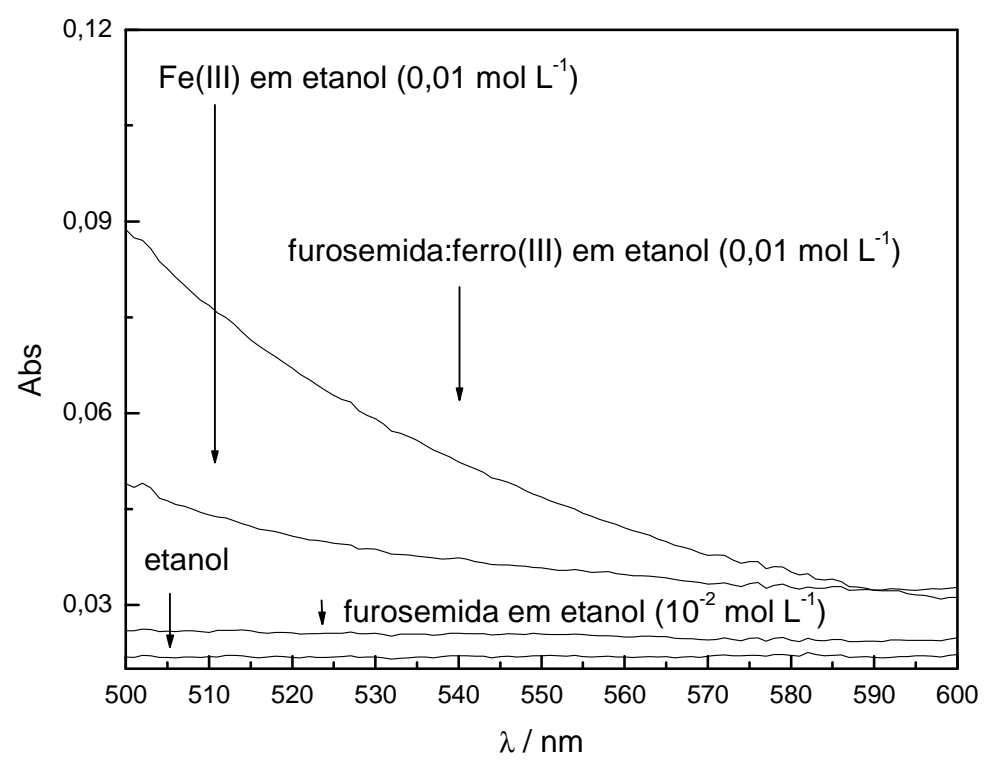

Figura 5.2.: Espectros de absorção do etanol e de soluções contendo apenas furosemida $0,01 \mathrm{~mol} \mathrm{~L}^{-1}, \mathrm{FeCl}_{3} \cdot 6 \mathrm{H}_{2} \mathrm{O} 0,01 \mathrm{~mol} \mathrm{~L}^{-1}$ e $\mathrm{FeCl}_{3} \cdot 6 \mathrm{H}_{2} \mathrm{O} 0,01 \mathrm{~mol} \mathrm{~L}^{-1} \mathrm{na}$ presença de $\mathrm{Fr} 0,01 \mathrm{~mol} \mathrm{~L}^{-1}$.

\subsubsection{Curva analítica}

Em balões volumétricos de $10 \mathrm{~mL}$ foram adicionados $5,0 \mathrm{~mL}$ das soluções padrão de furosemida em concentrações entre $4,0 \times 10^{-3} \mathrm{~mol} \mathrm{~L}^{-1} \mathrm{e}$ $1,2 \times 10^{-2} \mathrm{~mol} \mathrm{~L}^{-1}$; adicionou-se, posteriormente, $1,0 \mathrm{~mL}$ da solução de $\mathrm{Fe}^{+3}$ $0,010 \mathrm{~mol} \mathrm{~L}^{-1}, 1,0 \mathrm{~mL}$ de $\mathrm{KCl} 1,0 \mathrm{~mol} \mathrm{~L}^{-1}$ e $0,10 \mathrm{~mL}$ de $\mathrm{HCl} 0,10 \mathrm{~mol} \mathrm{~L}^{-1}$. Completou-se, então, o volume dos balões, com etanol absoluto.

A ordem de adição dos reagentes é fundamental para obter melhores resultados. Ajustando-se o volume, a solução resultante foi levada imediatamente para leitura em espectrofotômetro, no comprimento de onda de $513 \mathrm{~nm}$. As amostras passaram, rigorosamente, pelos mesmos procedimentos adotados para o preparo dos padrões.

Foram obtidos limites de detecção e de quantificação de $6,0 \times 10^{-4} \mathrm{e}$ $2,0 \times 10^{-3} \mathrm{~mol} \mathrm{~L}^{-1}$, respectivamente. 
A curva analítica obedece à equação:

$$
A b s=113,6 \times[F r]-0,0856, \quad(r=0,999, n=5)
$$

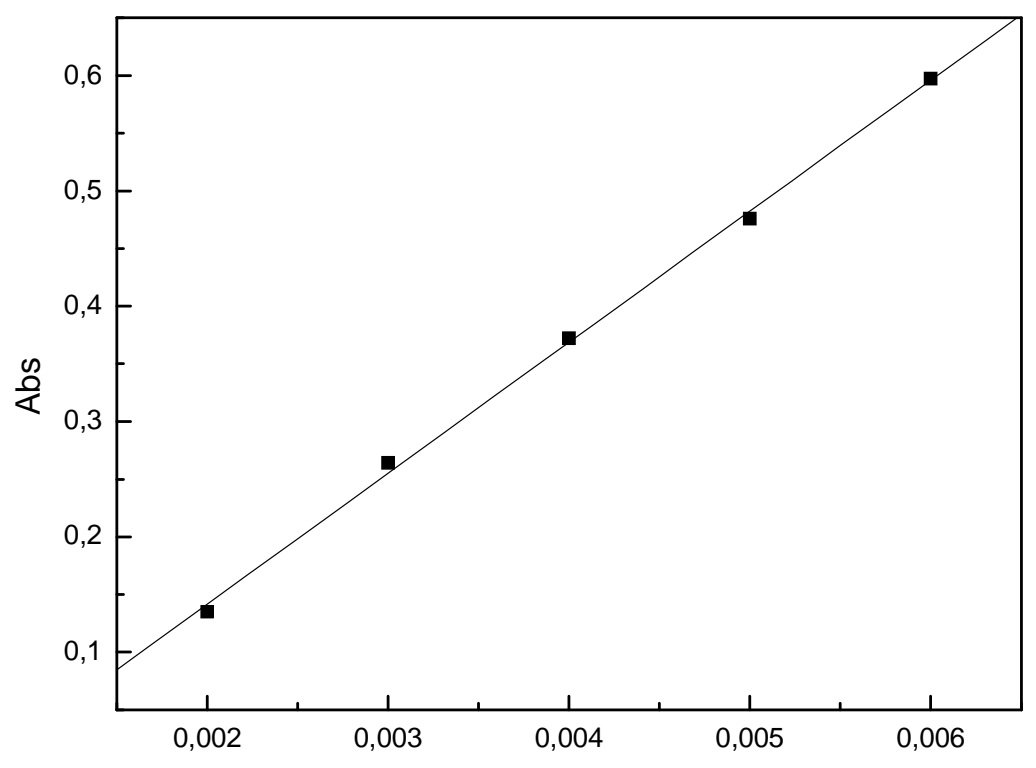

$[\mathrm{Fr}] / \mathrm{mol} \mathrm{L}^{-1}$

Figura 5.3: Curva analítica para a furosemida usando a reação de complexação com Fe ${ }^{+3}$, em etanol, com absorbância medida em 513 nm.

\subsubsection{Adição de padrão}

A amostra da marca Cinfa ${ }^{\circledR}$ apresentou, por ocasião da determinação por curva analítica, interferências, gerando desvios positivos na Lei de Lambert - Beer [52]. Com objetivo de minimizar este efeito de matriz foram realizados testes por adição de padrão. Em balões volumétricos de $10 \mathrm{~mL}$ foram adicionados 5,0 $\mathrm{mL}$ das amostras após preparo e 3,0 $\mathrm{mL}$ de solução padrão. A esta solução, foram adicionados os reagentes de interesse nas mesmas proporções e ordem descritas anteriormente. Após completar-se os volumes nos balões, as soluções obtidas foram imediatamente levadas à leitura. 


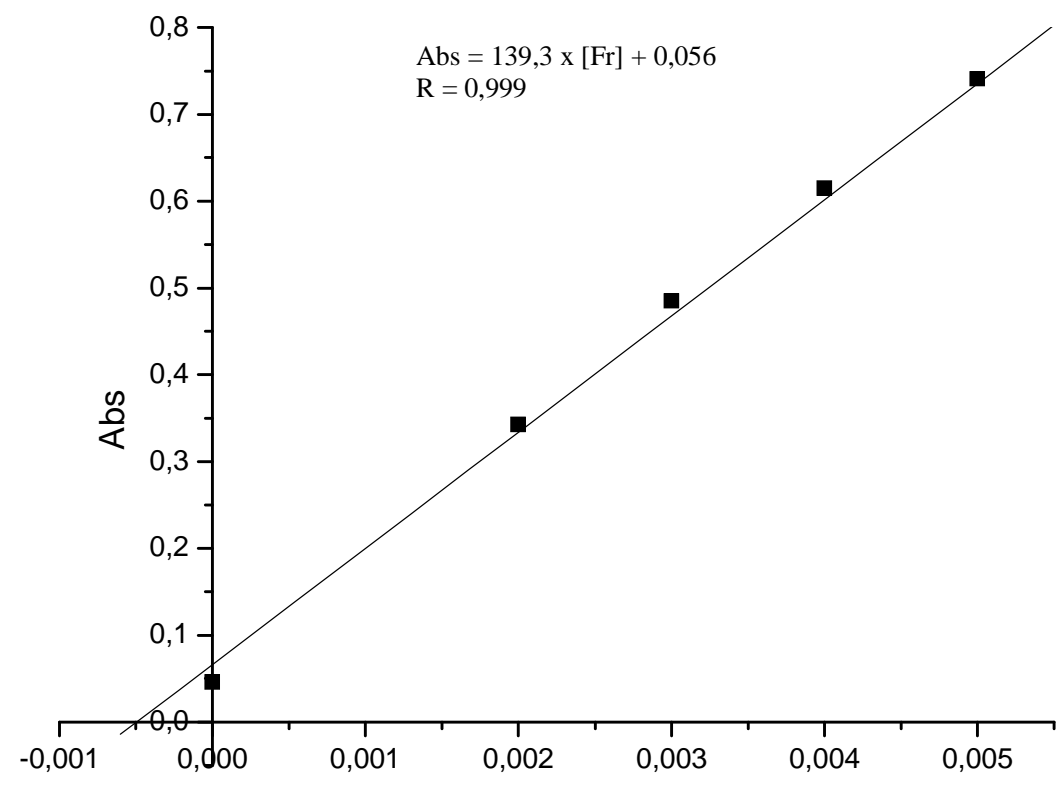

[Fr] adicionada / $\mathrm{mol} \mathrm{L}^{-1}$

Figura 5.4: Curva de adição de padrão para determinação de furosemida em comprimidos da marca Cinfa ${ }^{\circledR}$, como exemplo.

\subsection{Resultados obtidos}

Por meio do procedimento espectrofotométrico descrito foram obtidos os resultados descritos na Tabela 5.1.

Tabela 5.1.: Resultados obtidos por espectrofotometria

\begin{tabular}{|c|c|c|c|}
\hline Amostra & Rótulo $^{a}$ & Procedimento propostob & Método Oficial $^{b}$ \\
\hline Lasix $^{\circledR}$ comp. & 40 & $41 \pm 2$ & $39,5 \pm 0,9$ \\
\hline Neosemid ${ }^{\mathbb{Q}}$ comp. & 40 & $40,6 \pm 0,3$ & $39,1 \pm 0,6$ \\
\hline $\mathrm{Cinfa}^{\circledR}$ comp. & 40 & $42 \pm 1$ & $41 \pm 2$ \\
\hline
\end{tabular}

\footnotetext{
${ }^{a} \mathrm{mg}$ por comprimido;

${ }^{\mathrm{b}}$ valores médios e desvios, $\mathrm{n}=3$.
}

Os resultados numéricos são próximos e concordantes entre si com 95\% de confiança de acordo com o teste $t$-Student pareado. 
Isso permite afirmar que o método pode ser aplicado com segurança na determinação de furosemida em comprimidos.

A vantagem do método reside na não necessidade de preparo de amostras. O etanol usado pode ser recuperado facilmente por destilação, prevenindo geração de resíduos prejudiciais ao meio ambiente. 


\section{CAPITULO 6: DETERMINACÕES ESPECTOFOTOMÉTRICAS DE FUROSEMIDA EM FLUXO}

\subsection{Apresentação: análise por injeção em fluxo (FIA)}

Com o objetivo de minimizar as etapas de manipulação da amostra, o consumo de reagentes, amostras e tempo, e maximizar a freqüência analítica têm sido desenvolvidos sistemas nos quais a amostra é introduzida em um fluxo carregador no qual também se adicionam reagentes necessários e, após reação, o produto gerado é levado a um sistema detector, no qual são obtidos os sinais analíticos.

Tal sistema pode ser dividido em quatro partes principais: introdução de amostras, propulsão dos fluidos, reações e detecção [51,53]. O transporte dos fluidos é feito com auxílio de tubos de polietileno e/ou tygon, de diâmetros internos variáveis. Os sistemas em fluxo se apresentam versáteis pela possibilidade da inclusão de acessórios em seu percurso, como, por exemplo, membranas filtrantes, câmaras de mistura, confluências, entre outros. A propulsão dos fluidos pode ser gerada com o uso de bombas peristálticas, frascos pressurizados ou simplesmente através da ação da gravidade, sendo de fácil controle suas vazões [53-56].

Os procedimentos estáticos descritos nos capítulos anteriores foram adaptados a sistemas em fluxo, utilizando detecção espectrofotométrica. 


\subsection{Determinação espectrofotométrica em fluxo por meio da reação com $\mathrm{KMnO}_{4}$}

\subsubsection{Reagentes e soluções}

A furosemida foi obtida da Natural Pharma (Brasil) e foi caracterizada como padrão por ressonância magnética nuclear de prótons (RMN - ${ }^{1} \mathrm{H}$ ), espectrometria vibracional na região do infravermelho com transformada de Fourier (FTIR), análise elementar (EA), calorimetria exploratória diferencial (DSC), e cromatografia líquida de alta eficiência com detector em arranjo de fotodiodos (HPLC-DAD). A água utilizada foi previamente tratada em um sistema Milli-Q (Millipore, EUA). Todos os reagentes foram grau analítico (Mallinckrodt ,EUA).

A solução carregadora foi $\mathrm{KMnO}_{4} 3,0 \times 10^{-4} \mathrm{~mol} \mathrm{~L}^{-1} \mathrm{em} \mathrm{H} \mathrm{SO}_{4} 2,0 \mathrm{~mol} \mathrm{~L}^{-1}$. Uma solução estoque de furosemida $1,0 \times 10^{-2} \mathrm{~mol} \mathrm{~L}^{-1}$ foi preparada dissolvendo-se o reagente em $\mathrm{NaOH} \mathrm{0,02} \mathrm{mol} \mathrm{L}^{-1}$. Esta solução foi usada para a preparação das soluções de trabalho diluindo os volumes desejados com $\mathrm{NaOH} 0,02 \mathrm{~mol} \mathrm{~L}^{-1}$.

\subsubsection{Sistema em fluxo}

O sistema em fluxo aplicado compôs-se de um espectrofotômetro Genesys 20 (Spectronics, EUA), ajustado em 550 nm, e uma bomba peristáltica IPC 8 (Ismatec, Suíça), tubos de tygon (Cole Parmer, EUA) foram empregados para geração do fluxo por meio da bomba. As alças de amostra e

outros percursos foram preparados com tubos de polietileno $0.8 \mathrm{~mm}$ i.d. (Protubos, Brasil). 
Durante o processo de otimização, a temperatura do reator foi controlada por um banho termostático M-81 (Marconi, Brasil). O sistema é representado na Figura 6.1.

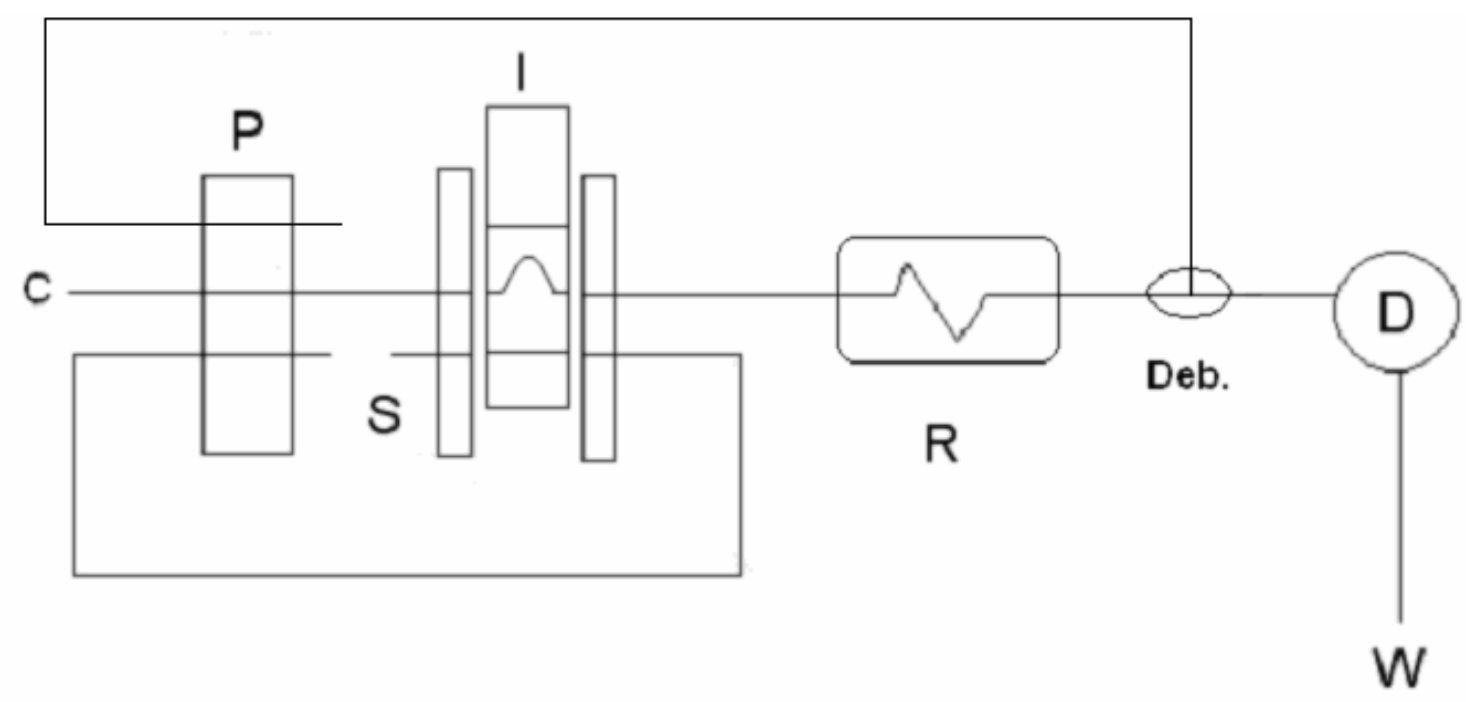

Figura 6.1.: Diagrama esquemático para o sistema em fluxo empregado neste trabalho. $\mathrm{C}=$ fluido carregador $\left(2,2 \mathrm{~mL} \mathrm{~min}^{-1}\right), \mathrm{S}=$ injeção de brancos, padrões ou amostras, $\mathrm{I}=$ injetor-comutador, $\mathrm{R}=$ reator termostatizado, Deb.= desborbulhador de vidro em "T", $\mathrm{D}=$ detector e $\mathrm{W}=$ descarte.

\subsubsection{Preparo de amostras}

As formulações farmacêuticas analisadas neste trabalho foram apresentadas como comprimidos e ampolas, de três marcas diferentes comercializadas no mercado brasileiro (Lasix ${ }^{\circledR}$, de Aventis ${ }^{\circledR}$; Neosemid ${ }^{\circledR}$, de Neoquimica ${ }^{\circledR}$; e Furosemida, de Biosintetica ${ }^{\circledR}$ ).

Para executar as determinações, os comprimidos foram pesados e triturados até que um pó fino e homogêneo fosse obtido. Amostras adequadas desse pó foram pesadas com precisão de $\pm 0,1 \mathrm{mg}$ e solubilizadas em $15 \mathrm{~mL}$ de $\mathrm{NaOH} 0,020 \mathrm{~mol} \mathrm{~L}^{-1}$, os sistemas foram submetidos ao ultrassom por 10 minutos 
e as soluções foram então filtradas. Os volumes foram ajustados com a mesma solução de $\mathrm{NaOH}$ para $25 \mathrm{~mL}$ em balões volumétricos.

As amostras em ampola foram preparadas pela diluição direta de alíquotas adequadas em $\mathrm{NaOH} 0,020 \mathrm{~mol} \mathrm{~L}^{-1}$, em balões volumétricos de 25 $\mathrm{mL}$.

Acredita-se que a oxidação ocorra nos grupos amino da saluamina, de acordo com a Equação a seguir (6.1.), com formação de $\mathrm{Mn}^{+2}$; entretanto não foi possível provar esta proposta como será apresentado no Capítulo 7.<smiles>Nc1cc(Cl)c(OS(N)(=O)=O)cc1C(=O)O</smiles>

Saluamina<smiles>O=C(O)c1cc([N+](=O)[O-])c(Cl)cc1[N+](=O)[O-]</smiles>

(6.1.)

\subsubsection{Otimização de parâmetros do sistema em fluxo}

As medidas foram realizadas com base no descoramento da solução de permanganato de potássio, após sua reação com o analito. Visando otimizar o sistema em fluxo, três parâmetros foram inicialmente estudados: vazão, alça de amostra, e extensão de reator. Nesses estudos, a temperatura foi inicialmente fixada em 22 C. Os parâmetros foram otimizados segundo planejamento fatorial $2^{n}$, com $n=3$ : alça de amostragem entre $10(50 \mu \mathrm{L})$ e $50 \mathrm{~cm}(250 \mu \mathrm{L})$, extensão de reator entre 30 e $100 \mathrm{~cm}$, e vazão entre $0,8 \mathrm{~mL} \mathrm{~min}^{-1}$ e 2,2 $\mathrm{mL}$ $\min ^{-1}$. Nesses testes algumas tendências foram observadas. Quando alça de 
amostragem e extensão de reator foram aumentados, os sinais analíticos tenderam a valores mais altos; por outro lado, o aumento na vazão gerou uma redução no sinal. sugerindo que o tempo de residência não é bastante para a reação se processar com rendimento suficiente. Em tais condições, uma freqüência analítica baixa foi obtida. Para compensar a necessidade da vazão mais alta, o efeito da temperatura também foi avaliado. Durante a otimização de temperatura, a velocidade da reação mostrou-se fortemente dependente de aquecimento. Esta variável foi estudada entre 20 e $60^{\circ} \mathrm{C}$ (Figura 6.2.). A melhor temperatura encontrada foi $50^{\circ} \mathrm{C}$, que demonstrou o melhor sinal analítico e repetibilidade sem o inconveniente da formação de bolhas.

Os parâmetros otimizados (alça de $50 \mathrm{~cm}$, reator de $100 \mathrm{~cm}$, e vazão de 2,2 $\mathrm{mL} \mathrm{min}^{-1}$, a uma temperatura de $50^{\circ} \mathrm{C}$ ) permitiram 40 leituras por hora, sem efeito de memória.

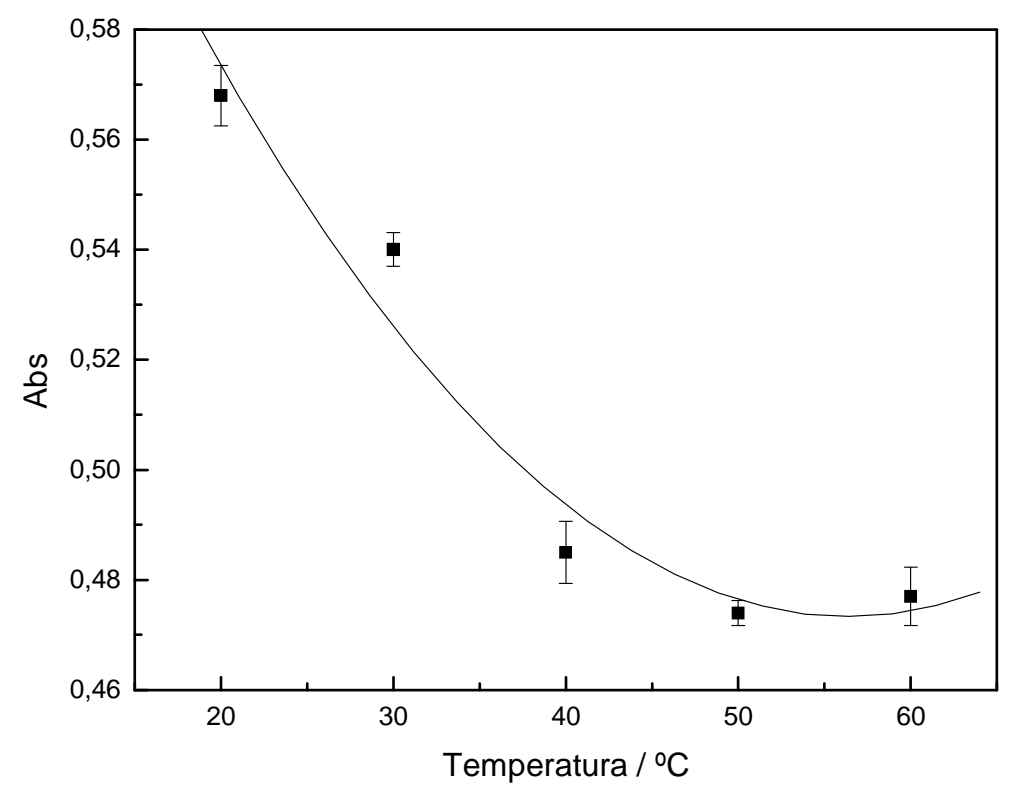

Figura 6.2.: Variação dos sinais de absorbância em função da temperatura. 


\subsubsection{Região linear}

Visando avaliar a região linear para determinação da furosemida, onze soluções padrão com concentrações diferentes (de A a K, Figura 6.3) entre $1,0 \times 10^{-4}$ e $3,0 \times 10^{-3} \mathrm{~mol} \mathrm{~L}^{-1}$ foram introduzidas no sistema em fluxo otimizado.

A curva mostrou um comportamento não linear, como demonstrado na Figura 6.4. A sensibilidade diminui com o aumento de concentrações de furosemida, provavelmente devido à reação limitada com $\mathrm{MnO}_{4}{ }^{-}$, nessas condições. Uma região linear foi observada entre 1,0 e $6,0 \times 10^{-4} \mathrm{~mol} \mathrm{~L}^{-1}$. A aquisição de sinais foi realizada via software desenvolvido por Carla C. S. Cavalheiro, explorando possibilidade de interfaceamento entre microcomputador e espectrofotômetro

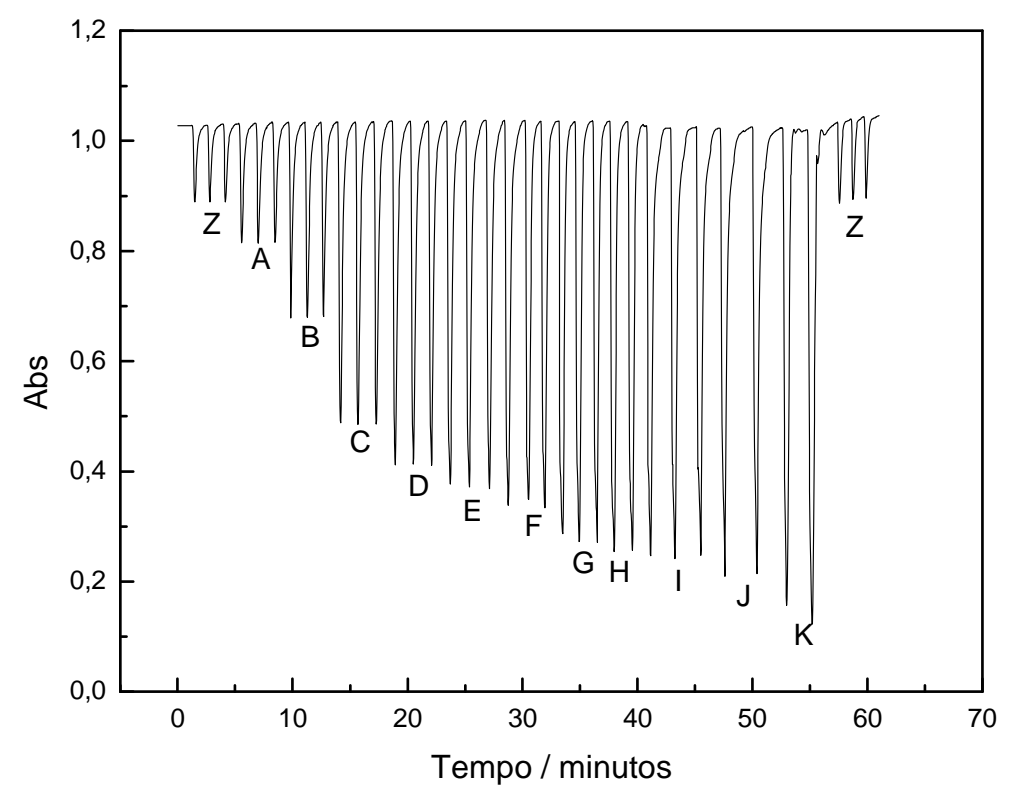

Figura 6.3.: Intervalo linear para determinação (padrões de furosemida de $A$ a $\mathrm{K}, \mathrm{mol} \mathrm{L}^{-1}: \mathrm{A}=1,5 \times 10^{-4}, \mathrm{~B}=2,9 \times 10^{-4}, \mathrm{C}=5,8 \times 10^{-4}, \mathrm{D}=8,7 \times 10^{-4}$, $E=1,2 \times 10^{-3}, F=1,5 \times 10^{-3}, G=1,7 \times 10^{-3}, H=2,0 \times 10^{-3}, I=2,3 \times 10^{-3}$, $\mathrm{J}=2,9 \times 10^{-3}, \mathrm{~K}=3,0 \times 10^{-3}$, Z é o branco). 


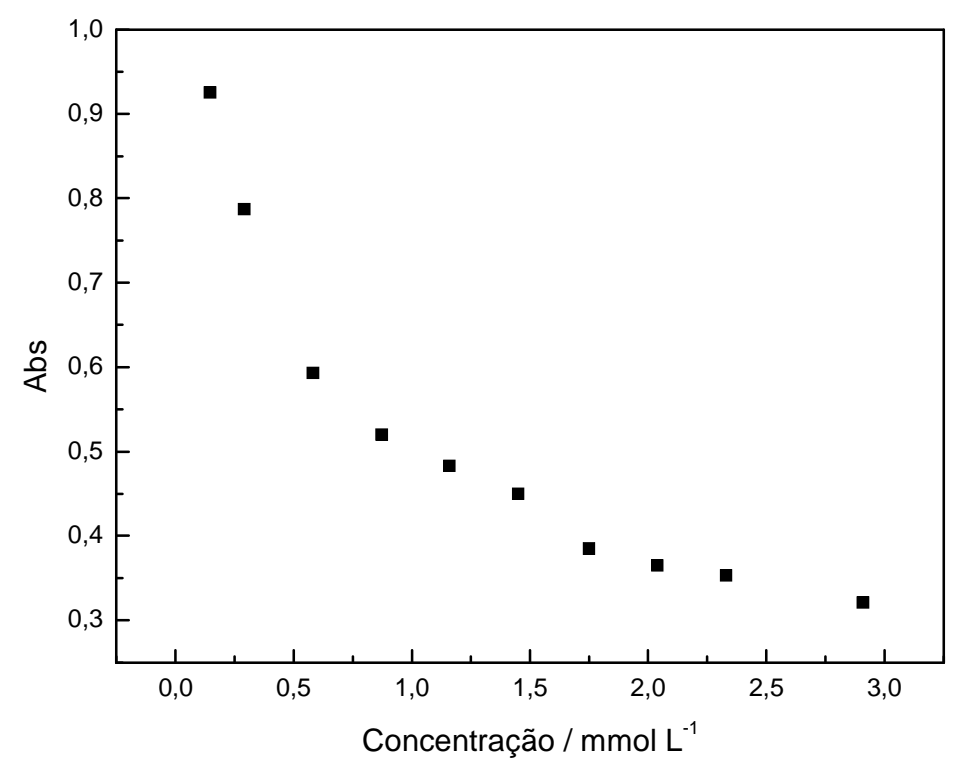

Figura 6.4.: Variação da absorbância em função da concentração de furosemida.

\subsubsection{Aplicações analíticas}

No método descrito, o sinal analítico foi o clareamento da solução transportadora, sendo necessário definir como se determina o sinal analítico. Como o branco gera sinal de diluição, deve ser subtraído do sinal de analito; para solucionar esta situação, foi proposta a Equação 6.2:

Clareamento $=[($ linha base - sinal da solução-problema $)-($ linha base - sinal do branco)]

Nesta equação o segundo termo representa o efeito de diluição.

Foram obtidos limites de detecção e quantificação de $3,3 \times 10^{-5}$ e $1,0 \times 10^{-4} \mathrm{~mol} \mathrm{~L}^{-1}$, respectivamente. As curvas analíticas foram obtidas usando 
soluções padrão de 1,0 a $6,0 \times 10^{-4} \mathrm{~mol} \mathrm{~L}^{-1}(\mathrm{n}=6)$, como apresentado na Figura 6.5.

O intervalo linear foi aplicado para calibrar o sistema, sendo representado pela Equação 6.3.:

$$
A b s=587,5 \times[F r]+0,09(r=0,995, n=6)
$$

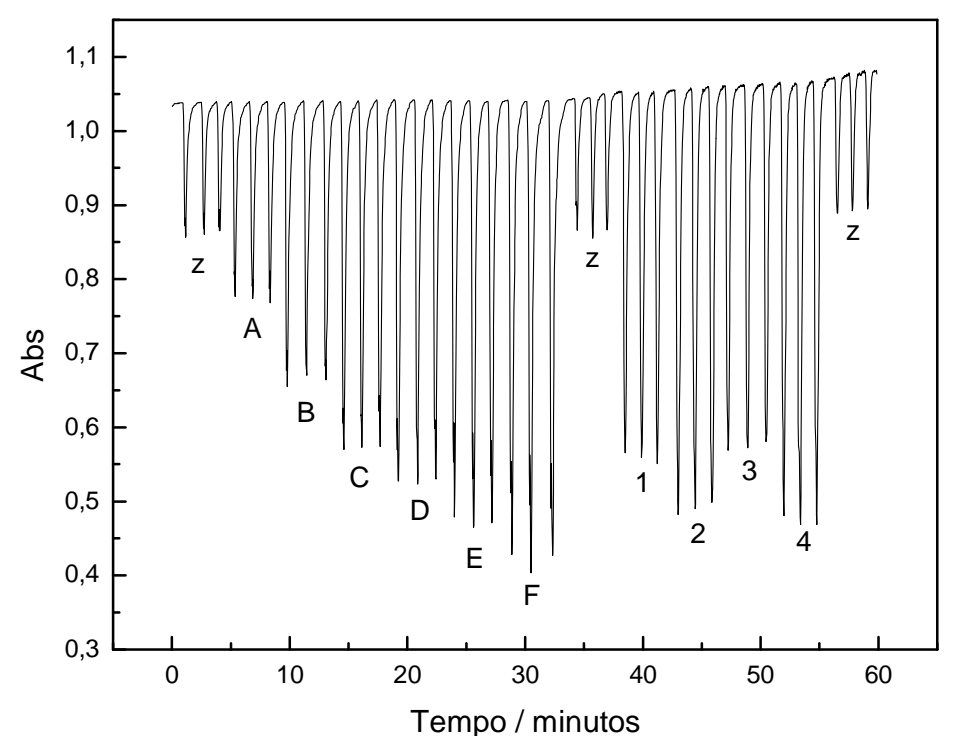

Figura 6.5.: Sinais gerados pelo branco $(Z)$, padrões de furosemida $(A-F$, mol L-1: $A=1,0 \times 10^{-4}, B=2,0 \times 10^{-4}, C=3,1 \times 10^{-4}, D=4,1 \times 10^{-4}$, $E=5,1 \times 10^{-4}$ e, $F=6,1 \times 10^{-4}$ ) e amostras (1: Lasix ${ }^{\circledR}$ injetável; 2: Lasix $^{\circledR}$ comprimidos; 3: Neosemid ${ }^{\circledR}$ comprimidos, e 4: Biosintetica ${ }^{\circledR}$ comprimidos).

O sistema foi usado para determinar furosemida em algumas amostras comerciais de injetáveis e comprimidos. Os valores rotulados e encontrados são apresentados na Tabela 6.1. 
Tabela 6.1.: Valores encontrados e rotulados

\begin{tabular}{lccc}
\hline Amostra & Rótulo & $\begin{array}{c}\text { Procedimento } \\
\text { proposto }^{\mathrm{C}}\end{array}$ & Método Oficial $^{\mathrm{C}}$ \\
\hline Lasix $^{\circledR}$ ampola & $10^{\mathrm{a}}$ & $10,6 \pm 0,1$ & $9,6 \pm 0,3$ \\
Lasix $^{\circledR}$ comp. $^{\circledR}$ comp. & $40^{\mathrm{b}}$ & $42,5 \pm 0,1$ & $40,5 \pm 1,5$ \\
Neosemid $^{\circledR}$ comp & $40^{\mathrm{b}}$ & $42,7 \pm 0,1$ & $41,8 \pm 0,1$ \\
Biosintetica $^{\circledR}$ comp. & $40^{\mathrm{b}}$ & $40,3 \pm 0,1$ & $40,6 \pm 0,9$ \\
\hline
\end{tabular}

${ }^{\mathrm{a}} \mathrm{mg}$ furosemida por $\mathrm{mL}$;

${ }^{\mathrm{b}} \mathrm{mg}$ furosemida por comprimido;

${ }^{\mathrm{c}}$ valores médios e desvios padrão.

O método desenvolvido mostrou ser rápido, simples e de fácil montagem, empregando instrumentação e acessórios simples. A freqüência analítica superou outras apresentadas na literatura. Embora a região linear tenha sido estreita, algumas formulações farmacêuticas como ampolas e comprimidos foram analisadas com resultados próximos ao método comparativo, com o qual concordam com 95\% de confiança, de acordo com o teste $t$ - Student pareado.

Embora o permanganato seja um agente oxidante forte que pode reagir com várias substâncias orgânicas, excipientes presentes nas amostras analisadas não apresentaram interferências no método proposto. Isto o faz conveniente para a determinação de furosemida em formulações comerciais.

\subsection{Determinação em fluxo por meio da reação com $\mathrm{Fe}^{+3}$ em meio etanólico com detecção espectrofotométrica}

\subsubsection{Reagentes e soluções}

Uma solução estoque de furosemida for preparada por solubilização direta do analito em etanol resultando em uma concentração de $0,010 \mathrm{~mol} \mathrm{~L}^{-1}$. A partir deste estoque, por diluição no mesmo solvente, foram preparadas as soluções de trabalho entre $1,0 \times 10^{-4}$ e $1,0 \times 10^{-2} \mathrm{~mol} \mathrm{~L}^{-1}$. 
Neste sistema, foi empregada como solução carregadora uma solução etanólica de $\mathrm{Fe}^{+3}$, a partir de $\mathrm{FeCl}_{3} \cdot 6 \mathrm{H}_{2} \mathrm{O}$ (Merck, Alemanha) em concentração de $1,0 \times 10^{-2} \mathrm{~mol} \mathrm{~L}^{-1}$. Esta solução foi obtida "on-line" a partir de diluição de um estoque $\mathrm{Fe}^{+3} 2,0 \times 10^{-2} \mathrm{~mol} \mathrm{~L}^{-1} \mathrm{com}$ etanol, por meio de uma confluência na qual ambos os fluxos de $\mathrm{Fe}^{+3}$ e etanol chegavam na mesma vazão. Não houve necessidade de padronizar o estoque em relação à concentração de ferro, pois ele é necessário em excesso apenas para gerar o reagente cromóforo.

\subsubsection{Sistema em fluxo}

O sistema em fluxo desenvolvido (Figura 6.6) empregou, como detector, um espectrofotômetro Genesys 20 (Spectronic, EUA), ajustando-se o comprimento de onda para leituras em $513 \mathrm{~nm}$, como previamente citado para os procedimentos estáticos. Para geração e manutenção do fluxo hidrodinâmico foi utilizada uma bomba peristáltica IPC 8 (Ismatec, Suíça) e tubos de tygon com diâmetros internos diferentes (Cole Parmer, EUA). Os percursos e alças de amostragem foram preparados em tubos de polietileno de 0,8 mm de diâmetro interno (Fiotubos, Brasil). 


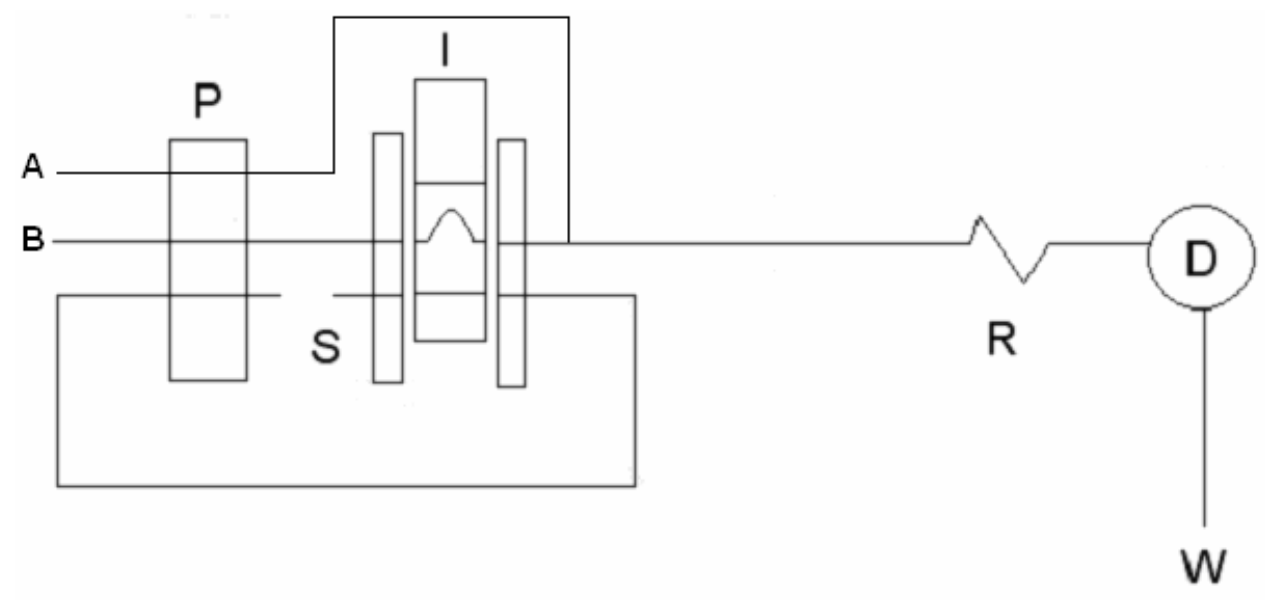

Figura 6.6.: Sistema em fluxo empregado: $A=\mathrm{Fe}^{+3} 2,0 \times 10^{-2} \mathrm{~mol} \mathrm{~L}^{-1}$, $B=$ etanol, $D=$ detector $(513 \mathrm{~nm}), I=$ injetor (alça de amostra $=50 \mathrm{~cm}$ ), $\mathrm{P}=$ bomba peristáltica (vazão $\left.1,0 \mathrm{~mL} \mathrm{~min}^{-1}\right), \mathrm{R}=$ reator helicoidal $(50 \mathrm{~cm})$, $\mathrm{S}=$ amostra $\mathrm{W}=$ descarte .

\subsubsection{Preparo de amostras}

No presente trabalho foram empregadas amostras comerciais nas formas sólidas (comprimidos de $40 \mathrm{mg}$ ) e líquidas (ampolas injetáveis de $10 \mathrm{mg}$ $\mathrm{mL}^{-1}$ ), bem como urina sintética.

Inicialmente dez comprimidos de cada marca avaliada (num total de três marcas) foram triturados até a obtenção de um pó fino e homogêneo, visando otimizar a representatividade das alíquotas a serem retiradas e analisadas. Tais alíquotas foram retiradas e solubilizadas em etanol com auxílio de banho ultra-sônico por 10 minutos. Os sistemas foram, então, filtrados e os volumes ajustados com o mesmo solvente.

O preparo das amostras injetáveis consistiu na obtenção de três ampolas de $10 \mathrm{mg} \mathrm{mL}^{-1}$, das quais se retirou alíquotas e diluiu-se em água visando uma concentração de $1,0 \times 10^{-3} \mathrm{~mol} \mathrm{~L}^{-1}$ de furosemida.

A solução obtida foi submetida à extração em fase líquida, tendo como líquido extrator acetato de etila, colocado na ampola de separação em volume 
igual ao da solução da amostra; o sistema foi homogeneizado por 10 minutos e deixado em repouso para que ocorresse a separação de fases, mantendo na fase superior o extrato orgânico.

Da fase orgânica retirou-se $5,0 \mathrm{~mL}$, transferindo-os para balão volumétrico de $10 \mathrm{~mL}$; este solvente foi retirado do sistema por meio de uma corrente de ar, até a secura; o analito foi re-suspenso no próprio balão utilizando-se etanol.

Com objetivo de avaliar o desempenho do sistema em análise de fluidos biológicos foi empregada uma urina sintética adicionada do analito. Optou-se por trabalhar com urina sintética em virtude de sua fácil preparação e inexistência de riscos de contaminação do sistema, do laboratório e do analista. A urina sintética foi preparada segundo Laube et al. [57], com pequenas modificações, de acordo com o que é apresentado na Tabela 6.2.

Tabela 6.2.: Composição da urina sintética empregada

\begin{tabular}{lc}
\hline Componente & Concentração $\left(\mathrm{g} \mathrm{L}^{-1}\right)$ \\
\hline $\mathrm{CaCl}_{2} \cdot 2 \mathrm{H}_{2} \mathrm{O}$ & 1,0 \\
$\mathrm{NaCl}$ & 3,0 \\
$\mathrm{Na}_{2} \mathrm{SO}_{4}$ & 2,0 \\
$\mathrm{KH}_{2} \mathrm{PO}_{4}$ & 1,0 \\
$\mathrm{KCl}$ & 2,0 \\
$\mathrm{NH}_{4} \mathrm{Cl}$ & 1,0 \\
$U$ Urea & 25 \\
\hline
\end{tabular}

* Preparada em água destilada e com pH ajustado para 6,00 com NaOH.

Os autores sugerem o uso de creatinina em concentração da ordem de $10^{-4} \mathrm{~mol} \mathrm{~L}^{-1}$. Entretanto, considerando a semelhança química em relação à uréia e a concentração muito maior desta última, optou-se por não usar a creatinina na preparação da urina sintética, usada neste trabalho. 
A urina sintética recebeu adição de padrão visando uma concentração de $10^{-3} \mathrm{~mol} \mathrm{~L}^{-1}$ de furosemida e submetida a extração da mesma forma que descrito para amostras de injetáveis.

\subsubsection{Otimização de parâmetros do sistema em fluxo}

Visando otimizar o sistema em fluxo a ser empregado, três parâmetros foram inicialmente estudados: vazão, alça de amostragem e extensão do reator. Tais parâmetros foram avaliados segundo um planejamento fatorial $2^{3}$, no qual a alça de amostragem variou entre 20 e $50 \mathrm{~cm}$, a extensão do reator foi avaliada entre 50 e $150 \mathrm{~cm}$, e a vazão, entre 1,0 e 2,0 $\mathrm{mL} \mathrm{min}^{-1}$.

Por meio destes estudos foram observadas algumas tendências: aumentos na alça de amostragem oferecem maiores sinais analíticos, por outro lado, aumentos na extensão do reator e na vazão do sistema ocasionam redução nos sinais analíticos, provavelmente causados por efeitos de dispersão. Para as aplicações analíticas fixaram-se as condições: alça de amostragem de $50 \mathrm{~cm}(250 \mu \mathrm{L})$, reator de $50 \mathrm{~cm}$ de extensão e vazão em 1,0 $\mathrm{mL} \min ^{-1}$. Nestas condições, uma freqüência analítica de 95 medidas por hora foi alcançada.

\subsubsection{Figuras de mérito}

Soluções de calibração foram preparadas a partir da diluição do estoque 0,010 mol $\mathrm{L}^{-1}$, observando-se uma região linear entre $1,0 \times 10^{-4} \mathrm{e}$ $1,0 \times 10^{-2} \mathrm{~mol} \mathrm{~L}^{-1}$, obedecendo à Equação 6.4.:

$$
A b s=22,624 \times[F r]+0,0089 \quad(r=0,998, n=7)
$$


Limites de detecção $(3 \sigma / \mathrm{m})$ e quantificação $(10 \sigma / \mathrm{m})$ calculados foram de $3,3 \times 10^{-5}$ e $1,0 \times 10^{-4} \mathrm{~mol} \mathrm{~L}^{-1}$, respectivamente. Experimentos de adição e recuperação foram realizados, apresentando recuperações entre 105,5 e $110,0 \%$.

\subsubsection{Aplicações analíticas}

Amostras comerciais de comprimidos $\left(\right.$ Lasix $^{\circledR}$, Neosemid $^{\circledR}$ e Biosintetica ${ }^{\circledR}$ ) e injetáveis $\left(\right.$ Lasix $^{\circledR}$ ), bem como de urina sintética adicionada, foram analisadas pelo sistema em fluxo desenvolvido, sendo cada uma destas preparada conforme descrito anteriormente.

Na Figura 6.7 podem ser observados os sinais gerados para as soluções de calibração, brancos e amostras de comprimidos.

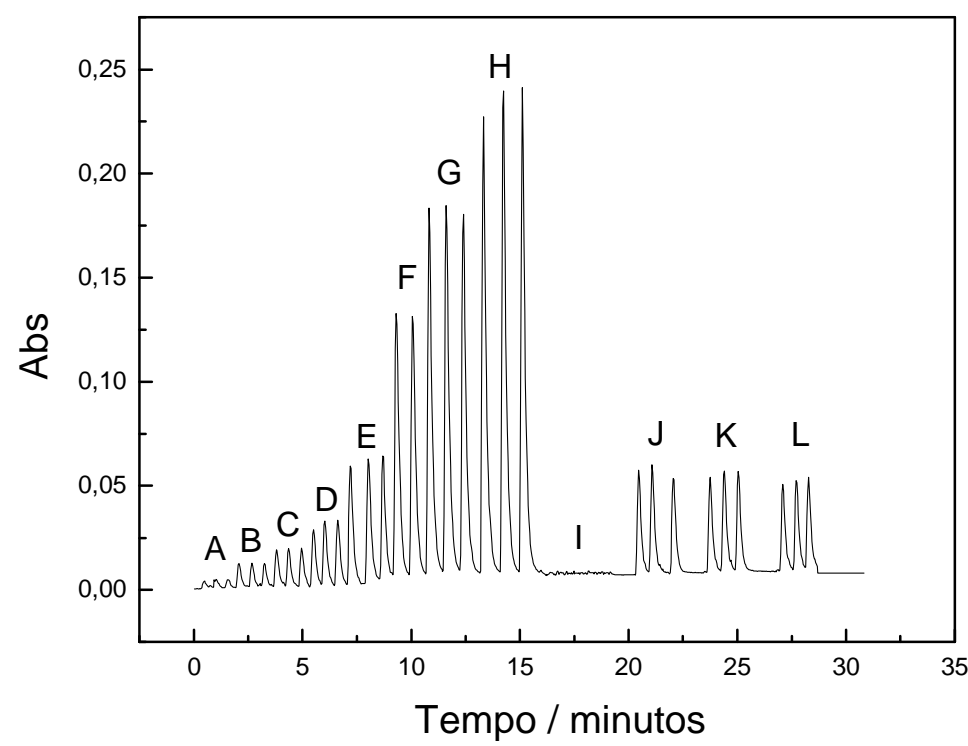

Figura 6.7.: Sinais transientes para curva de calibração (concentração, $\mathrm{mol} \mathrm{L}^{-1}$ : $A=10^{-4}, B=3,0 \times 10^{-4}, C=5,0 \times 10^{-4}, D=10^{-3}, E=2,0 \times 10^{-3}, F=6,0 \times 10^{-3}$, $\left.\mathrm{G}=8,0 \times 10^{-3}, \mathrm{H}=10^{-2}\right)$, brancos ( $;$; 10 medidas) e amostras de comprimidos $\left(\mathrm{J}=\right.$ Lasix $^{\circledR}, \mathrm{K}=$ Neosemid $^{\circledR}, \mathrm{L}=$ Biosintetica $\left.^{\circledR}\right)$. 
Amostras de injetáveis e urina sintética adicionada foram avaliadas por adição de padrão. Na Figura 6.8 observa-se o registro de sinais obtido durante análise da amostra injetável Lasix ${ }^{\circledR}$. Os sinais obtidos durante análise da furosemida em urina sintética são ilustrados pela Figura 6.9.

A Tabela 6.3. apresenta os resultados encontrados para as amostras comerciais analisadas, tanto comprimidos quanto injetáveis.

Tabela 6.3.: Resultados obtidos na análise de formas farmacêuticas comerciais

\begin{tabular}{|c|c|c|c|}
\hline Amostra & Rótulo $^{a}$ & Método proposto ${ }^{b}$ & Método Oficial $^{b}$ \\
\hline Lasix $^{\circledR}$ comprimido & 40 & $42 \pm 2$ & $42 \pm 0,3$ \\
\hline Neosemid ${ }^{\circledR}$ comprimido & 40 & $39 \pm 2$ & $42 \pm 0,1$ \\
\hline Biosintetica ${ }^{\circledR}$ comprimido & 40 & $42 \pm 1$ & $40,3 \pm 0,1$ \\
\hline Lasix ${ }^{\circledR}$ injetável & 10 & $10,1 \pm 0,3$ & $9,6 \pm 0,3$ \\
\hline
\end{tabular}

a furosemida por dose: $\mathrm{mg}$ por comprimido ou $\mathrm{mg} \mathrm{mL}^{-1}$ em injetáveis;

${ }^{\mathrm{b}}$ valores médios e desvios, $\mathrm{n}=3$.

Os resultados se mostraram concordantes com nível de confiança de $95 \%$, de acordo com teste $t$ - Student pareado.

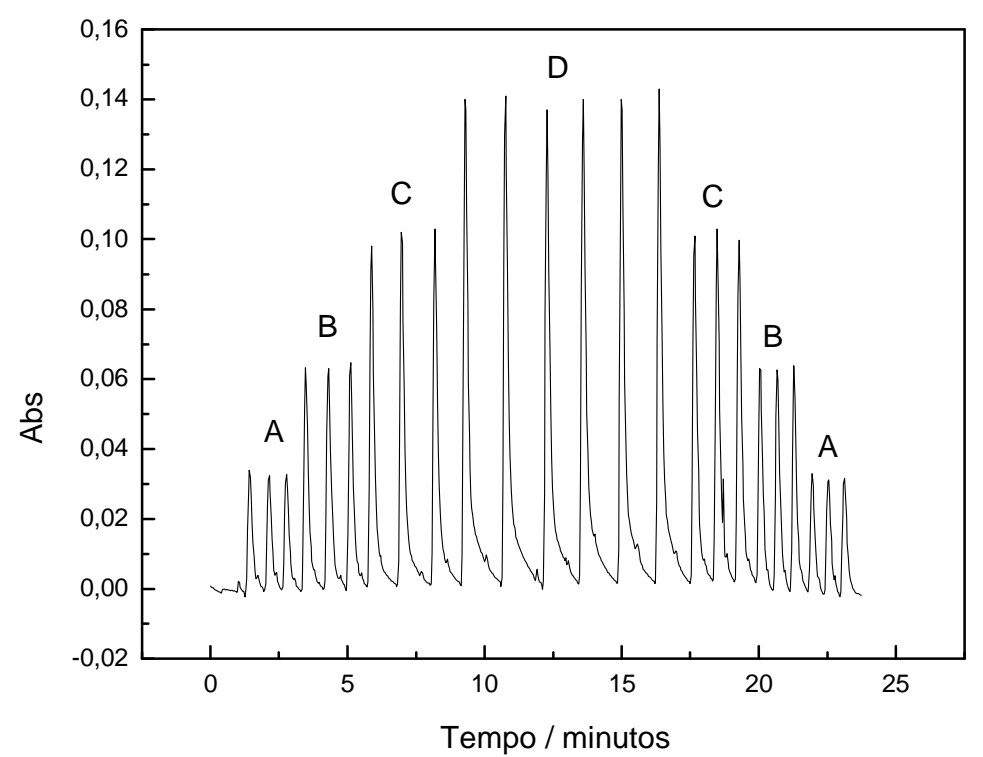

Figura 6.8.: Sinais transientes obtidos na análise de amostra injetável (Lasix ${ }^{\circledR}$ preparada para $1,5 \times 10^{-3} \mathrm{~mol} \mathrm{~L}^{-1}$ ). Adição de padrão de furosemida: $\mathrm{mol} \mathrm{L} \mathrm{L}^{-1}: A=0, B=10^{-3}, C=2,0 \times 10^{-3}, \mathrm{D}=3,0 \times 10^{-3}$. 


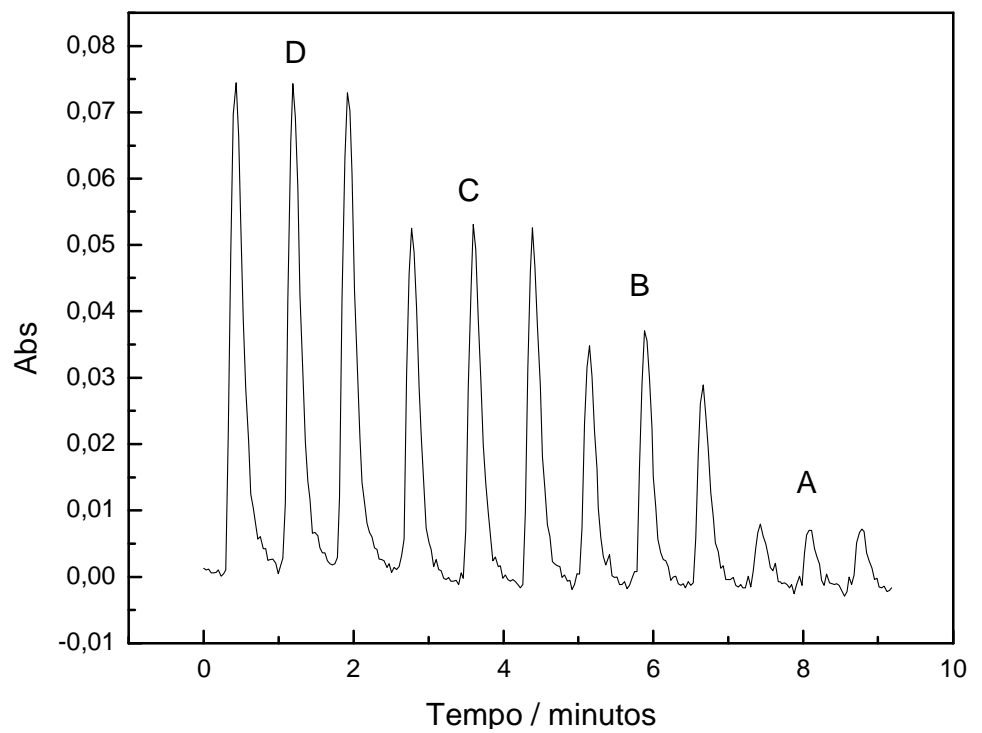

Figura 6.9.: Sinais transientes obtidos para amostra de urina adicionada (preparada para $10^{-3} \mathrm{~mol} \mathrm{~L}^{-1}$ ). Adição de padrão de furosemida: $\mathrm{mol} \mathrm{L}^{-1}: \mathrm{A}=0$, $B=10^{-3}, C=2,0 \times 10^{-3}, D=3,0 \times 10^{-3}$.

Os resultados para três amostras de urina sintética adicionada são apresentados na Tabela 6.4.

Tabela 6.4.: Resultados obtidos para furosemida na urina sintética

\section{Furosemida mol L-1}

\begin{tabular}{lccc}
\hline & Adicionado & Encontrado & Recuperação (\%) \\
\hline Urina A & $1,00 \times 10^{-3}$ & $9,65 \times 10^{-4}$ & 97 \\
Urina B & $2,12 \times 10^{-3}$ & $2,20 \times 10^{-3}$ & 105 \\
Urina C & $1,00 \times 10^{-3}$ & $9,81 \times 10^{-4}$ & 98 \\
\hline
\end{tabular}

O método em discussão é uma nova aplicação da reação de complexação entre furosemida e $\mathrm{Fe}^{+3}$ com finalidades analíticas. Tal sistema apresentou-se simples, rápido e com baixo custo. A freqüência analítica atingiu 95 medidas por hora, com uma região linear ampla $\left(10^{-4}\right.$ a $\left.10^{-2} \mathrm{~mol} \mathrm{~L}^{-1}\right)$, o que permitiu sua aplicação nas amostras apresentadas. $\mathrm{O}$ uso de etanol como solvente mostrou-se prático e com baixo custo quando comparado com solventes rotineiramente empregados em determinações cromatográficas, 
como metanol e acetonitrila, o etanol também é menos tóxico e mais facilmente recuperável.

Excipientes e veículos das formas comerciais não apresentaram interferências significativas. O interferente mais severo foi a água, problema contornado pelo emprego da extração em fase líquida com acetato de etila nos casos de amostras aquosas. 


\section{CAPÍTULO 7: ESTUDOS DOS PRODUTOS DE REAÇÂO}

\subsection{Estudos por cromatografia líquida de alta eficiência (HPLC)}

Tendo por objetivo procurar desvendar os produtos da reação entre a furosemida e o $\mathrm{KMnO}_{4}$ em meio acido, empregada na titrimetria e em um dos sistemas de análise em fluxo desenvolvidos, foram realizados estudos envolvendo cromatografia líquida de alta eficiência (HPLC). Em tais experimentos foram avaliados os produtos de hidrólise da furosemida [46], bem como seus produtos de oxidação, pelo $\mathrm{KMnO}_{4}$.

\subsubsection{Materiais e métodos}

Para o presente estudo foi utilizado um sistema HPLC com detector UV SPD 10AVP, controladora SCL 10AVP, bomba LC 6AD. Foi usada coluna $\mathrm{C}_{18}$ Supelco (15 cm x 4,6 mm, $5 \mu \mathrm{m}$ ), loop de $20 \mu \mathrm{L}$, detector ajustado em $234 \mathrm{~nm}$, tendo como fases móveis misturas de metanol : tampão fosfato $10 \mathrm{mmol} \mathrm{L}^{-1} \mathrm{pH}$ 5,5 nas proporções de 50:50 $(v / v, 1)$ e $30: 70(v / v, 2)$, a 1,0 mL min ${ }^{-1}$.

Uma solução estoque $10 \mathrm{mmol} \mathrm{L}^{-1}$ de furosemida foi preparada em $\mathrm{NaOH} 0,01 \mathrm{~mol} \mathrm{~L}^{-1}$, a qual foi submetida a reação de hidrólise empregando $\mathrm{H}_{2} \mathrm{SO}_{4} 2 \mathrm{~mol} \mathrm{~L}^{-1}$, e posteriormente, a oxidação, empregando $\mathrm{KMnO}_{4} 3 \times 10^{-4} \mathrm{~mol} \mathrm{~L}^{-1}$ (em meio de $\mathrm{H}_{2} \mathrm{SO}_{4} 2 \mathrm{~mol} \mathrm{~L}^{-1}$ ).

\subsubsection{Resultados e discussão}

Observou-se, por ocasião da hidrólise, a formação de pelo menos dois produtos principais (saluamina e álcool furfurílico), sendo que, aparentemente, 
apenas um destes é oxidado pelo $\mathrm{KMnO}_{4}$, o que se percebe pelo deslocamento significativo de um dos picos cromatográficos e mudança de absortividade da espécie.

Os tempos de retenção observados foram de 2,0;2,7; 10,8 e 12,4 minutos para $X(E)$, álcool furfurílico $(C)$, furosemida $(A)$ e saluamina $(B)$, sendo X o produto de oxidação da saluamina (Figura.7.1.). Nos cromatogramas (D) representa excesso de $\mathrm{H}_{2} \mathrm{SO}_{4}$ empregado.

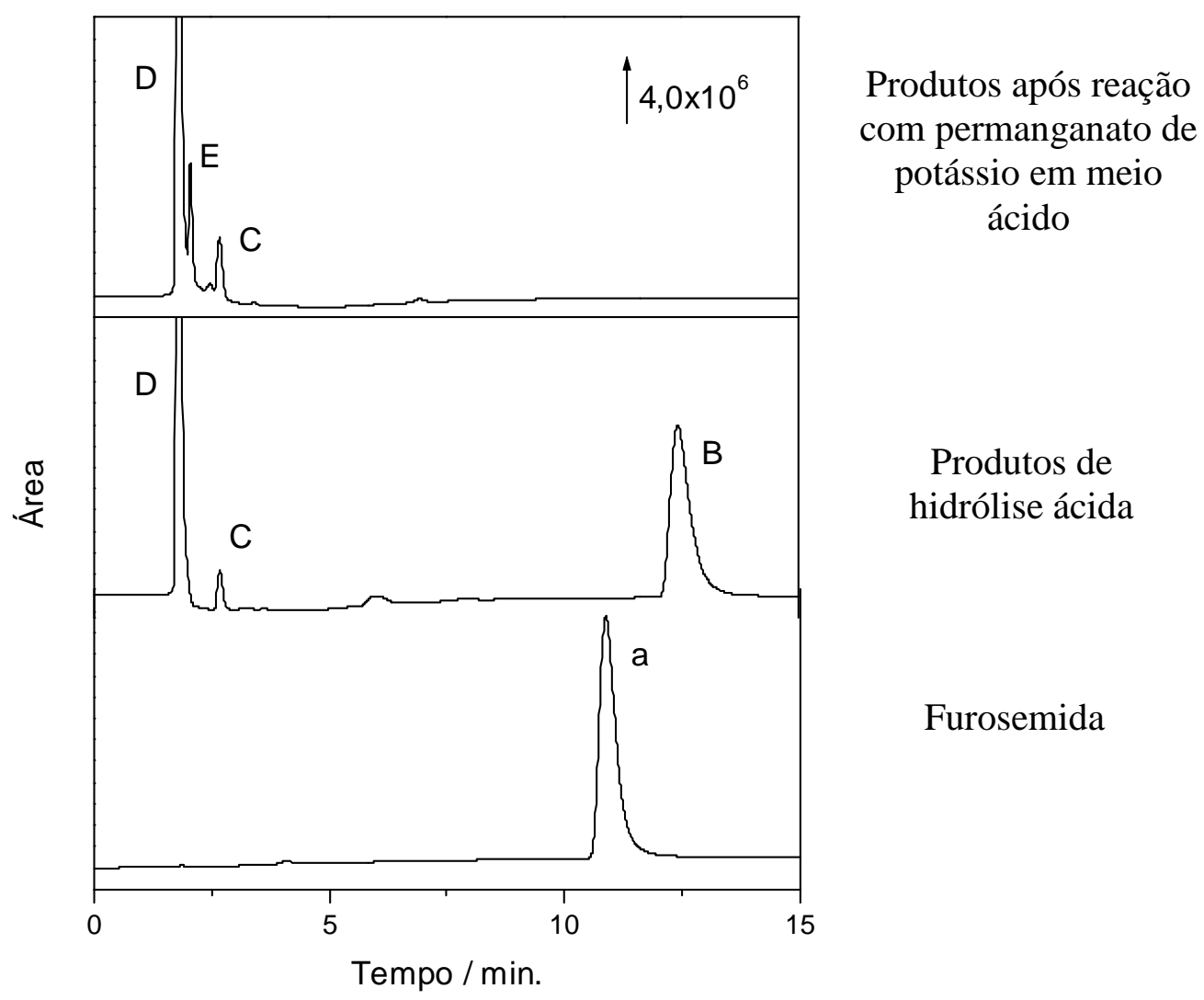

Figura 7.1.: Cromatogramas obtidos no estudo de produtos de reação empregando fase móvel 2. $A=$ furosemida, $B=$ saluamina, $C=$ álcool furfurílico, $D=$ excesso de ácido sulfúrico $E$ = produto de oxidação da saluamina.

As estruturas (A), (B) e (C) são apresentadas na Equação 4.2., na seção 4; já para a substância (E) não foi possível elucidar sua estrutura em virtude de sua instabilidade e dificuldade operacional de se otimizar o acoplamento LC- 
MS no presente caso. A separação dos produtos é realizada em fase móvel contendo fosfato, o que ocasiona entupimento dos sistemas de espectrometria de massas por ocasião da fragmentação, quer seja esta por via "electron spray" (ESI), quer seja por ionização química à pressão atmosférica (APCI). Sendo assim, tal sal foi substituído por acetato de amônio, o que minimizou a precipitação, mas, ainda assim, infelizmente, não viabilizou a definição estrutural do produto de oxidação.

\subsection{Estudos termoanalíticos}

Visando melhor compreensão dos possíveis mecanismos de degradação térmica do fármaco em estudo foram realizadas medidas termogravimétricas, estudos de cinética não-isotérmica e calorimétricas diferenciais. Para tais experimentos foi empregado um sistema SDT Q600, TA Instruments.

\subsubsection{Materiais e métodos}

Estudos do comportamento térmico da furosemida foram realizados empregando uma massa de $5 \mathrm{mg}$ deste composto em suporte de alumina aberto, no intervalo de temperatura entre 40 e $600^{\circ} \mathrm{C}$, com razão de aquecimento de $5^{\circ} \mathrm{C} \mathrm{min}^{-1}$, em atmosfera de nitrogênio com vazão de $50 \mathrm{~mL}$ $\min ^{-1}$, utilizando-se de um módulo calorimétrico diferencial DSC-910, acoplado ao termoanalisador 2000, ambos da TA Instruments.

A fusão ocorre entre 203 e $206^{\circ} \mathrm{C}$, com sobreposição entre fusão e decomposição, conforme descrito em [12, 36, 38], porém não pode ser observada com clareza na curva DSC. Ensaio qualitativo empregando amostra 
de $500 \mathrm{mg}$ do fármaco em tubo de ensaio foi realizado observando-se mudança de sólido cristalino branco para líquido incolor, o qual se torna rapidamente sólido e castanho-escuro, evidenciando visualmente a sobreposição da fusão e decomposição.

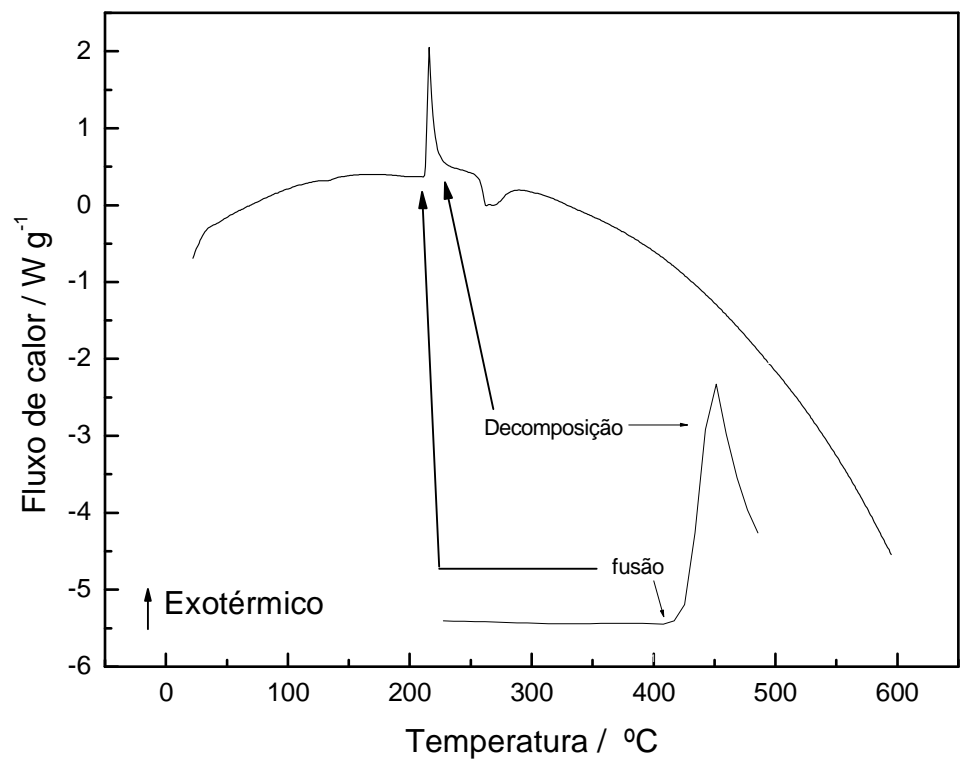

Figura 7.2.: Curva obtida para DSC da furosemida padrão.

As curvas TG/DTG e TG/DTA para furosemida foram obtidas empregando $5 \mathrm{mg}$ de amostra, sob atmosfera inerte de nitrogênio com vazão de $100 \mathrm{~mL} \mathrm{~min}{ }^{-1}$, empregando as razões de aquecimento 5,10 e $20^{\circ} \mathrm{C} \mathrm{min}^{-1}$, em suporte de amostras de alumina.

As curvas TG/DTG e TG/DTA, conforme ilustram as Figuras 7.3. e 7.4., apresentam dois eventos consecutivos, o primeiro com perda de massa de $3,28 \%$, entre 201 e $229^{\circ} \mathrm{C}$, o qual corresponde à perda de uma molécula de $\mathrm{NH}_{3}$ a cada duas moléculas do analito (perda calculada de 2,7\%), sendo especial atenção despendida a um pico exotérmico em $217^{\circ} \mathrm{C}$. O segundo 
processo, com perda de massa de 32,0\%, com pico endotérmico observado em $260^{\circ} \mathrm{C}$, se relaciona com a carbonização da amostra.

Beyers et al. [58], fizeram um estudo sobre a decomposição térmica do analito, obtendo perfis TG/DTG bastante próximos dos observados; estes autores afirmam que a decomposição ocorre com formação de saluamina a $218 \stackrel{\circ}{ } \mathrm{C}$ entretanto, a perda de massa é de apenas $3 \%$, de acordo com curvas TG obtidas, que não pode estar relacionado com esta proposta.

Visando comprovar a saída de amônia, foi colocada massa de furosemida próxima a $500 \mathrm{mg}$ em tubo de ensaio; o sistema foi levado a aquecimento em banho de óleo até temperaturas próximas a $220 \stackrel{0}{C}$.

Foi observada fusão do analito para uma fase líquida incolor que imediatamente se converte em uma fase sólida castanha escura, resultado da degradação térmica que sobrepõe a fusão. Tal degradação gera liberação de odores característicos de amônia, em temperatura próxima à correspondente ao pico exotérmico da decomposição, não sendo observada condensação nas paredes do tubo.

Espectros na região do infravermelho foram obtidos a partir do sólido castanho após degradação da amostra tais espectros se mostraram bastante semelhantes ao da furosemida inicial, o que concorda com a proposta da saída de um mol de $\mathrm{NH}_{3}$ para cada dois moles de analito e não com a saída do álcool furfurílico.

Testes com algodão embebido em fenolftaleína 0,5\% não indicaram claramente presença de amônia, porém tal fato pode ser explicado pela pequena quantidade de material aquecido. 
Empregando o método isoconversional de Flynn-Wall-Ozawa [59] foram obtidos valores de energia de ativação igual a $282 \pm 8 \mathrm{KJ}$ e log $A$ igual a 26,6 \pm $0,8 \mathrm{~min}^{-1}$, para o segundo evento térmico $(0,05 \leq \alpha \leq 0,25)$. Para um tempo de meia-vida de 60 min e $\alpha=0,05$, foi estimada a temperatura de $243^{\circ} \mathrm{C}$. Tais resultados sugerem fraqueza na amina secundária da estrutura, ponto no qual possivelmente ocorra a hidrólise ácida.

A curvas $\log \beta$ vs $1 / T$ forneceram retas paralelas que foram usadas nos cálculos. A Tabela 7.1. traz resultados para log A e Ea, obtidos no intervalo estudado. O perfil de Ea vs a é apresentado na Figura 7.5., sugerindo que o mecanismo da reação não é único.

Tabela 7.1.: Parâmetros cinéticos obtidos em diferentes razões de conversão

\begin{tabular}{|c|c|c|c|}
\hline $\begin{array}{c}\text { Nível de } \\
\text { conversão / \% }\end{array}$ & $\mathrm{Ea} / \mathrm{KJ} \mathrm{mol}^{-1}$ & $\begin{array}{l}\text { Fator pré-exponencial } \\
\qquad / \mathrm{min}^{-1}\end{array}$ & $\begin{array}{l}\text { Temperatura de } \\
\text { meia-vida* / 으 }\end{array}$ \\
\hline 5,0 & 234,4 & 21,73 & 244,2 \\
\hline 10,0 & 250,1 & 23,33 & 244,0 \\
\hline 15,0 & 259,2 & 24,26 & 243,6 \\
\hline 20,0 & 254,4 & 23,82 & 242,8 \\
\hline 25,0 & 244,9 & 22,90 & 241,8 \\
\hline 30,0 & 236,5 & 22,09 & 241,1 \\
\hline 35,0 & 231,1 & 21,56 & 240,8 \\
\hline 40,0 & 229,6 & 21,39 & 241,0 \\
\hline 45,0 & 225,8 & 20,99 & 241,3 \\
\hline 50,0 & 218,6 & 20,24 & 241,8 \\
\hline
\end{tabular}




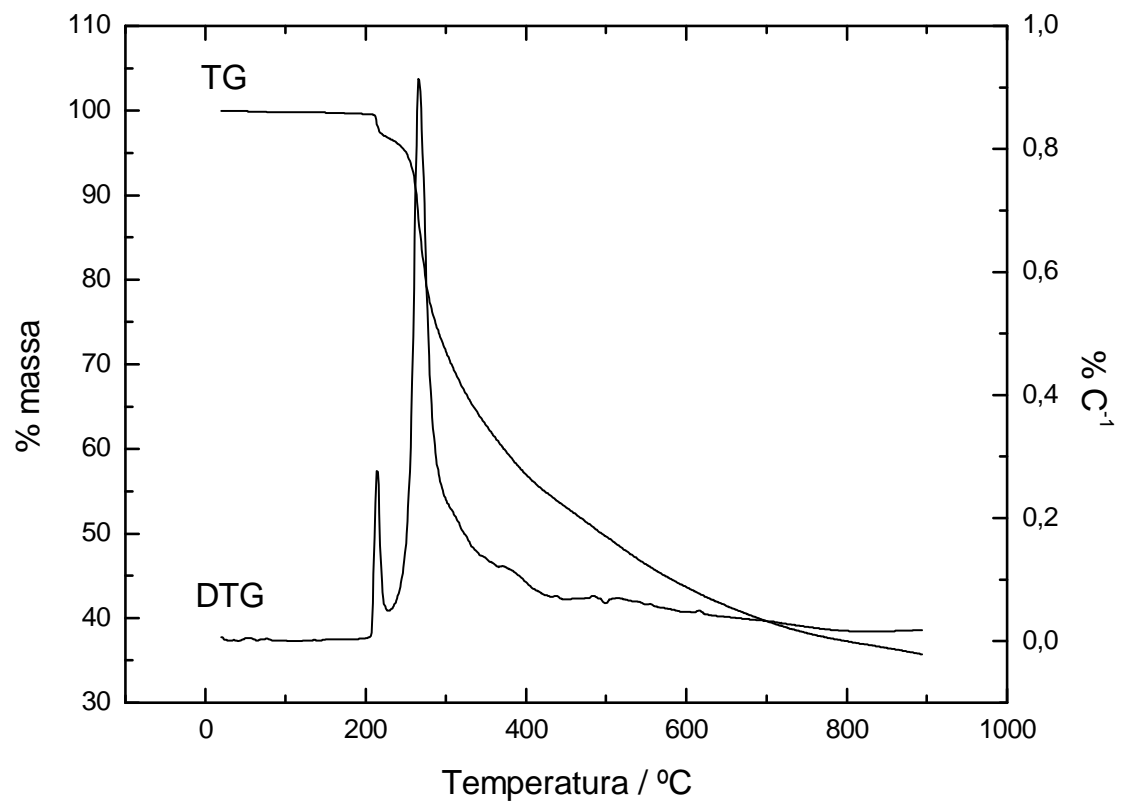

Figura 7.3.: Curvas TG e DTG obtidas a $5^{\circ} \mathrm{C} \mathrm{min}^{-1}$, massa de furosemida de $5 \mathrm{mg}$ em suporte de alumina, atmosfera inerte de nitrogênio a $100 \mathrm{~mL} \mathrm{~min}^{-1}$.

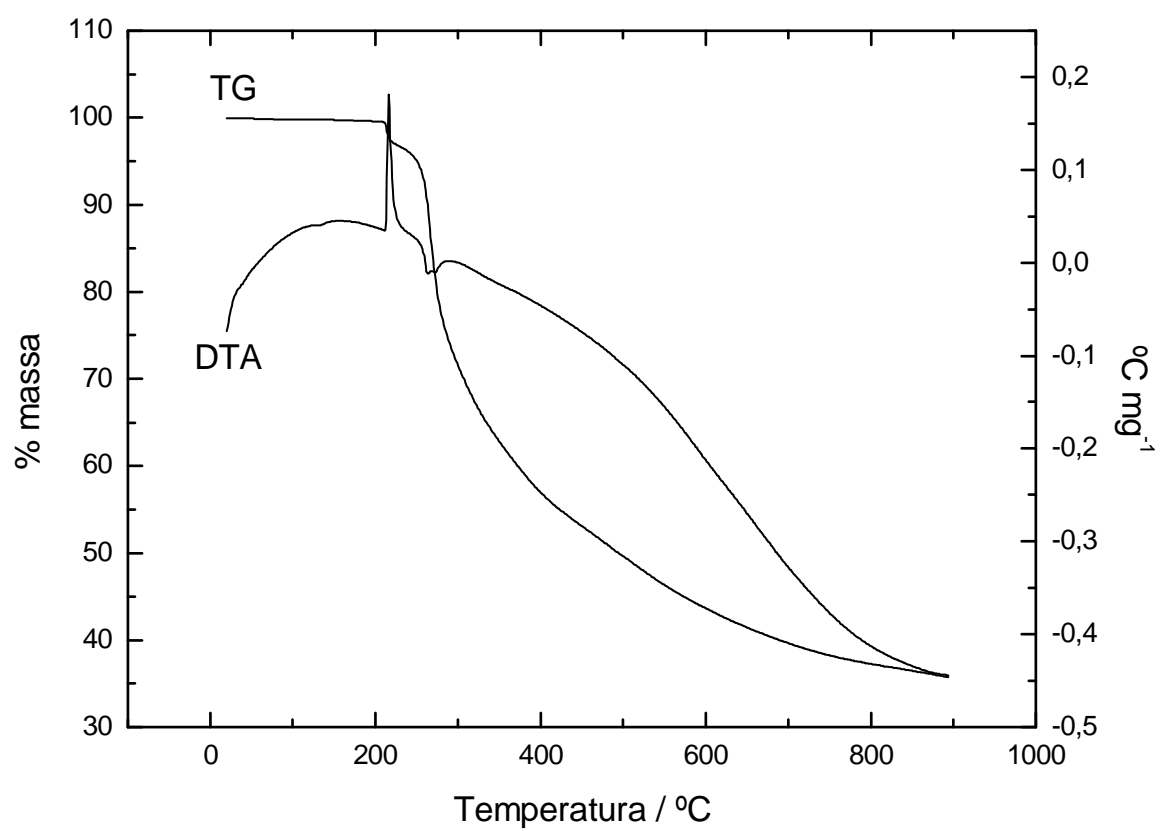

Figura 7.4.: Curvas TG e DTA obtidas a $5^{\circ} \mathrm{C} \mathrm{min}^{-1}$, massa de furosemida de $5 \mathrm{mg}$ em suporte de alumina, atmosfera inerte de nitrogênio a $100 \mathrm{~mL} \mathrm{~min}^{-1}$. 


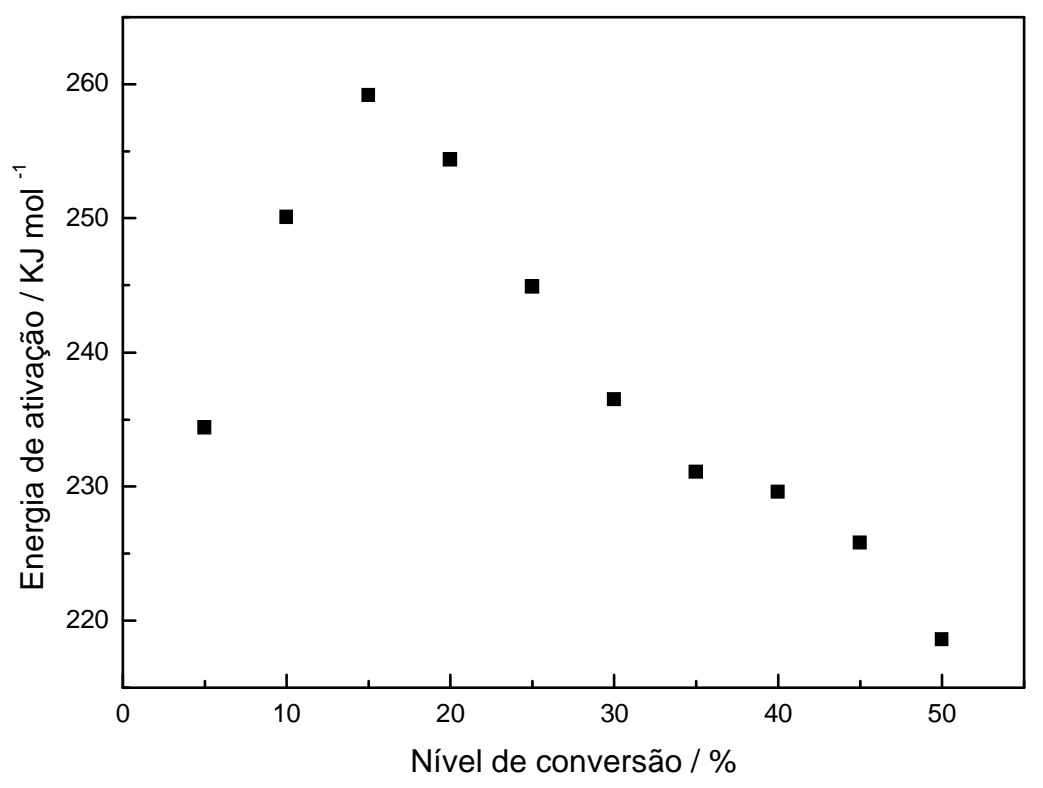

Figura 7.5.: Curva Ea vs a, para estudo dos mecanismos de degradação térmica da furosemida. 


\section{CAPÍTULO 8: DETERMINAÇÕES COM BASE EM ESPECTROSCOPIA DE FLUORESCÊNCIA}

\subsection{Determinação de furosemida por espectroscopia de fluorescência}

Nesta seção são descritos procedimentos de otimização e emprego da espectroscopia de fluorescência e sua adaptação na determinação da furosemida em amostras comerciais sólidas (comprimidos) e líquidas (injetáveis), bem como em amostras de urina sintética fortificada. A presente técnica apresenta-se mais sensível e seletiva que as anteriores, o que, em associação às características dos sistemas em fluxo, torna interessante 0 presente desenvolvimento.

\subsubsection{Soluções de calibração e reagentes}

Solução estoque do fármaco foi preparada por simples dissolução do mesmo em $\mathrm{NaOH} 0,01 \mathrm{~mol} \mathrm{~L}^{-1}$, objetivando uma concentração final de $10^{-3} \mathrm{~mol} \mathrm{~L}^{-1}$, a partir da qual, por diluição de alíquotas em tampão fosfato $\mathrm{pH}$ 3,00 e força iônica $(\mu)=0,2$ (ajustada com $\mathrm{KCl}$ ), foram preparadas soluções de calibração entre $10^{-8} \mathrm{e} 10^{-5} \mathrm{~mol} \mathrm{~L}^{-1}$.

No presente procedimento não foi empregada nenhuma reação química, sendo a detecção direta do analito otimizada por meio de estudos de $\mathrm{pH}$, comprimentos de onda de excitação e emissão ( $\lambda_{\text {excit. }}$ e $\left.\lambda_{\text {emiss. }}\right)$. A solução carregadora consistia de tampão fosfato $\mathrm{pH} 3,00, \mu=0,2 \mathrm{~mol} \mathrm{~L}^{-1}$, a qual foi considerada ideal em virtude dos resultados da otimização, a serem apresentados a seguir. 


\subsubsection{Equipamentos, ajustes na detecção e sistema em fluxo}

O sistema utilizado empregou como detector um espectrômetro de fluorescência Hitachi F-4500 (Japão), cujos comprimentos de onda foram ajustados para $\lambda_{\text {excit. }}=271 \mathrm{~nm}$ e $\lambda_{\text {emiss. }}=410 \mathrm{~nm}$ em virtude de experimentos preliminares de otimização, os quais indicaram maior sensibilidade; as fendas de excitação e emissão foram ajustadas em 10 e 20 nm, respectivamente.

O fluxo foi gerado e mantido por bomba persitáltica Ismatec IPC 8 (Suíça), sendo o percurso analítico composto por tubos de polietileno de 0,8 mm de diâmetro interno. A propulsão foi feita sobre tubos de Tygon de forma a se obter uma vazão ótima.

\subsubsection{Otimização dos parâmetros da determinação}

Visando otimizar o sistema em fluxo a ser empregado, três variáveis principais foram inicialmente estudadas: efeito do $\mathrm{pH}$ sobre a fluorescência, alça de amostragem (volume de amostra) e vazão do fluxo. Inicialmente, estudos sobre o efeito do $\mathrm{pH}$ na resposta analítica foram realizados empregando tampões fosfato com força iônica $0,2 \mathrm{~mol} \mathrm{~L}^{-1}$ constante, mas com valores de $\mathrm{pH}$ entre 2,00 e 10,00. Tais estudos demostraram que valores de $\mathrm{pH}$ abaixo de 4,00 são interessantes para tal detecção, sendo o pH 3,00 o melhor; o que pode ser observado na Figura 8.1. 


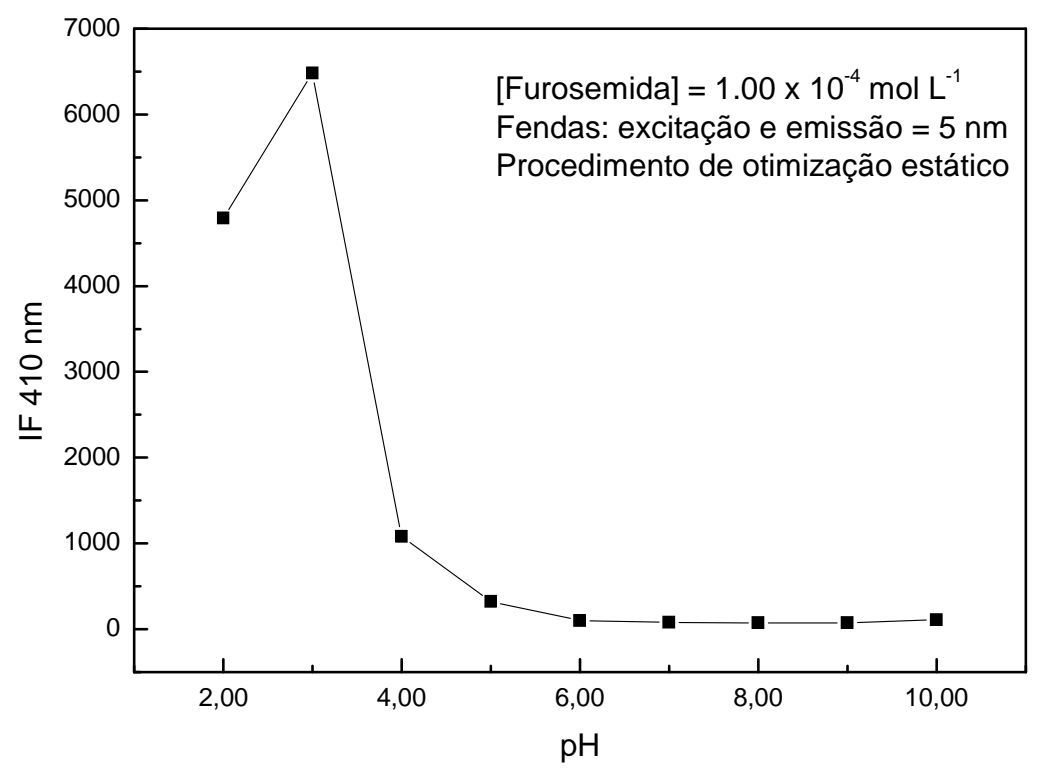

Figura 8.1.: Efeito estático da influência do pH sobre a intensidade de fluorescência (IF) do analito.

O segundo estudo de otimização envolveu o volume de amostras a ser usado na análise, por meio do estudo da alça de amostragem. A alça a ser empregada teve seu comprimento estudado entre 20 e $100 \mathrm{~cm}$ (tubo de polietileno de $0,8 \mathrm{~mm}$ de diâmetro interno), que corresponde a 100 e $500 \mu \mathrm{L}$ de amostra. Sinais transientes tendem a se tornar maiores à medida que as alças são aumentadas de 20 a $80 \mathrm{~cm}$, sendo a alça de $80 \mathrm{~cm}(400 \mu \mathrm{L})$ a de maior sinal. A partir deste comprimento de alça os sinais tornam-se mais morosos e de mesma intensidade, o que apenas torna o sistema mais lento, sem ganho em sensibilidade. Para tal estudo foi fixada uma vazão de $2,0 \mathrm{~mL} \mathrm{~min}^{-1}$.

Finalizando esta etapa de otimizações, foi realizado um estudo de vazão, o que pôde ser manipulado não apenas por meio da velocidade da bomba, mas também, pelo diâmetro dos tubos de tygon, de propulsão. Foram estudadas vazões de 1,5 e $3,0 \mathrm{~mL} \mathrm{~min}^{-1}$. 
Como esperado, aumentando a vazão, ocorre perda na intensidade do sinal analítico em função do menor tempo de residência da amostra na cubeta e à dispersão causada pela maior diferença de velocidade entre as camadas de líquido no percurso. Em adição, o aumento na vazão ocasiona aumento no consumo de reagentes.

Por outro lado, vazões mais altas permitem maior freqüência analítica, o que deve ser avaliado também no momento de se propor o procedimento. No presente caso, uma vazão mais alta foi adotada, pois a perda de sinal analítico não foi significativa, principalmente quando comparada ao ganho em freqüência analítica; como não há reação química no percurso e as injeções são de volumes baixos e de soluções de baixas concentrações, a solução carregadora pôde ser facilmente reutilizada, eliminando o problema de gastos de reagentes em virtude de altas vazões.

Desta forma, o sistema otimizado apresentou a seguinte configuração: alça de amostragem de $80 \mathrm{~cm}(400 \mu \mathrm{L})$, reator de $40 \mathrm{~cm}$, antes do detector e $\lambda_{\text {excit. }}=271 \mathrm{~nm}$ e $\lambda_{\text {emiss. }}=410 \mathrm{~nm}$ (fendas de excitação e emissão de $10 \mathrm{e}$ $20 \mathrm{~nm}$ ), fluxo carregador de tampão fosfato $\mathrm{pH}=3,00, \mu=0,2 \mathrm{~mol} \mathrm{~L}^{-1}$, a uma vazão de 3,0 mL min ${ }^{-1}$. O sistema é ilustrado na Figura 8.2. 


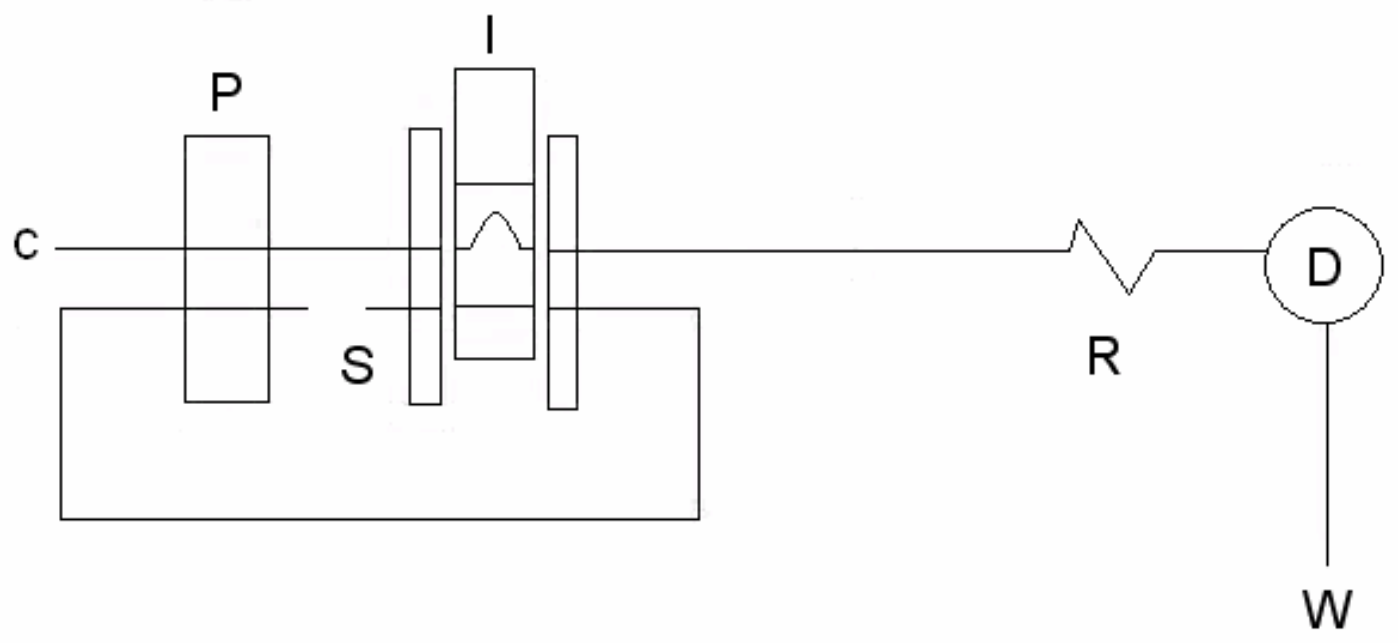

Figura 8.2.: Esquema do sistema de análise em fluxo proposto com detecção por fluorescência. $C=$ solução carregadora $(3,0 \mathrm{~mL} \mathrm{~min}-1) ; P=$ bomba peristáltica, $S=$ amostra; $I=$ injetor-comutador; $R=$ reator $(40 \mathrm{~cm}), D=$ detector e $\mathrm{W}=$ descarte.

\subsubsection{Figuras de mérito}

Foram obtidas curvas analíticas entre $1,00 \times 10^{-7}$ e $1,00 \times 10^{-5} \mathrm{~mol} \mathrm{~L}^{-1}$, as quais obedeceram à Equação 8.1:

$$
\text { I.F. }=1,00 \times 10^{8}[\mathrm{Fr}]+53,278,(r=0,998, n=7)(8.1 .)
$$

Limites de detecção $(3 \sigma / \mathrm{m})$ e quantificação $(10 \sigma / \mathrm{m})$ foram $3,00 \times 10^{-8} \mathrm{e}$ $1,00 \times 10^{-7} \mathrm{~mol} \mathrm{~L}^{-1}$, respectivamente. A freqüência analítica observada foi de 90 medidas por hora, com consumo de cerca de $180 \mathrm{~mL}$ de solução carregadora.

Experimentos de adição-recuperação foram realizados apresentando resultados entre 105 e $107 \%$. 


\subsubsection{Preparo de amostras}

Inicialmente foram pesados e pulverizados até obtenção de um pó fino e homogêneo um lote de 20 comprimidos de cada fornecedor. Massas adequadas foram retiradas e solubilizadas em béquer empregando $\mathrm{NaOH}$ $0,01 \mathrm{~mol} \mathrm{~L}^{-1}$, com o auxílio de banho ultrassônico por 10 minutos. A solução obtida foi filtrada, transferida para balões volumétricos, nos quais o volume foi ajustado com o mesmo solvente. Alíquotas desta solução inicial foram transferidas para balões de $10 \mathrm{~mL}$, os quais foram ajustados com tampão fosfato $\mathrm{pH} 3,00$, força iônica $0,2 \mathrm{~mol} \mathrm{~L}^{-1}$. No preparo de amostras injetáveis, alíquotas das mesmas foram diretamente diluídas em tampão fosfato.

Amostras de urina sintética [57] foram empregadas visando simular o desempenho do sistema proposto na análise de amostras biológicas, como descrito anteriormente, o emprego destas amostras sintéticas se deveu principalmente à minimização do risco de contaminação biológica do analista por ocasião dos ensaios preliminares, no qual o objetivo é avaliar a viabilidade de método, não a amostra.

A presente amostra foi preparada conforme descrição da Tabela 6.2. As amostras de urina sintética foram acrescidas de analito em diferentes concentrações, sendo posteriormente submetidas à extração em fase liquida (“clean-up"), utilizando como solvente extrator o acetato de etila, em uma proporção de 1:1 $(v / v)$. Alíquotas da fase orgânica foram transferidas para balões volumétricos de $10 \mathrm{~mL}$ e evaporadas com emprego de corrente de ar seco, sendo o analito, então, re-suspenso em tampão fosfato. 


\subsubsection{Aplicações analíticas}

Duas amostras comerciais de comprimidos contendo $40 \mathrm{mg}$ de furosemida por unidade posológica e uma amostra comercial de solução injetável contendo $10 \mathrm{mg}$ de furosemida por $\mathrm{mL}$ foram analisadas. Amostras de urina sintética adicionada do analito foram também analisadas com o presente procedimento.

A Figura 8.3 apresenta registro de sinais transientes obtido para curva analítica e análise de amostras comerciais de comprimidos e urina sintética à qual foi adicionado $o$ analito:

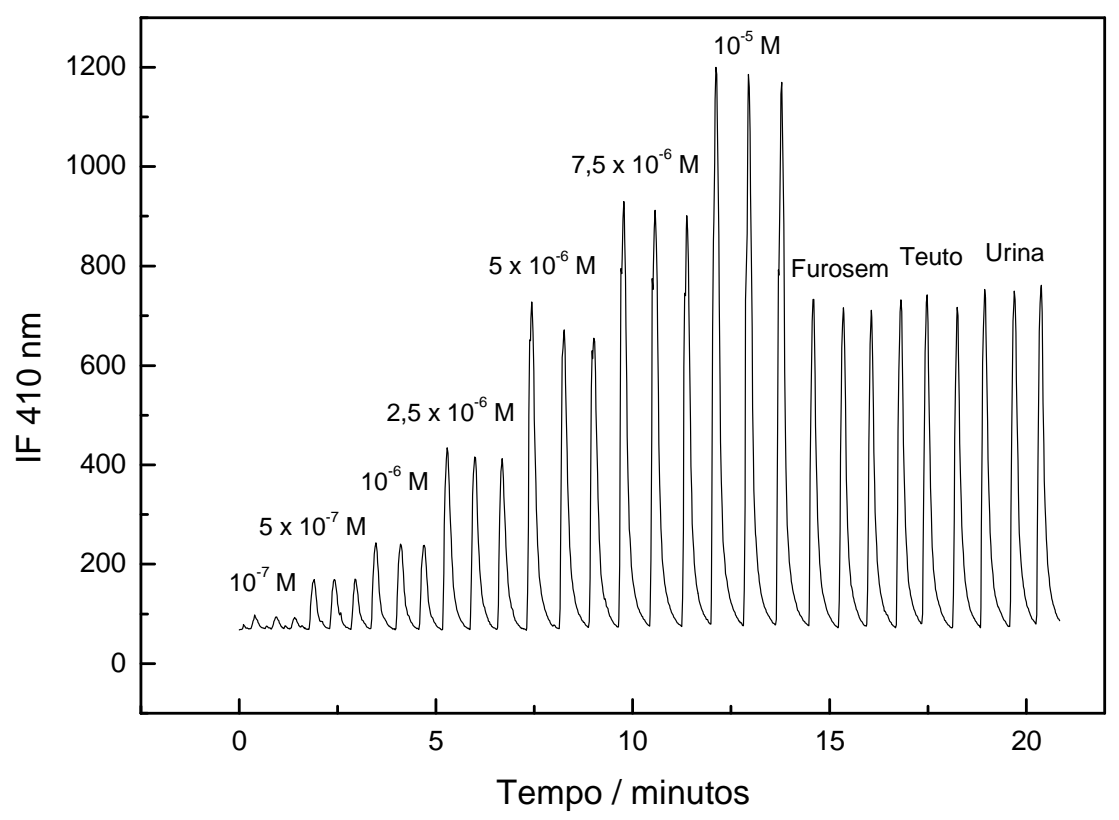

Figura 8.3.: Sinais transientes para curva analítica $\left(1,0 \times 10^{-7}, 5,0 \times 10^{-7}\right.$, $1,0 \times 10^{-6}, 2,5 \times 10^{-6}, 5,0 \times 10^{-6}, 7,5 \times 10^{-6}$ e $\left.1,0 \times 10^{-5} \mathrm{~mol} \mathrm{~L}^{-1}\right)$, amostras comerciais (Furosem ${ }^{\circledR}$, Teuto $^{\circledR}$ ) e urina sintética.

Na Figura 8.4 são apresentados sinais transientes para curva analítica, análise de amostras de injetáveis, urina sintética à qual se adicionou o analito e testes de adição e recuperação. 


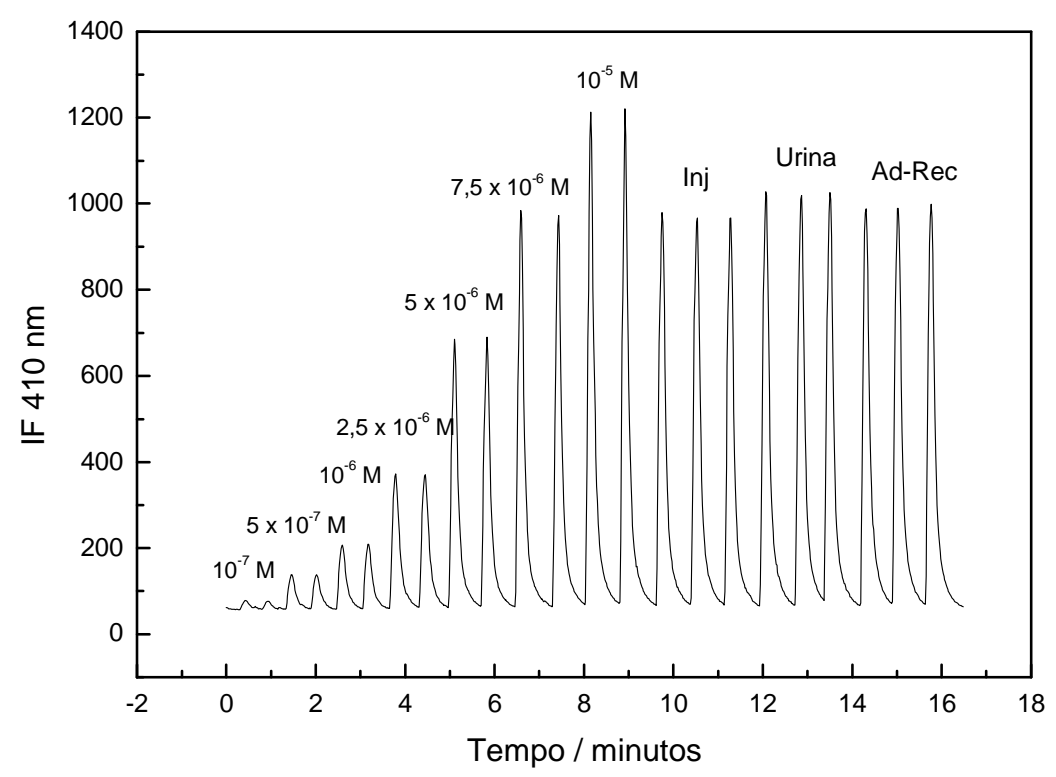

Figura 8.4.: Sinais transientes para curva analítica $\left(1,0 \times 10^{-7}, 5,0 \times 10^{-7}\right.$, $1,0 \times 10^{-6}, 2,5 \times 10^{-6}, 5,0 \times 10^{-6}, 7,5 \times 10^{-6}$ e $1,0 \times 10^{-5} \mathrm{~mol} \mathrm{~L}^{-1}$ ), amostra (Lasix ${ }^{\circledR}$ Inj,como exemplo), urina sintética adicionada e testes de adição-recuperação.

Resultados para amostras comerciais e para amostras de urina sintética adicionada são apresentados nas Tabelas 8.1 e 8.2, respectivamente.

Tabela 8.1.: Resultados obtidos para amostras comerciais de furosemida Amostra Rótulo $^{\mathrm{a}}$ Resultados encontrados

\begin{tabular}{|c|c|c|c|}
\hline & & 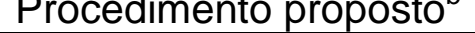 & Tietude Uictal \\
\hline Furosem $^{\Theta}$ comp. & 40 & $40,2 \pm 0,7$ & 39,2 \\
\hline Teuto ${ }^{\circledR}$ comp. & 40 & $40,9 \pm 0,8$ & 41,9 \\
\hline Lasix $^{\circledR}$ ampola & 10 & $10,2 \pm 0,7$ & - \\
\hline
\end{tabular}

a furosemida por dose (mg por comprimido) e ampolas $\left(\mathrm{mg} \mathrm{mL}^{-1}\right)$

${ }^{b}$ valores médios e seus respectivos desvios padrões, $n=3$.

Tabela 8.2.: Resultados obtidos para urina sintética adicionada Amostra Furosemida / $\mathrm{mol} \mathrm{L}^{-1}$ Recuperação (\%)

\begin{tabular}{lr}
\hline Adicionado & Encontrado \\
$5,0 \times 10^{-6}$ & $5,3 \times 10^{-6}$ \\
$5,0 \times 10^{-6}$ & $5,2 \times 10^{-6}$ \\
$5,0 \times 10^{-6}$ & $5,2 \times 10^{-6}$
\end{tabular}
106 104

Urina $A$ Urina B $5,2 \times 10^{-6}$ 104 
Os resultados são concordantes adotando grau de confiança de $95 \%$, observando-se, ainda, recuperação na ordem de 104 - 105\% para amostras de urina.

\subsection{Emprego de ambientes micelares na determinação de furosemida por espetroscopia de fluorescência}

\subsubsection{Considerações iniciais}

Micelas são estruturas supramoleculares, na forma de agregados, formadas por compostos orgânicos com características peculiares. Tais compostos devem apresentar, obrigatoriamente, uma parte hidrofílica e outra hidrofóbica, em uma mesma estrutura, ou seja, uma estrutura anfifílica com forte assimetria com relação à sua polaridade, o que gera por conseqüência um forte momento de dipolo. Um tensoativo típico apresenta estrutura geral R-X, na qual $R$ representa uma cadeia contendo entre 8 e 18 átomos de carbono, em geral, linear; e X é o grupo polar ou iônico, o qual confere ao tensoativo sua classificação em catiônico, aniônico, não-iônico ou anfótero [47, 60].

Soluções tensoativas apresentam propriedades nem sempre comuns: quando diluídas, agem como eletrólitos normais, porém, a partir de determinadas concentrações, passam a demonstrar variações bruscas em uma série de parâmetros como condutância, pressão osmótica, turbidez, tensão superficial, entre outros. Tal fato se deve ao início da organização do sistema em micelas ou agregados a partir de um valor de concentração denominado concentração micelar crítica (CMC) [60,61]. 
A concentração micelar crítica depende quase totalmente da natureza da parte hidrofóbica da estrutura, desta forma, espera-se que uma baixa CMC seja favorecida por:

1- aumento da parte hidrofóbica das moléculas de substâncias tensoativas (em uma série homóloga, cada novo grupo $\mathrm{CH}_{2}$ reduz a $\mathrm{CMC}$ aproximadamente à metada);

2- diminuição da temperatura;

3- adição de sais simples como $\mathrm{KCl}$, que, por reduzirem as forças eletrostáticas repulsivas, apresentam ação canceladora.

O ponto 2 acima, não é tão rígido quanto os demais; de modo geral a formação de micelas é um processo exotérmico e portanto favorecido pela diminuição de temperatura, porém, não se trata de uma regra universal, o que se pode notar em experimentos empregando, por exemplo, dodecil sulfato de sódio em água [61,62]; deve-se avaliar cada caso em específico.

\subsubsection{Reagentes e soluções}

$\mathrm{Na}$ presente etapa, visando o uso de agentes tensoativos para incremento de sensibilidade no sistema proposto, o tampão fosfato $\mathrm{pH} 3,02$ empregado como solução carregadora no estudo anterior foi substituído pela solução de Clark \& Lubbs (CL) pH 1,0. Tal solução é preparada pela mistura de $50 \mathrm{~mL}$ de $\mathrm{KCl} 0,20 \mathrm{~mol} \mathrm{~L}^{-1}$ e $97 \mathrm{~mL}$ de $\mathrm{HCl} 0,20 \mathrm{~mol} \mathrm{~L}^{-1}$, sendo o volume ajustado para $200 \mathrm{~mL}$ com água destilada. Esta mudança foi realizada com o intuito de preservar a acidez do meio e neutralizar as cargas eletrostáticas repulsivas geradas por ocasião do acréscimo de tensoativo na solução. Para os experimentos a seguir foram utilizados como agentes tensoativos o dodecil 
sulfato de sódio (SDS), o brometo de cetil trimetil amônio (CTAB) e o Triton $\mathrm{X}-100$. As características destes tensoativos em meio aquoso são apresentadas na Tabela 8.3.

Tabela 8.3.: Características dos tensoativos empregados em solução aquosa

\begin{tabular}{cccc}
\hline Tensoativo & Caráter & CMC $^{a,[60,61,63]}$ & Concentração preparada \\
\hline SDS & Aniônico & 8 & 16 \\
CTAB & Catiônico & 0,9 & 1,8 \\
Triton X-100 & Não-iônico & 0,2 & 0,5 \\
\hline${ }^{2}$ concentrações em mmol L ${ }^{-1}$ & &
\end{tabular}

A solução estoque do fármaco foi preparada por simples dissolução do mesmo em $\mathrm{NaOH}$ 0,010 $\mathrm{mol} \mathrm{L}^{-1}$, objetivando uma concentração final de $1,0 \mathrm{mmol} \mathrm{L}^{-1}$, a partir da qual, por diluição de alíquotas em solução $\mathrm{CL}$, se obtiveram as soluções de trabalho.

\subsubsection{Equipamentos, ajustes na detecção e sistema em fluxo}

O sistema utilizado empregou como detector um Espectrômetro de Fluorescência Hitachi F-4500 (Japão). O fluxo foi gerado e mantido por bomba persitáltica Ismatec IPC 8 (Suíça), sendo o percurso analítico composto por tubos de polietileno de $0,8 \mathrm{~mm}$ de diâmetro interno. A propulsão foi feita sobre tubos de Tygon de forma a se obter uma vazão ótima.

Os comprimentos de onda de excitação e de emissão, bem como as fendas de excitação e emissão foram novamente avaliados em virtude da presença de tensoativo ao sistema.

Inicialmente, foram obtidos espectros de absorção na região do Ultra-Violeta visando avaliar os comprimentos de onda de excitação a serem estudados; tais espectros são apresentados na Figura 8.5. 


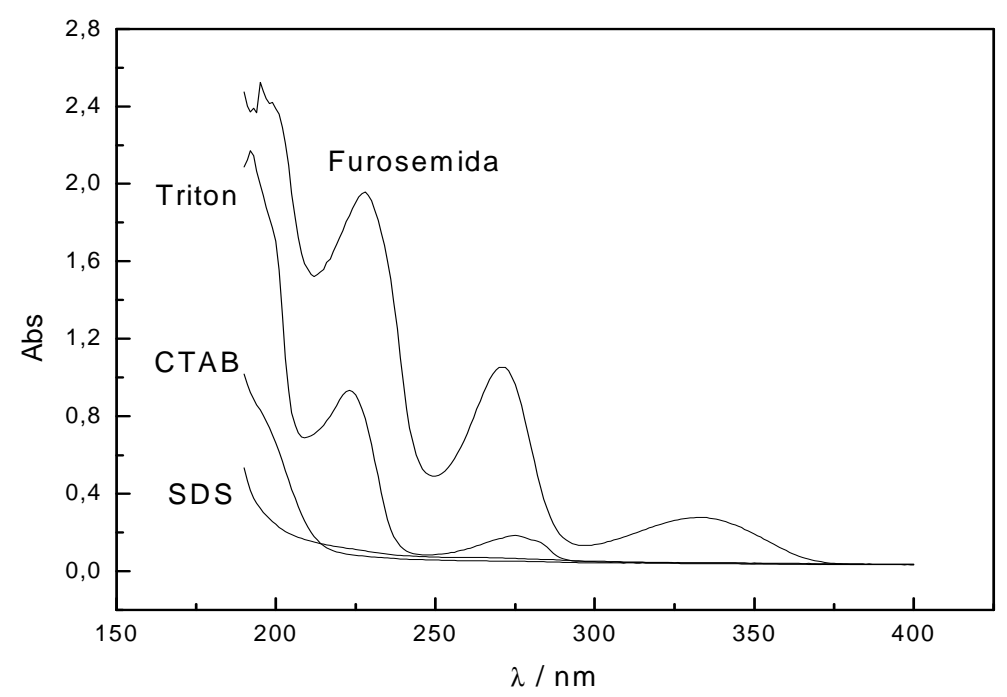

Figura 8.5.: Espectros de absorção na região ultra-violeta de soluções aquosas de furosemida, SDS, CTAB e Triton X-100, todos a $5 \times 10^{-5} \mathrm{~mol} \mathrm{~L}^{-1}$.

Tendo por base as informações obtidas no espectro anterior, experimentos estáticos de fluorescência foram realizados visando definir melhores comprimentos de onda de excitação, emissão e aberturas de fendas. A partir do espectro, observa-se pontos de máximo em 225, 271 e $330 \mathrm{~nm}$, os quais foram sistematicamente avaliados como comprimentos de onda de excitação.

Empregando como comprimento de onda de excitação $225 \mathrm{~nm}$, foi observada baixa sensibilidade, quando comparado o espectro obtido (Figura 8.6) com os demais (Figuras 8.7 e 8.8), ocorrendo, ainda, sobreposição entre sinal analítico e harmônico do sistema (em $450 \mathrm{~nm}$ ). 


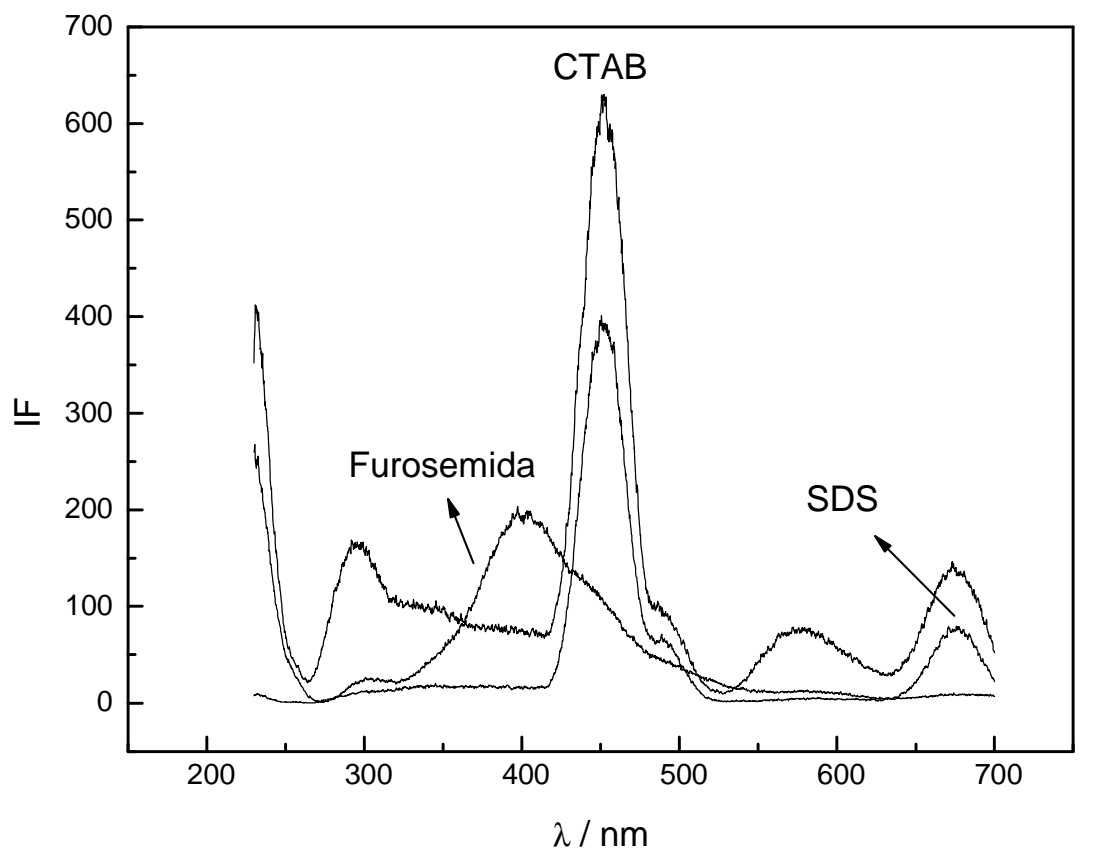

Figura 8.6.: Espectro de emissão de fluorescência para soluções aquosas de furosemida, SDS, CTAB em concentração de $5 \times 10^{-5} \mathrm{~mol} \mathrm{~L}^{-1}$. Comprimento de excitação em $225 \mathrm{~nm}$.

Avaliando-se comprimentos de onda de excitação em 271 e $330 \mathrm{~nm}$, foram observadas sensibilidades compatíveis, sendo em 271 nm ligeiramente maior. 


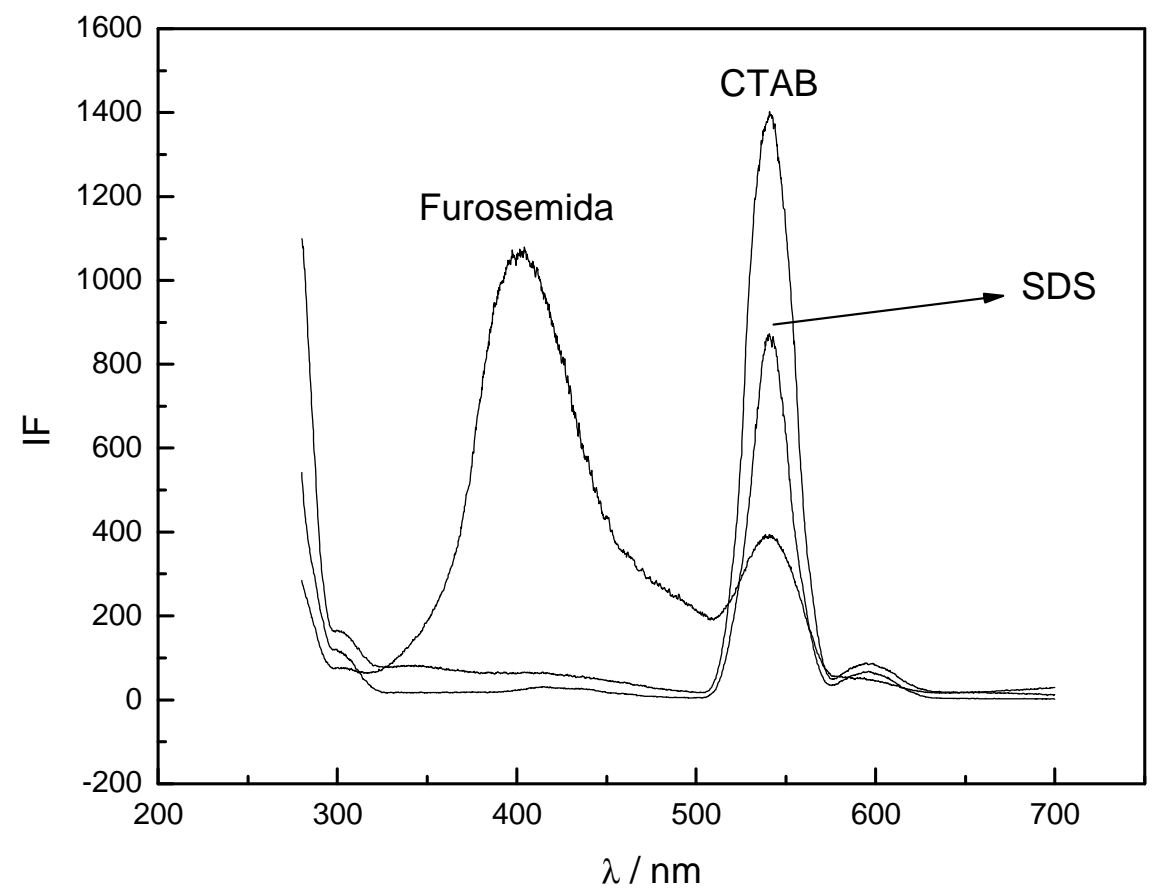

Figura 8.7.: Espectro de emissão de fluorescência para soluções aquosas de furosemida, SDS, CTAB em concentração de $5 \times 10^{-5} \mathrm{~mol} \mathrm{~L}^{-1}$. Comprimento de excitação em $271 \mathrm{~nm}$.

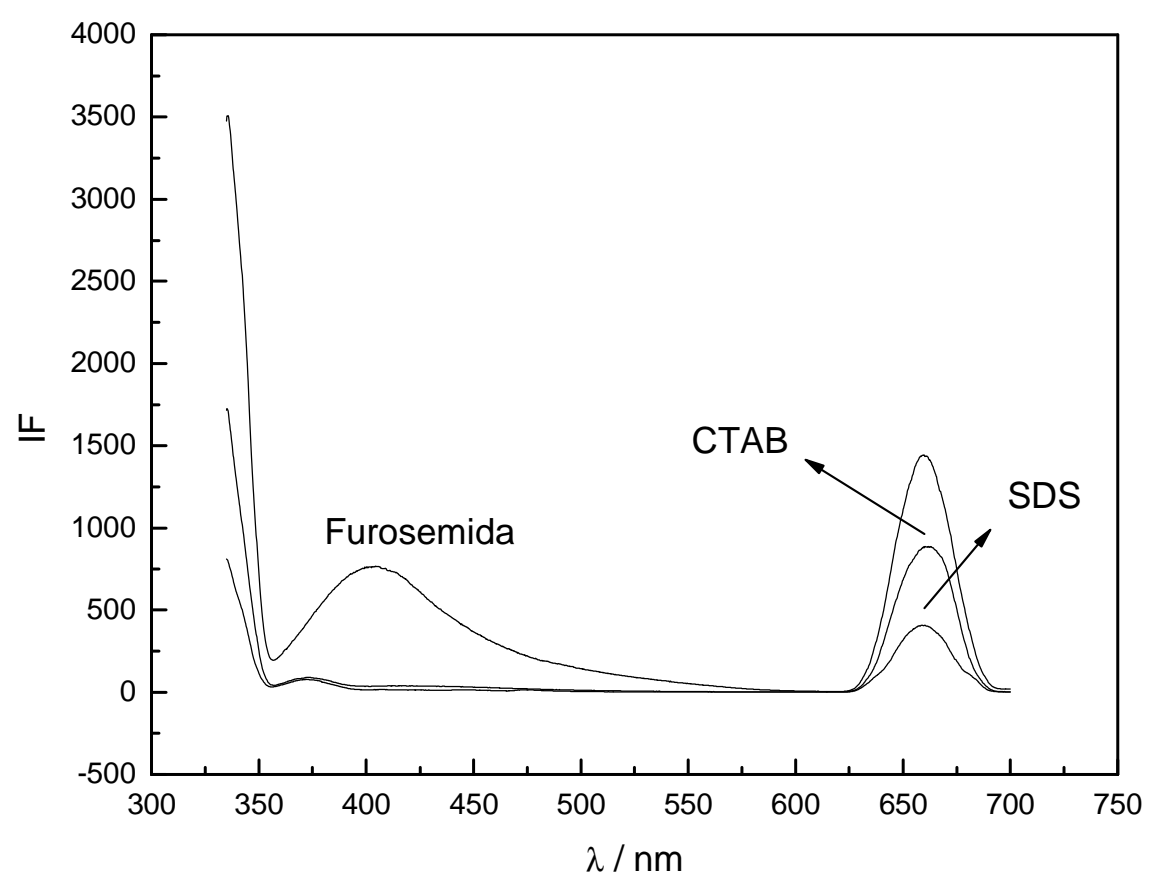

Figura 8.8.: Espectro de emissão de fluorescência para soluções aquosas de furosemida, SDS, CTAB em concentração de $5 \times 10^{-5} \mathrm{~mol} \mathrm{~L}^{-1}$. Comprimento de excitação em $330 \mathrm{~nm}$. 
Estudos preliminares demonstraram que o tensoativo Triton X-100 não é adequado, uma vez que apresenta emissão de fluorescência na mesma região que $o$ analito e com intensidade significativamente maior, ocorrendo sobreposição de espectro e inadequação do sistema à medidas quantitativas, sendo portanto, excluído dos demais estudos.

Tendo sido obtidos e avaliados tais resultados, foram fixados como comprimentos de onda de excitação e emissão, bem como abertura de fendas, os mesmos valores iniciais, não tendo sido observadas necessidades de maiores alterações na detecção.

Com relação à configuração do sistema em fluxo a ser empregado foram realizadas modificações sutis, visando acrescentar um canal por meio do qual foi adicionado o agente tensoativo à solução, antes da detecção. Considerando a diluição do tensoativo por ocasião de sua introdução ao fluxo, sua concentração foi previamente planejada, sendo o dobro da CMC visto que as vazões, tanto da solução carregadora de CL, quanto a solução de tensoativo serão iguais a $1,8 \mathrm{~mL} \mathrm{~min}^{-1}$, o que sugere um consumo final de $3,6 \mathrm{~mL}$ de reagentes por minuto. O diagrama do sistema FIA utilizado pode ser visto na Figura 8.9. 


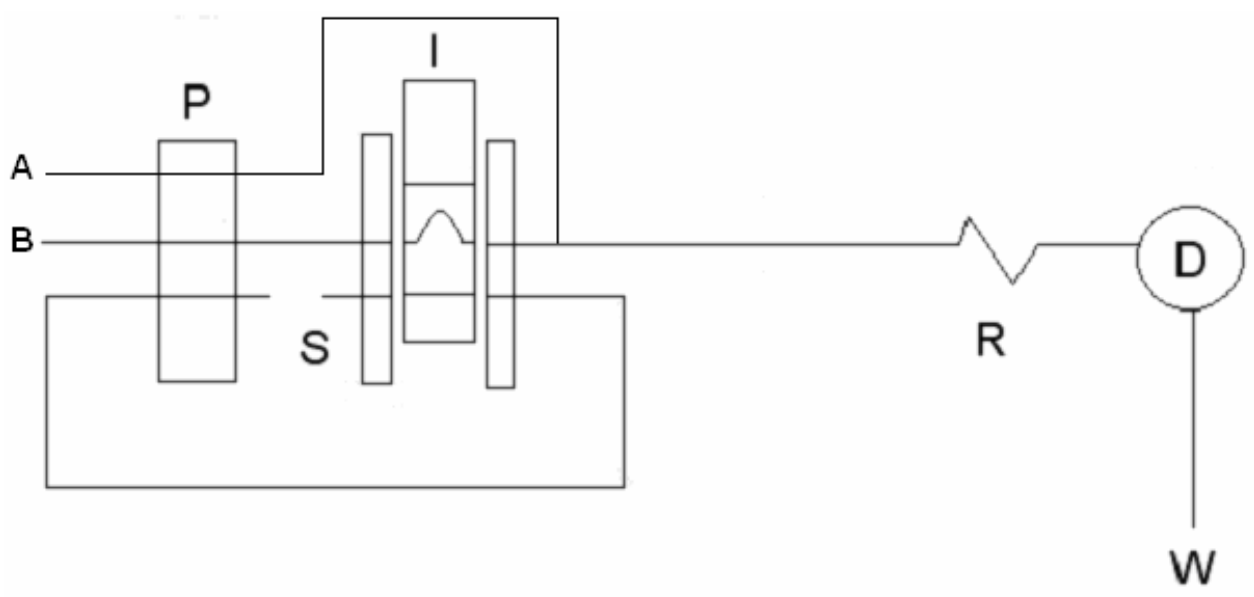

Figura 8.9.: Sistema em fluxo empregado: $\mathrm{A}=$ tensoativo em concentração igual ao dobro de sua $\mathrm{CMC}, \mathrm{B}=$ solução carregadora de Clark \& Lubbs pH 1,00, $\mathrm{D}=$ detector $\left(\lambda_{\text {excit. }}=271 \mathrm{~nm}, \lambda_{\text {emissão }}=410 \mathrm{~nm}\right.$, fendas de excitação e emissão em 10 e $20 \mathrm{~nm}$, respectivamente), I = injetor (alça de amostra $=80 \mathrm{~cm}$, que corresponde a $400 \mu \mathrm{L}$ ), $\mathrm{P}=$ bomba peristáltica (vazão $1,8 \mathrm{~mL} \mathrm{~min}{ }^{-1}$ para cada solução), $\mathrm{R}=$ reator helicoidal $(40 \mathrm{~cm}), \mathrm{S}=$ amostra, $\mathrm{W}=$ descarte.

\subsubsection{Figuras de mérito}

Foram obtidas curvas analíticas entre $1,00 \times 10^{-7}$ e $1,00 \times 10^{-5} \mathrm{~mol} \mathrm{~L}^{-1}$. Neste intervalo o sistema obedeceu às seguintes Equações lineares:

$$
\begin{gathered}
I F=3,00 \times 10^{8}[\mathrm{Fr}]+101,42,(r=0,998, n=7), \text { empregando SDS, (8.2.); } \\
I F=3,00 \times 10^{8}[\mathrm{Fr}]+633,87,(r=0,997, n=7), \text { empregando CTAB, (8.3.) }
\end{gathered}
$$

Limites de detecção $(3 \sigma / \mathrm{m})$ e quantificação $(10 \sigma / \mathrm{m})$ foram $3,00 \times 10^{-8} \mathrm{e}$ $1,00 \times 10^{-7} \mathrm{~mol} \mathrm{~L}^{-1}$, respectivamente. A freqüência analítica observada foi de 60 medidas por hora. No presente sistema foram observados resultados compatíveis entre SDS e CTAB.

Comparado com o sistema sem uso de tensoativo, embora os limites de detecção e quantificação não se alterem, observa-se maior sensibilidade, visto serem os coeficientes angulares das curvas de calibração o triplo do sistema 
inicial sem tensoativo, observa-se ainda, perda na freqüência analítica em virtude da alteração de viscosidade do carregador adicionado de tensoativo.

Experimentos de adição-recuperação foram realizados apresentando resultados entre 97 e $102 \%$.

\subsubsection{Preparo de amostras}

O preparo de amostras seguiu rigorosamente os mesmos passos que descrito na seção 8.1.4., com a diferença de ter sido empregado a solução de Clark \& Lubbs em substituição ao tampão fosfato.

\subsubsection{Aplicações analíticas}

Empregando ambiente micelar foram analisadas as mesmas amostras que na etapa anterior: Comprimidos de $40 \mathrm{mg}$ dos Laboratórios Teuto ${ }^{\circledR}$ (Furosemida genérica) e Pharlab $^{\circledR}\left(\right.$ Furosem $\left.^{\circledR}\right)$, solução injetável Lasix ${ }^{\circledR}$ $10 \mathrm{mg} \mathrm{mL}^{-1}$, da Aventis ${ }^{\circledR}$, e amostras de urina sintética adicionada.

As Figuras $8.10 \mathrm{a}$ e $8.10 \mathrm{~b}$ apresentam os registros obtidos para curva analítica, bem como aplicação às amostras, empregando SDS e CTAB. 


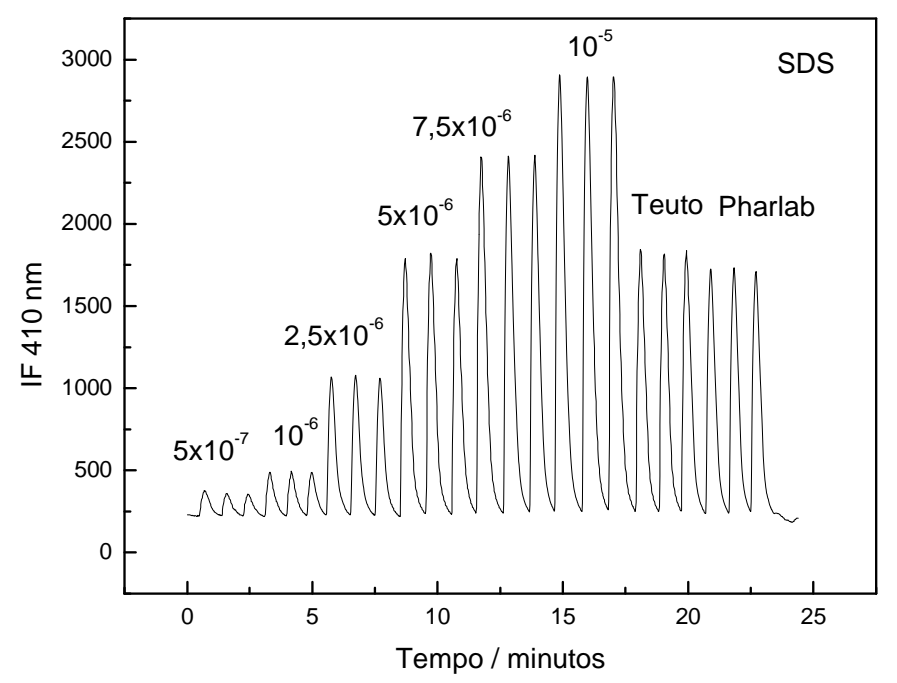

Figura 8.10a.: Sinais transientes para curva analítica $\left(1,0 \times 10^{-7}, 5,0 \times 10^{-7}\right.$, $1,0 \times 10^{-6}, 2,5 \times 10^{-6}, 5,0 \times 10^{-6}, 7,5 \times 10^{-6}$ e $\left.1,0 \times 10^{-5} \mathrm{~mol} \mathrm{~L}^{-1}\right)$, e amostras $\left(\right.$ Teuto $^{\circledR}$ e Pharlab ${ }^{\circledR}$ ), em meio de SDS.

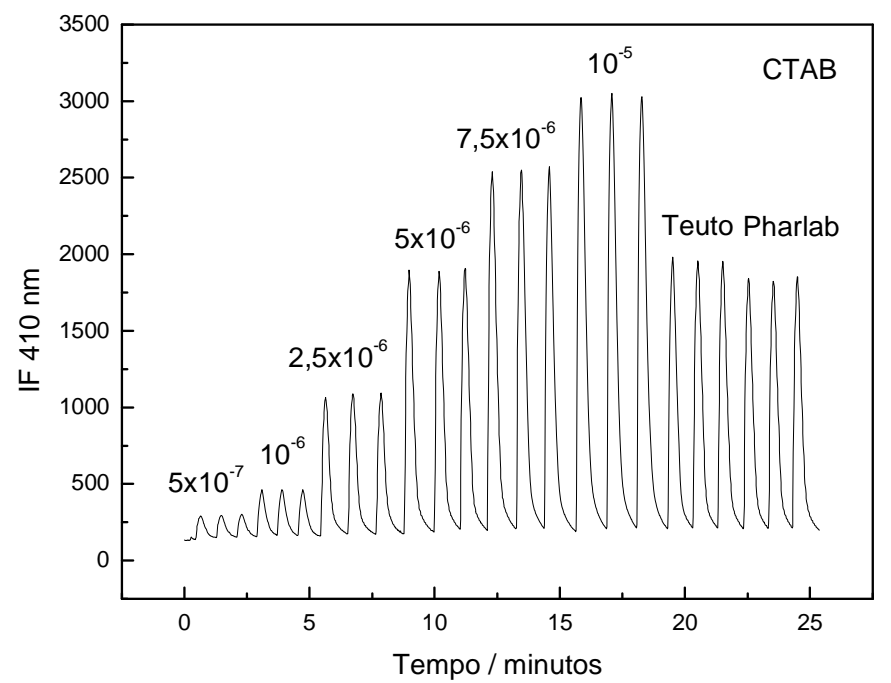

Figura 8.10b.: Sinais transientes para curva analítica $\left(1,0 \times 10^{-7}, 5,0 \times 10^{-7}\right.$, $1,0 \times 10^{-6}, 2,5 \times 10^{-6}, 5,0 \times 10^{-6}, 7,5 \times 10^{-6}$ e $\left.1,0 \times 10^{-5} \mathrm{~mol} \mathrm{~L}^{-1}\right)$, e amostras $\left(\right.$ Teuto $^{\circledR}$ e Pharlab $\left.{ }^{\circledR}\right)$, em meio de CTAB.

Os resultados obtidos são apresentados nas Tabelas 8.4. e 8.5., a seguir. 
Tabela 8.4.: Resultados obtidos para amostras comerciais de furosemida

\begin{tabular}{lccc}
\hline \multicolumn{1}{c}{ Amostra } & Rótulo $^{a}$ & \multicolumn{2}{c}{ Resultados encontrados } \\
\cline { 3 - 4 } & & $\begin{array}{c}\text { Procedimento proposto } \\
\text { SDS / CTAB }\end{array}$ & Método Oficial \\
\hline Furosem ${ }^{\circledR}$ comp. & 40 & $37,9 \pm 0,3 / 39,3 \pm 0,4$ & 39,2 \\
Teuto $^{\circledR}$ comp. & 40 & $40,8 \pm 0,4 / 42,6 \pm 0,5$ & 41,9 \\
Lasix $^{\circledR}$ ampola & 10 & $10,2 \pm 0,3 / 10,1 \pm 0,2$ & - \\
\hline
\end{tabular}

a furosemida por dose (mg por comprimido) e ampolas ( $\mathrm{mg} \mathrm{mL}^{-1}$ )

${ }^{b}$ valores médios e seus respectivos desvios padrões, $n=3$.

Tabela 8.5.: Resultados obtidos para urina sintética adicionada Amostra

\begin{tabular}{ccc}
\multicolumn{2}{c}{ Furosemida / $\mathrm{mol} \mathrm{L}^{-1}$} & $\begin{array}{c}\text { Recuperação (\%) } \\
\text { SDS / CTAB }\end{array}$ \\
\cline { 1 - 2 } Adicionado & $\begin{array}{c}\text { Encontrado } \\
\text { SDS / CTAB }\end{array}$ & \\
\hline $6,0 \times 10^{-6}$ & $5,9 \times 10^{-6} / 6,0 \times 10^{-6}$ & $97,7 / 100,0$ \\
$6,0 \times 10^{-6}$ & $5,8 \times 10^{-6} / 5,9 \times 10^{-6}$ & $97,2 / 99,8$ \\
$6,0 \times 10^{-6}$ & $5,9 \times 10^{-6} / 6,1 \times 10^{-6}$ & $98,5 / 101,1$ \\
\hline
\end{tabular}

Dados descritos nos permitem tecer comparações a respeito do uso de tensoativos na melhoria do procedimento fluorimétrico em fluxo, tais comparações são reunidas na Tabela 8.6.

Tabela 8.6.: Comparação entre figuras de mérito obtidas

\begin{tabular}{|c|c|c|c|c|c|}
\hline Ambiente & Equação & $\begin{array}{l}\text { Região } \\
\text { Linear }^{c}\end{array}$ & $\mathrm{LD} / \mathrm{LQ}^{\mathrm{C}}$ & $\begin{array}{c}\text { Freqüência } \\
\text { analítica }\end{array}$ & $\begin{array}{c}\text { Consumo de } \\
\text { Reagente }^{d}\end{array}$ \\
\hline Tampão $^{a}$ & $\begin{array}{c}\mathrm{IF}=1,0 \times 10^{8}[\mathrm{Fr}]+ \\
53,278, \mathrm{r}=0,998 \\
\mathrm{n}=7\end{array}$ & $10^{-7}$ a $10^{-5}$ & $\begin{array}{c}3,0 \times 10^{-8} / \\
1,0 \times 10^{-7}\end{array}$ & $90 \mathrm{~h}^{-1}$ & $180 \mathrm{~mL} \mathrm{~h}^{-1}$ \\
\hline SDS $^{b}$ & $\begin{array}{c}\mathrm{IF}=3,0 \times 10^{8}[\mathrm{Fr}]+ \\
101,42, \mathrm{r}=0,998 \\
\mathrm{n}=7\end{array}$ & $10^{-7}$ a $10^{-5}$ & $\begin{array}{r}3,0 \times 10^{-8} / \\
1,0 \times 10^{-7}\end{array}$ & $60 \mathrm{~h}^{-1}$ & $360 \mathrm{~mL} \mathrm{~h}^{-1}$ \\
\hline $\mathrm{CTAB}^{\mathrm{b}}$ & $\begin{array}{c}\mathrm{IF}=3,0 \times 10^{8}[\mathrm{Fr}]+ \\
633,87, \mathrm{r}=0,997 \\
\mathrm{n}=7\end{array}$ & $10^{-7}$ a $10^{-5}$ & $\begin{array}{c}3,0 \times 10^{-8} / \\
1,0 \times 10^{-7}\end{array}$ & $60 \mathrm{~h}^{-1}$ & $360 \mathrm{~mL} \mathrm{~h}^{-1}$ \\
\hline \multicolumn{6}{|c|}{$\begin{array}{l}\text { a tampão fosfato, } \mathrm{pH} 3,00, \mu=0,02 \mathrm{~mol} \mathrm{~L}^{-1} \text {; } \\
\text { b concentrações micelares críticas por ocasião da leitura; } \\
{ }^{c} \text { mol L } \mathrm{L}^{-1} \text {; } \\
\text { d no caso de ambientes micelares o consumo se refere ao final, onde } 50 \% \text { é } \\
\text { solução de tensoativo e } 50 \% \text { solução Clark \& Lubbs pH } 1,00 \text {. Nas três } \\
\text { situações os reagentes são passíveis de re-uso. }\end{array}$} \\
\hline
\end{tabular}




\section{CAPITULO 9: DETERMINAÇÕES ELETROANALÍTICAS USANDO ELETRODOS COMPÓSITOS}

\subsection{Apresentação}

O uso de eletrodos compósitos não é recente; a primeira descrição, feita por Adams, data de 1958, quando novos materiais começaram a ser estudados com o objetivo de substituir o mercúrio e ampliar o uso de técnicas eletroanalíticas na região anódica, em que o mercúrio não se apresentava útil [66].

Tallman e Petersen [67] definiram compósitos com sendo uma mistura de diferentes componentes, com diferentes características, na qual ao menos um apresenta características condutoras, e ao menos um com características isolantes, obtendo-se um novo material, com novas propriedades.

Na presente etapa descreve-se o preparo e aplicação de um compósito obtido pela mistura de resina poliuretana (fase isolante) e pó de grafite (fase condutora), sem modificações.

A aplicabilidade deste novo compósito começou a ser explorada em 2002 [67], quando foi publicado o primeiro artigo apresentando as melhores condições de preparo e emprego deste material; sendo tal artigo seguido por algumas aplicações analíticas [69,70].

Algumas vantagens do uso de compósitos tem sido percebidas, como possibilidade de preparo de eletrodos com formas e tamanhos diferentes, adição de modificadores, aplicabilidade em faixas amplas de $\mathrm{pH}$ bem como em meios contendo solventes orgânicos, baixos custos de produção, entre outras.

O presente trabalho visa apresentar a aplicabilidade deste material de eletrodo na análise de furosemida em amostras farmacêuticas comerciais.

Barroso et al. [28] descrevem a determinação eletroanalítica de furosemida com base na sua oxidação; atingindo limites de detecção próximos a $1,5 \times 10^{-7} \mathrm{~mol} \mathrm{~L}^{-1}$, empregando eletrodos de carbono vítreo, porém a necessidade de renovação e tratamento de superfície após cada medida, é citada. Ainda empregando eletrodos de carbono vítreo podemos citar limites de detecção de $1,7 \times 10^{-7} \mathrm{~mol} \mathrm{~L}^{-1}$ (para aplicações em fluxo) e $5,5 \times 10^{-7} \mathrm{~mol} \mathrm{~L}^{-1}$ (para aplicações cromatográficas) [5]; neste caso, potenciais para picos 
anódicos são relativamente elevados, atingindo $+1,25 \mathrm{~V}\left(\mathrm{vs}\right.$. $\left.\mathrm{Ag}^{+} / \mathrm{AgCl}\right)$. Tanto em [15] quanto em [28], cada medida foi realizada após tratamento de superfície.

Trabalhos de revisão [64,65] foram publicados recentemente, apresentando o "estado da arte" no que se refere à quantificação da furosemida, o que dispensa maiores detalhamentos dos mesmos no presente texto, tornando-o mais direto e focado no trabalho realizado.

\subsection{Reagentes e soluções}

Todos os reagentes e soluções foram de grau analítico e água purificada em sistema Milli-Q. Solução estoque de furosemida foi preparada visando 1,0 $\mathrm{mmol} \mathrm{L}^{-1}$ em NaOH 1,0 $\mathrm{mmol} \mathrm{L}^{-1}$, soluções de trabalho foram preparadas por diluição direta do estoque em água.

Amostras comerciais de comprimidos contendo $40 \mathrm{mg}$ do analito por comprimido foram trituradas até obtenção de um pó fino, homogêneo, a partir do qual alíquotas foram tomadas; tais alíquotas foram solubilizadas em $\mathrm{NaOH} 1,0 \mathrm{mmol} \mathrm{L}^{-1}$, da mesma forma que a furosemida padrão, no preparo do estoque; nenhuma etapa de pré-purificação ou preparo foi necessária.

Diversas soluções tampão foram preparadas $(\mathrm{pH}$ de 1,2 a 13,0) e empregadas no estudo da influência do meio e na definição do processo, fornecendo as melhores condições de determinação. Tais soluções foram preparadas conforme Tabela 9.1.

Tabela 9.1.: Composição das soluções tampão empregadas

\begin{tabular}{|c|c|c|}
\hline Parte A & Parte B & $\mathrm{pH}$ \\
\hline $25 \mathrm{~mL} \mathrm{KCl} 0.2 \mathrm{M}$ & $42.5 \mathrm{~mL} \mathrm{HCl} 0.2 \mathrm{M}$ & 1.2 \\
\hline $25 \mathrm{~mL} \mathrm{KCl} 0.2 \mathrm{M}$ & $6.5 \mathrm{~mL} \mathrm{HCl} 0.2 \mathrm{M}$ & 2.0 \\
\hline $3.7 \mathrm{~mL} \mathrm{NaAc} 0.2 \mathrm{M}$ & $46.3 \mathrm{~mL} H A c 0.2 \mathrm{M}$ & 3.3 \\
\hline $13.2 \mathrm{~mL} \mathrm{NaAc} 0.2 \mathrm{M}$ & $36.8 \mathrm{~mL}$ HAc $0.2 \mathrm{M}$ & 4.0 \\
\hline $41.2 \mathrm{~mL} \mathrm{NaAc} 0.2 \mathrm{M}$ & $8.8 \mathrm{~mL}$ HAc $0.2 \mathrm{M}$ & 5.3 \\
\hline $6.15 \mathrm{~mL} \mathrm{Na}_{2} \mathrm{HPO}_{4} 0.2 \mathrm{M}$ & $43.85 \mathrm{~mL} \mathrm{NaH}_{2} \mathrm{PO}_{4} 0.2 \mathrm{M}$ & 5.8 \\
\hline $30.5 \mathrm{~mL} \mathrm{Na}_{2} \mathrm{HPO}_{4} 0.2 \mathrm{M}$ & $19.5 \mathrm{~mL} \mathrm{NaH}_{2} \mathrm{PO}_{4} 0.2 \mathrm{M}$ & 6.9 \\
\hline $42.35 \mathrm{~mL} \mathrm{Na} \mathrm{HPO}_{4} 0.2 \mathrm{M}$ & $2.65 \mathrm{~mL} \mathrm{NaH}_{2} \mathrm{PO}_{4} 0.2 \mathrm{M}$ & 8.0 \\
\hline $50 \mathrm{~mL} \mathrm{Na} \mathrm{B}_{4} \mathrm{O}_{7} .10 \mathrm{H}_{2} \mathrm{O} 0.025 \mathrm{M}$ & $3 \mathrm{~mL} \mathrm{NaOH} 0.2 \mathrm{M}$ & 9.3 \\
\hline $25 \mathrm{~mL} \mathrm{KCl} 0.2 \mathrm{M}$ & $6 \mathrm{~mL} \mathrm{NaOH} 0.2 \mathrm{M}$ & 12.2 \\
\hline $25 \mathrm{~mL} \mathrm{KCl} 0.2 \mathrm{M}$ & $42 \mathrm{~mL} \mathrm{NaOH} 0.2 \mathrm{M}$ & 13.0 \\
\hline
\end{tabular}

* para volume final de $100 \mathrm{~mL}$ 


\subsection{Equipamentos}

Os experimentos voltamétricos foram realizados empregando um potenciostato-galvanostato $\mu$-Autolab Tipo II, controlado por computador com software GPES 4,9 (Eco Chemie); célula de $20 \mathrm{~mL}$ com três eletrodos.

Empregou-se como eletrodo de referência o calomelano saturado e contra-eletrodo uma placa de platina de $1,0 \mathrm{~cm}^{2}$ de área.

As medidas de impedância eletroquímica foram realizadas na mesma célula utilizando-se um analisador de resposta de freqüência Solartron 1250 acoplado a uma interface Solartron 1286, software empregado foi ZPlot 2.4 (Solartron).

Para realização do método Oficial foi empregado um espectrofotômetro Specord S100 Carl Zeiss.

\subsection{Eletrodos compósitos}

A resina poliuretana (PU) foi preparada misturando-se 0,85 partes de pré-polímero A-249 e 1,0 parte de poliol B-471, ambos da Poliquil (Araraquara/SP, Brasil); quantidades adequadas de pó de grafite, 1-2 $\mu \mathrm{m}$ (Aldrich) foram adicionadas visando atingir $60 \%$ de grafite $(\mathrm{m} / \mathrm{m})$. Tal mistura foi homogeneizada em almofariz durante 15 minutos e submetida a extrusão e cura por 24 horas.

Após cura, material foi cortado em tarugos de $10 \mathrm{~mm}$ de comprimento e $3 \mathrm{~mm}$ de diâmetro, contatos foram feitos empregando cola epóxido de prata e selados em tubo de vidro (diâmetro de $5 \mathrm{~mm}$ ), empregando resina epóxi não condutora. As superfícies foram polidas empregando lixa 600 e, depois, $\alpha-\mathrm{Al}_{2} \mathrm{O}_{3} 1,0 \mu \mathrm{m}$ (Altech). A área geométrica resultante foi de $0,135 \mathrm{~cm}^{2}$.

\subsection{Procedimentos}

Todas as medidas foram realizadas sem desaeração prévia das soluções. Inicialmente, um estudo exploratório foi realizado empregando voltametria cíclica, em diferentes meios, com valores de pH entre 1,2 e 13,0; a $25 \mathrm{mV} \mathrm{s}^{-1}$, entre $-1,0 \mathrm{e}+1,2 \mathrm{~V}$ (vs. ECS), cinco ciclos sucessivos foram obtidos 
e comparados, bem como as diferenças entre voltamogramas de soluções em branco e padrão $\left(6,5 \times 10^{-5} \mathrm{~mol} \mathrm{~L}^{-1}\right)$. Diferentes valores de velocidade de varredura $\left(25,50\right.$ e $\left.100 \mathrm{mV} \mathrm{s}^{-1}\right)$ também foram empregados nos estudos preliminares.

Resultados obtidos na avaliação da influência do meio foram aplicados na voltametria de pulso diferencial; neste caso, os potenciais estudados foram de $0 \mathrm{a}+1,2 \mathrm{~V}$ (vs. ECS). Aplicando $10 \mathrm{mV} \mathrm{s}^{-1}$, a amplitude de pulso foi avaliada (10, 25, 50 e $100 \mathrm{mV})$. Fixando-se a melhor amplitude, foram avaliadas diferentes velocidades de varredura $\left(10,25,50\right.$ e $\left.100 \mathrm{mV} \mathrm{s}^{-1}\right)$. Os resultados foram analisados comparando-se voltamogramas de soluções em branco e de padrões a $9,7 \times 10^{-6} \mathrm{~mol} \mathrm{~L}^{-1}$, como anteriormente.

Estudos empregando espectroscopia de impedância eletroquímica foram realizados visando avaliar o comportamento interfacial solução-eletrodo, adsorção, entre outros. Inicialmente, o sistema foi submetido a medidas com freqüências entre 0,16462 e 1646,2 Hz, aplicando-se +1,0 V (vs. ECS), soluções em branco e padrões a $0,12 \mathrm{mmol} \mathrm{L}^{-1}$ foram analisadas.

Estudos mais detalhados foram realizados aplicando-se diferentes potenciais $(+0,5,+0,75$. $+1,0 \mathrm{e}+1,1 \mathrm{~V}$ vs. ECS) a soluções em branco $\mathrm{e}$ diferentes concentrações de analito (8 e $16 \mu \mathrm{mol} \mathrm{L}^{-1}$ ), no mesmo intervalo de freqüência.

Estudos por voltametria de onda quadrada foram realizados entre $+0,6 \mathrm{e}$ $+1,2 \mathrm{~V}$ (vs. ECS), estudando-se freqüências de 10, 20, 50 e $100 \mathrm{~Hz}$, amplitudes de pulso de 10, 25 e $50 \mathrm{mV}$, bem como degrau de potencial de 1, 2 e $5 \mathrm{mV}$.

\subsection{Resultados e discussão}

\subsubsection{Voltametria cíclica (CV)}

Experimentos preliminares foram desenvolvidos visando escolher 0 melhor meio para as medidas voltamétricas, soluções tampão em diferentes valores de $\mathrm{pH}$ foram avaliadas ( $\mathrm{pH}$ entre 1,2 e 13,0), melhores condições foram atingidas em $\mathrm{pH} 3,3$, tampão acetato.

Avaliando-se as relações entre $\mathrm{pH}$ e potencial de pico anódico, a inclinação encontrada (próxima a $-30 \mathrm{mV}$ ) sugere envolvimento de dois elétrons 
para cada próton na oxidação da furosemida (Figura 9.1). O mecanismo proposto para tal processo é apresentado na Figura 9.2.

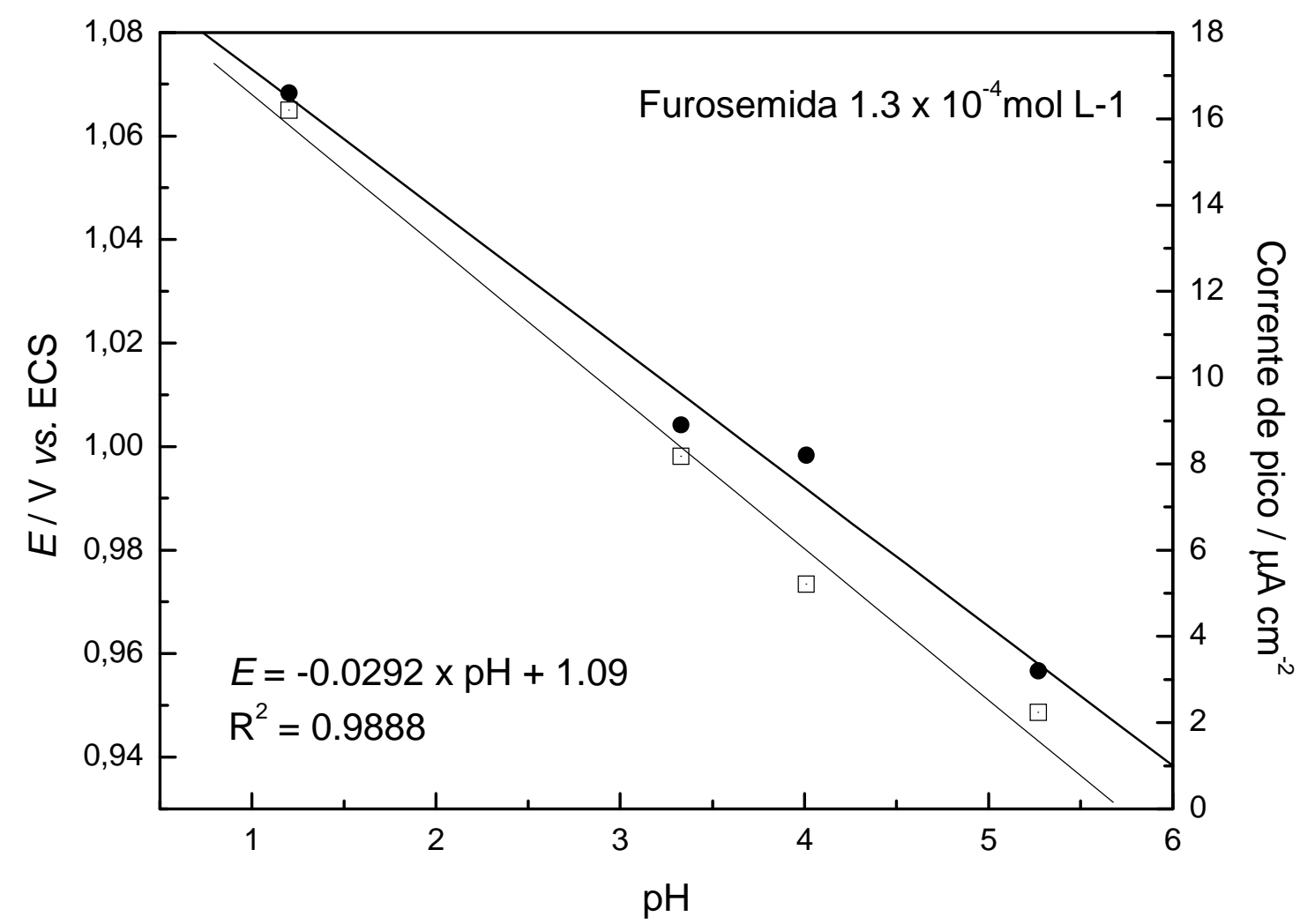

Figura 9.1.: Variação da intensidade de corrente $\left(\bullet, \mu \mathrm{A} \mathrm{cm}{ }^{-2}\right)$ e de potencial ( $\square, E$ vs. ECS), de pico anódico da furosemida, em função do $\mathrm{pH}$, usando-se voltametria cíclica, $v=100 \mathrm{mV} \mathrm{s}^{-1}$ e o eletrodo compósito.

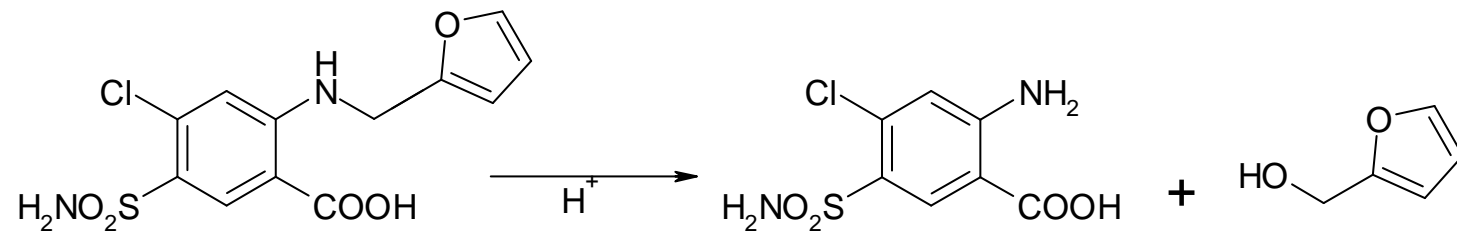<smiles>N=C1C=C(Cl)C(=S(N)O)C=C1C(=O)O</smiles>

Figura 9.2.: Mecanismo proposto para hidrólise seguida de oxidação da saluamina, envolvendo dois elétrons por próton. 
A reversibilidade do processo foi avaliada pela ausência de picos catódicos, bem como pela comparação com [28], onde valores para an foram apresentados em concordância com um processo de dois elétrons por próton. Em [28] o eletrodo de trabalho empregado foi de carbono vítreo, com constante renovação de superfície.

Aplicações quantitativas da voltametria cíclica foram realizadas em $\mathrm{pH}$ 3,3, tampão acetato, avaliando-se parâmetros como citado anteriormente. Melhores condições foram atingidas em $100 \mathrm{mV} \mathrm{s}^{-1}$, entre $0 \mathrm{e}+1,2 \mathrm{~V} v \mathrm{~s}$. ECS, analisando-se cinco ciclos sucessivos. Pico anódico foi observado em $+1,0 \mathrm{~V}$ (Figura 9.3). A região linear obtida foi de 3 a $21 \mu \mathrm{mol} \mathrm{L}^{-1}$, seguindo a Equação 9.1:

$$
j_{p a}=0,16[\mathrm{Fr}] A \mathrm{~mol}^{-1} \mathrm{~L}+3 \times 10^{-6} \mathrm{~A},\left(\mathrm{r}^{2}=0,999, n=5\right)
$$

Limites de detecção e quantificação de 2,8 e $8,4 \mu \mathrm{mol} \mathrm{L}^{-1}$, respectivamente, foram encontrados. Ensaios de adição-recuperação resultaram em 96,0 e 109,5\%, empregando-se amostra comercial de Neosemid ${ }^{\circledR}$.

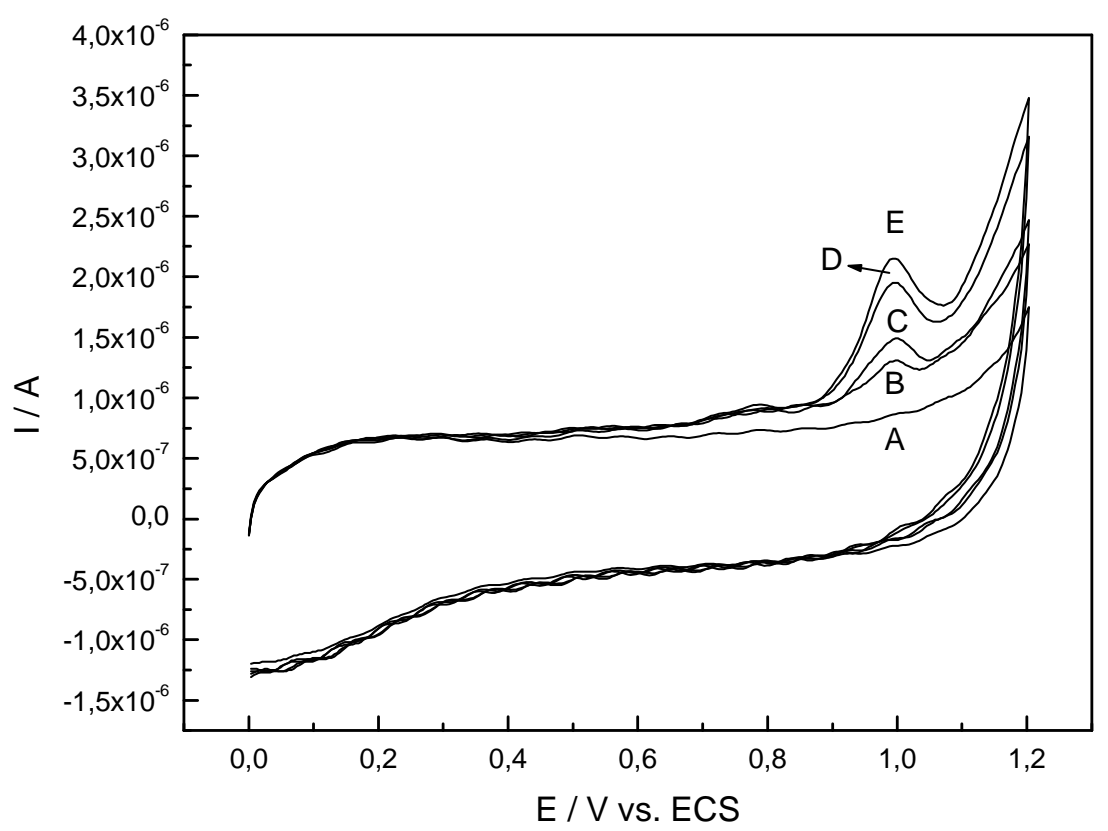

Figura 9.3.: Voltamogramas cíclicos para análise de Neosemid ${ }^{\circledR}$, por adições sucessivas de padrão, sob condições otimizadas. Concentrações, em $\mu \mathrm{mol} \mathrm{L}^{-1}$ : (a) branco, (b) amostra, (c) 8, (d) 16, (e) 20. 


\subsubsection{Espectroscopia de impedância eletroquímica (EIS)}

Experimentos empregando espectroscopia de impedância eletroquímica foram realizados objetivando avaliar a possibilidade de adsorção do analito na superfície do eletrodo; espectros de impedância foram obtidos a partir de soluções em branco, antes e depois de quinze sucessivos ciclos em furosemida $0,12 \mathrm{mmol} \mathrm{L}^{-1}$ (os eletrodos eram lavados em água sem polimento ou renovação de superfície e recolocados na célula); nenhuma alteração espectral foi observada, sugerindo a não ocorrência de adsorção. Estes resultados permitiram a realização de medidas sucessivas sem necessidade de renovação ou tratamento da superfície do eletrodo.

Estudos mais detalhados foram desenvolvidos em potenciais maiores e menores ao pico anódico $(+0,5,+0,75,+1,0$ e $+1,1 \vee v s$. ECS $)$, em soluções em branco e diferentes concentrações de analito (8 e $\left.16 \mu \mathrm{mol} \mathrm{L} \mathrm{L}^{-1}\right)$. Figuras $9.4 \mathrm{a}$ a $9.4 d$ apresentam espectros obtidos em $+0,5,+0,75,+1,0$ e $+1,1 \mathrm{~V}$ vs. ECS.

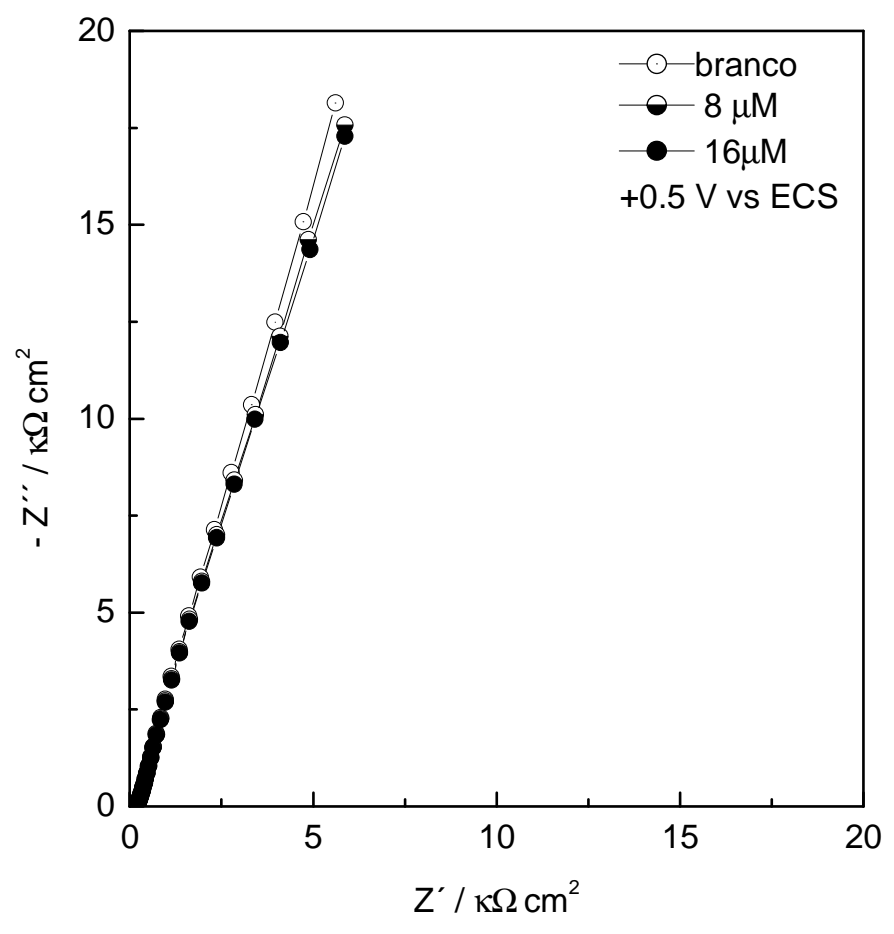

Figura 9.4a: Espectros de impedância eletroquímica para branco e adições em $+0.5 \mathrm{~V}$ vs. ECS. 


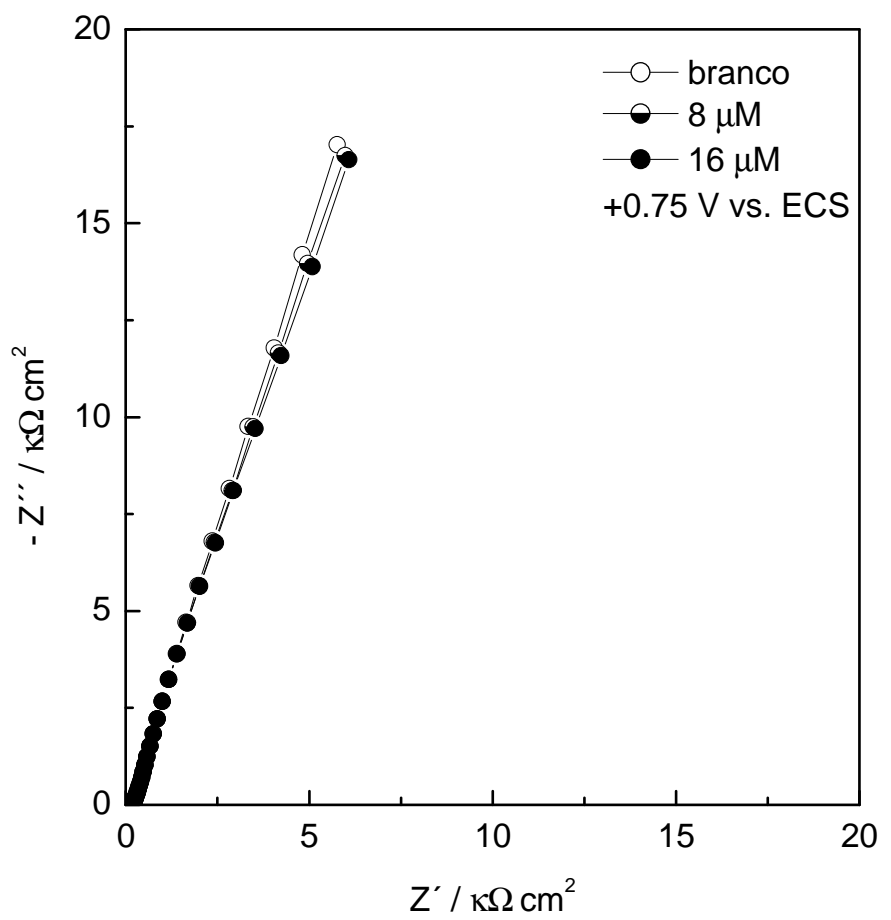

Figura 9.4b: Espectros de impedância eletroquímica para branco e adições em $+0.75 \mathrm{~V}$ vs. ECS.

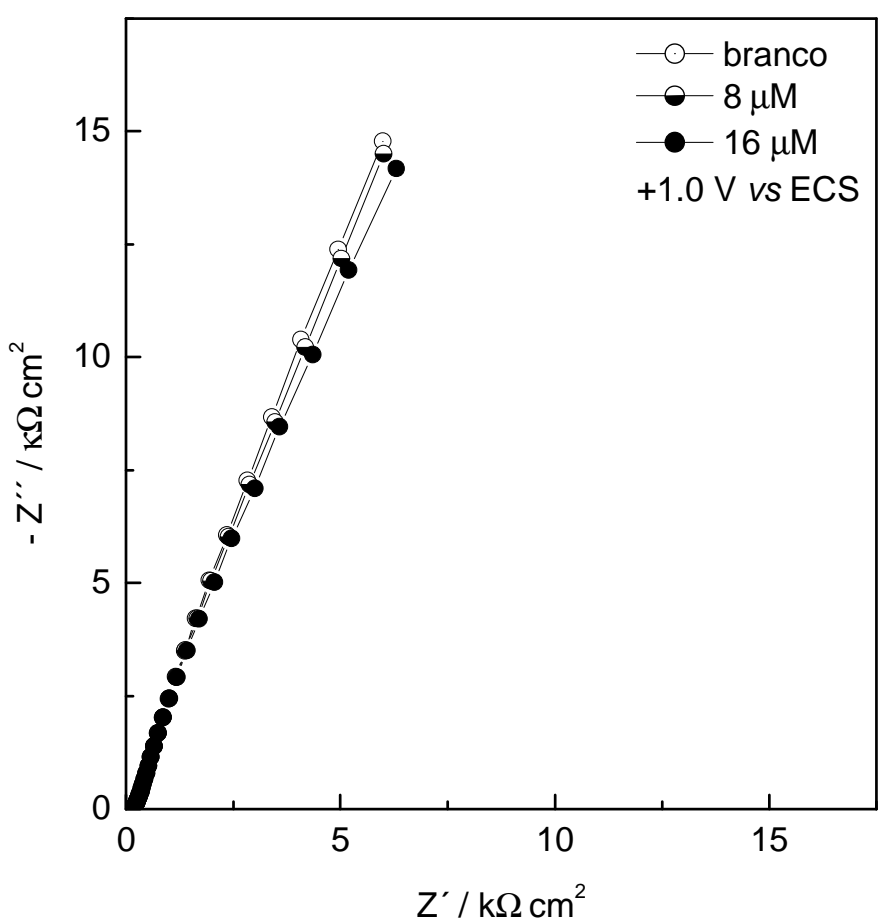

Figura 9.4c: Espectros de impedância eletroquímica para branco e adições em $+1,0 \vee$ vs. ECS. 


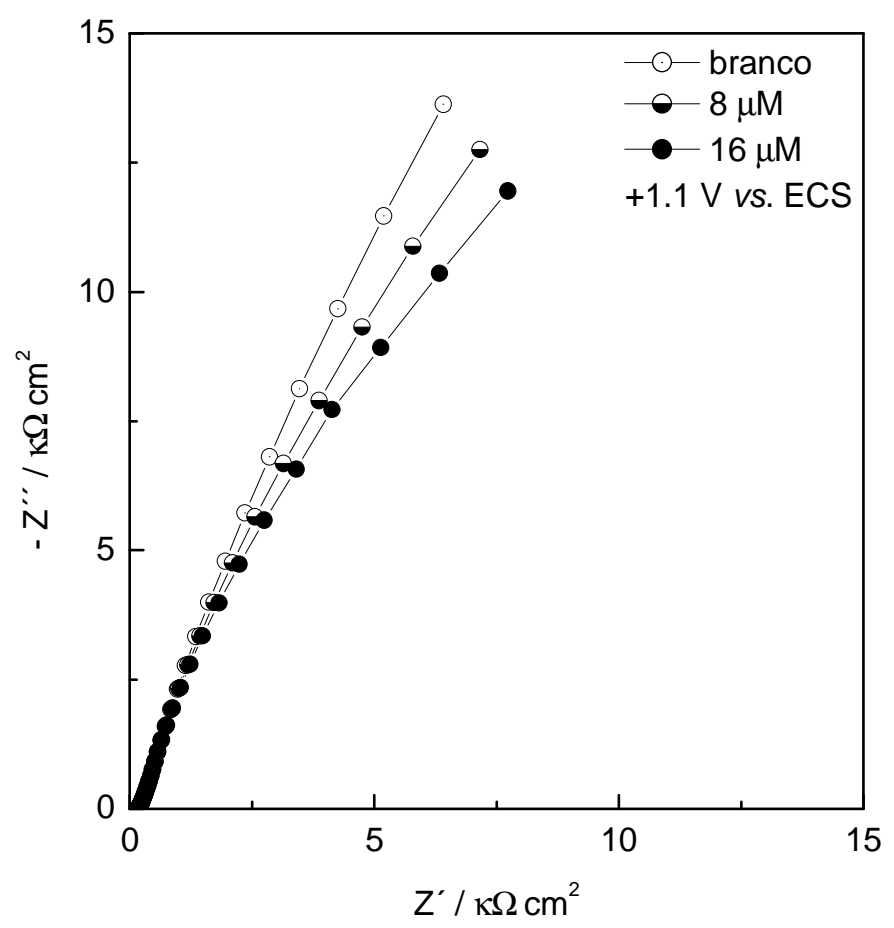

Figura 9.4d: Espectros de impedância eletroquímica para branco e adições em $+1,1 \mathrm{~V}$ vs. ECS.

Um circuito modificado de Randles com um resistor, $R_{\Omega}$, em séria a um circuito de combinação entre um elemento constante de fase (CPE), em paralelo a um resistor de transferência de cargas foi empregado para ajustar as curvas, conforme visto na Figura 9.5. Em todos os casos considerados, o CPE $\left(\mathrm{CPE}=\left\{(\mathrm{Ci} \omega)^{\alpha}\right\}^{-1}\right)$ apresenta um capacitor de modelo não-linear.

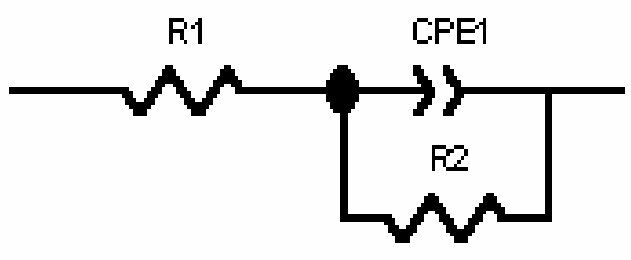

Figura 9.5: Circuito modificado de Randles proposto para o sistema em estudo.

O CPE mostrou-se necessário em função da heterogeneidade do material, expressa pela exponencial $\alpha$. Um valor típico de $\alpha$ próximo a 0,8 foi 
obtido para todos os espectros avaliados, independente da presença ou ausência de furosemida. A resistividade da célula mostrou-se próxima a $192 \Omega \mathrm{cm}^{2}$ (Tabela 9.2).

Tabela 9.2.: Resultados obtidos após ajuste dos espectros de impedância eletroquímica empregando modelo selecionado

\begin{tabular}{|c|c|c|c|c|}
\hline Condições & Rs \pm erro $\Omega$ & CPE-T & CPE-P & $\mathrm{Rp} \pm$ erro $\Omega$ \\
\hline $\mathrm{Bco},+0,5 \mathrm{~V}$ & $\begin{array}{c}191.5 \pm \\
0.79 \% \\
\end{array}$ & $5.26 \times 10^{-5} \pm 1.09 \%$ & $0.80 \pm 0.39 \%$ & $1,68 \times 10^{20} \pm 1.73 \times 10^{-7} \%$ \\
\hline $\mathrm{Bco},+0,75 \mathrm{~V}$ & $\begin{array}{l}190.2 \pm \\
0.79 \%\end{array}$ & $5.58 \times 10^{-5} \pm 1.09 \%$ & $0.79 \pm .40 \%$ & $1.31 \times 10^{19} \pm 2.18 \times 10^{-6} \%$ \\
\hline $\mathrm{Bco},+1,0 \mathrm{~V}$ & $\begin{array}{l}189.1 \pm \\
0.79 \%\end{array}$ & $6.3 \times 10^{-5} \pm 1.31 \%$ & $0.78 \pm 0.50 \%$ & $1.73 \times 10^{6} \pm 182.2 \%$ \\
\hline $\mathrm{Bco},+1,1 \mathrm{~V}$ & $\begin{array}{c}188.9 \pm \\
0.80 \% \\
\end{array}$ & $6.58 \times 10^{-5} \pm 1.35 \%$ & $0.78 \pm 0.52 \%$ & $234165 \pm 26.88 \%$ \\
\hline $8 \mu \mathrm{M},+05 \mathrm{~V}$ & $\begin{array}{l}188.5 \pm \\
0.84 \%\end{array}$ & $5.40 \times 10^{-5} \pm 1.15 \%$ & $0.80 \pm 0.42 \%$ & $5.02 \times 10^{19} \pm 6.06 \times 10^{-7} \%$ \\
\hline $8 \mu \mathrm{M},+0,75 \mathrm{~V}$ & $\begin{array}{c}188.0 \pm \\
0.82 \% \\
\end{array}$ & $5.62 \times 10^{-5} \pm 1.13 \%$ & $0.79 \pm 0.42 \%$ & $1.10 \times 10^{19} \pm 2.68 \times 10^{-6} \%$ \\
\hline $8 \mu \mathrm{M},+1,0 \mathrm{~V}$ & $\begin{array}{l}187.4 \pm \\
0.81 \%\end{array}$ & $6.34 \times 10^{-5} \pm 1.34 \%$ & $0.77 \pm 0.51 \%$ & $927461 \pm 100.79 \%$ \\
\hline $8 \mu \mathrm{M},+1,1 \mathrm{~V}$ & $\begin{array}{c}188.9 \pm \\
0.80 \% \\
\end{array}$ & $6.58 \times 10^{-5} \pm 1.35 \%$ & $0.78 \pm 0.52 \%$ & $234165 \pm 26.88 \%$ \\
\hline $16 \mu \mathrm{M},+0,5 \mathrm{~V}$ & $\begin{array}{l}186.9 \pm \\
0.87 \%\end{array}$ & $5.48 \times 10^{-5} \pm 1.19 \%$ & $0.79 \pm 0.44 \%$ & $6.01 \times 10^{19} \pm 5.16 \times 10^{-7} \%$ \\
\hline $16 \mu \mathrm{M},+0,75 \mathrm{~V}$ & $\begin{array}{c}186.4 \pm \\
0.86 \% \\
\end{array}$ & $5.64 \times 10^{-5} \pm 1.18 \%$ & $0.79 \pm 0.44 \%$ & $1.22 \times 10^{15} \pm 0.025 \%$ \\
\hline $16 \mu \mathrm{M},+1,0 \mathrm{~V}$ & $\begin{array}{l}185.9 \pm \\
0.83 \% \\
\end{array}$ & $6.34 \times 10^{-5} \pm 1.39 \%$ & $0.77 \pm 0.53 \%$ & $369306 \pm 41.7 \%$ \\
\hline $16 \mu \mathrm{M},+1,1 \mathrm{~V}$ & $\begin{array}{l}186.1 \pm \\
0.85 \% \\
\end{array}$ & $6.40 \times 10^{-5} \pm 1.5 \%$ & $0.78 \pm 0.56 \%$ & $69880 \pm 8.9 \%$ \\
\hline
\end{tabular}

A Figura 9.4a apresenta o espectro típico obtido para medidas em $+0,50$ V vs. ECS. O perfil se mostra muito similar antes e após as adições de analito, caracterizado por uma linha de grande resistência a polarização. O efeito observado pode ser considerado puramente capacitivo, em virtude de características intrínsecas ao material, dentre as quais a alta resistência à transferência de cargas neste potencial. Demais espectros desta mesma figura, obtidos após adições de analito, mostram mesmo perfil, sem alterações significativas, o que sugere a não ocorrência de nenhum processo de superfície ou adsorção. Entretanto, uma sutil alteração nos valores de capacitância é observada, em função da adição de analito.

$\mathrm{Em}+0,75 \mathrm{~V}$ e $+1,0 \mathrm{~V}$ vs. ECS as mesmas tendências são observadas, o que indica que nenhum processo considerável esteja ocorrendo na superfície. Uma informação importante, obtida pela comparação entre todos os espectros, é que os valores imaginários de impedância (Z') não se alteram 
significativamente com o acréscimo de potencial, indicando que a superfície do eletrodo apresenta um comportamento bem conhecido e previsível, mesmo em regiões de potencial onde é possível ocorrer evolução de oxigênio.

$\mathrm{Em}+1,1 \mathrm{~V}$ vs. ECS, próximo ao limite de aplicação do eletrodo, o espectro assume um novo perfil, similar a um semi-círculo, com uma correspondente redução nos valores de resistência. De forma diferente aos perfis anteriores, no presente caso a capacitância apresenta-se relativamente constante em branco e adições.

Existem evidências de que não ocorre adsorção do analito na superfície do eletrodo, nos meios empregados para a determinação, nenhum processo dependente de transferência de massa foi evidenciado. As diferenças obtidas na transferência de cargas se devem principalmente ao potencial aplicado.

\subsubsection{Voltametria de pulso diferencial (DPV)}

O mecanismo de oxidação foi estudado também empregando voltametria de pulso diferencial, onde a largura de pico à meia altura, $W_{1 / 2}$, próxima a $70 \mathrm{mV}$, confirma a hipótese de um processo irreversível envolvendo dois elétrons por próton, resultados que se encontram e concordância com [39].

Voltametria de pulso diferencial foi também empregada na quantificação do analito em amostras farmacêuticas comerciais ; neste caso, melhores condições experimentais foram alcançadas em $100 \mathrm{mV}$ como amplitude de pulso, a $25 \mathrm{mV} \mathrm{s}^{-1}$, entre $+0,5 \mathrm{e}+1,2 \mathrm{~V}$ vs. ECS. Picos anódicos foram observados em +0,9 V (Figura 7), com região linear entre 0,75 e $6,5 \mu \mathrm{mol} \mathrm{L}{ }^{-1}$, seguindo Equação 9.2.:

$$
I_{p a}=0,19[\mathrm{Fr}] A \mathrm{~mol}^{-1} \mathrm{~L}+1,6 \times 10^{-6} A,\left(r^{2}=0,998, n=6\right)
$$

Com limites de detecção e quantificação de 0,15 e $0,46 \mu \mathrm{mol} \mathrm{L}^{-1}$, respectivamente. Ensaios de adição-recuperação empregando amostras comerciais Teuto $^{\circledR}$ ofereceram resultados entre 101,9 e $106,6 \%$. 


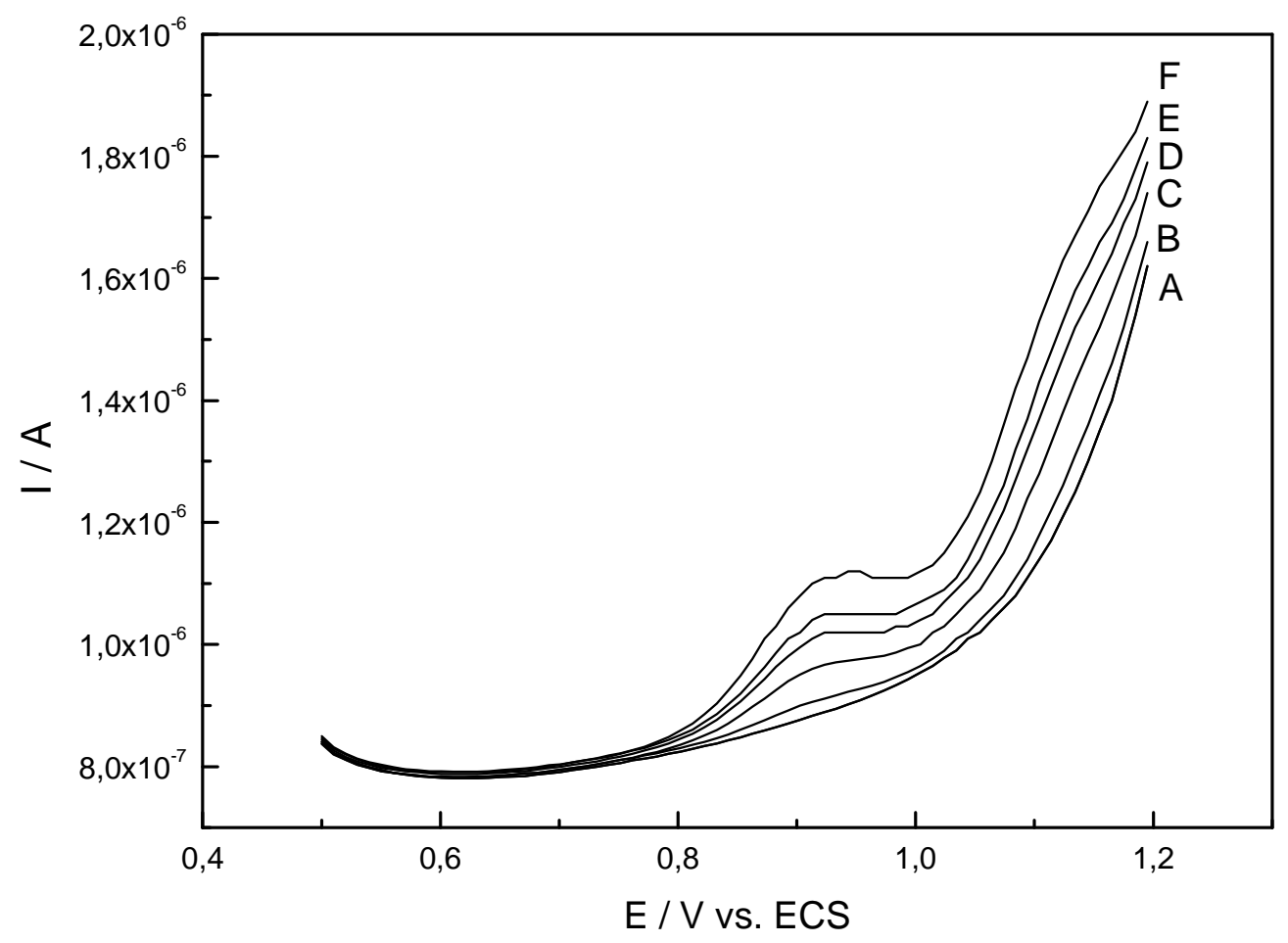

Figura 9.6.: Voltamogramas de pulso diferencial para análise de Furosix ${ }^{\circledR}$,sob condições otimizadas. Concentrações, em $\mu \mathrm{mol} \mathrm{L}^{-1}$ : (a) branco, (b) amostra, (c) 2,2, (d) 3,7 , (e) 5,1, (f) 6,5 .

\subsubsection{Voltametria de onda quadrada (SWV)}

Quantificações empregando voltametria de onda quadrada foram realizadas aplicando condições otimizadas, ou seja, freqüência de $10 \mathrm{~Hz}$, amplitude de $25 \mathrm{mV}$, com degraus de potencial de $5 \mathrm{mV}$, o que confirma a proposta de mecanismo apresentada, potenciais avaliados foram de $+0,6$ a +1,2 V vs. ECS, em pH 3,3, tampão acetato.

Picos anódicos foram observados em $+0,96 \mathrm{~V}$, com região linear entre 3 e $9 \mu \mathrm{mol} \mathrm{L} \mathrm{L}^{-1}$ e Equação:

$$
I_{p a}=0,1[\mathrm{Fr}] A \mathrm{~mol}^{-1} \mathrm{~L}+1,5 \times 10^{-7} \mathrm{~A},\left(\mathrm{r}^{2}=0,988, n=6\right)
$$

Foram observados limites de detecção e quantificação de 0,96 e 3,20 $\mu \mathrm{mol} \mathrm{L}{ }^{-1}$, respectivamente. Tais resultados se apresentam compatíveis com os encontrados na voltametria de pulso diferencial, conforme espera, tratando-se de processo irreversível. A presente técnica apresenta como principal vantagem a rapidez nas medidas (Figura 9.7.). 


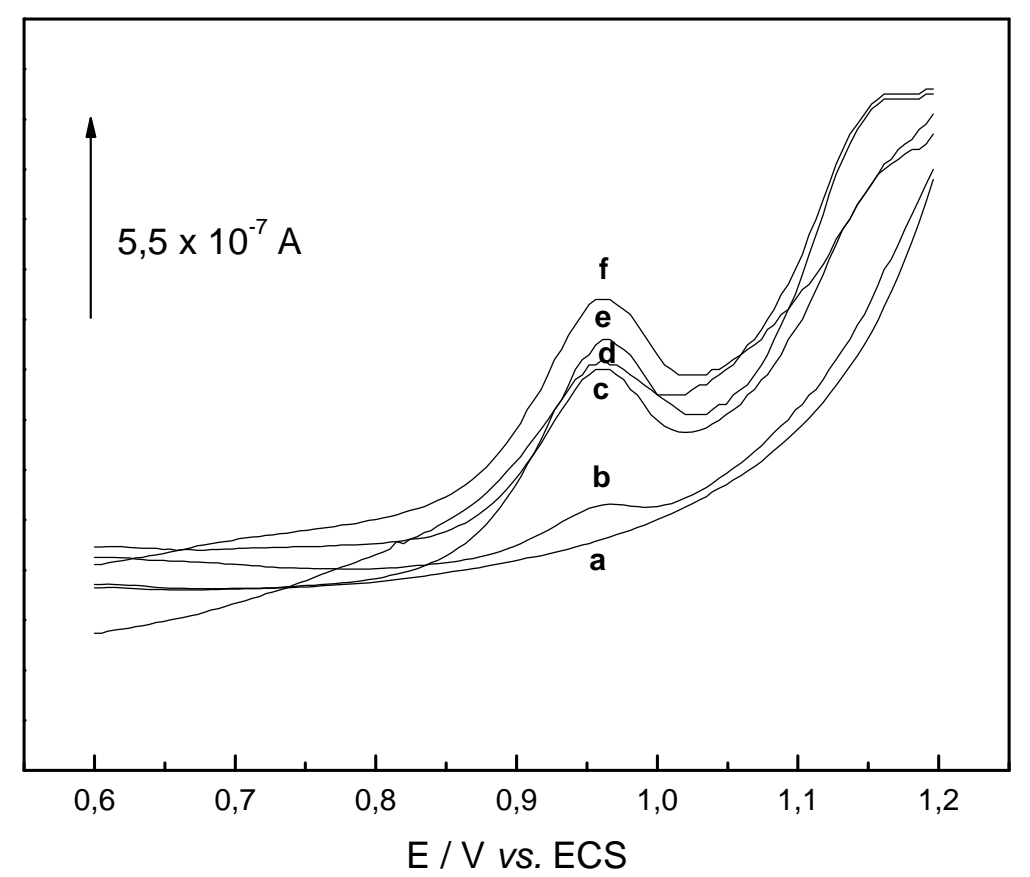

Figura 9.7.: Voltamogramas de onda quadrada para análise de Pharlab ${ }^{\circledR}$, sob condições otimizadas. Concentrações, em $\mu \mathrm{mol} \mathrm{L}^{-1}$ : (a) branco, (b) amostra, (c) $0,8,(d) 2,2,(e) 4,4$, (f) 6,5 .

Ensaios de adição-recuperação foram realizados empregando amostras comerciais de Furosix ${ }^{\circledR}$, atingindo-se resultados entre 103 e 104\%.

\subsubsection{Análises por injeção em fluxo (FIA)}

Visando dinamizar as determinações e explorar a não ocorrência de adsorção do analito foram avaliados parâmetros para desenvolvimento de procedimento em fluxo para determinação do analito via amperometria, fixando-se a aquisição de sinais em $+1,00 \mathrm{~V}$ (vs. ECS).

Empregando cela especialmente planejada para três eletrodos, foram realizados experimentos por fluxo contínuo. Esquema da cela é apresentado em Figura 9.8. 


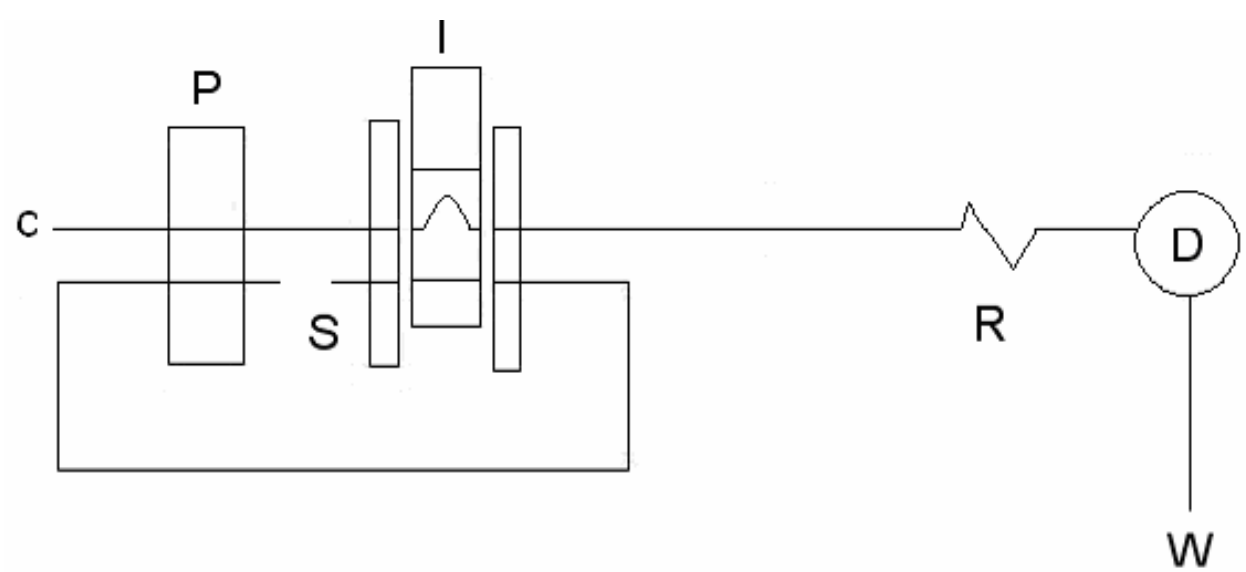

Figura 9.8.: diagrama ilustrativo do sistema em fluxo explorado. $\mathrm{C}=$ carregador

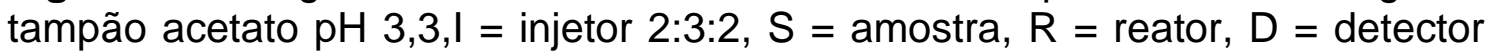
amperometrico (três eletrodos), $\mathrm{W}=$ descarte.

Inicialmente foram estudados parâmetros como alça de amostragem e vazões, tendo-se como sonda o analito em uma concentração de $10^{-4} \mathrm{~mol} \mathrm{~L}^{-1}$. Empregando tampão acetato $\mathrm{pH} \mathrm{3,3} \mathrm{em} \mathrm{uma} \mathrm{vazão} \mathrm{fixa} \mathrm{de} \mathrm{2,2} \mathrm{mL} \mathrm{min}^{-1}$ foram avaliadas alças de amostragem de 20, 40, 60 e $100 \mathrm{~cm}$, correspondendo a volumes de 100, 200, 300 e $500 \mu \mathrm{L}$.

Melhores relações entre magnitude de sinal, consumo de reagentes, freqüência analítica e reprodutibilidade são encontradas empregando-se alça de $300 \mu \mathrm{L}$, conforme Figura 9.9.

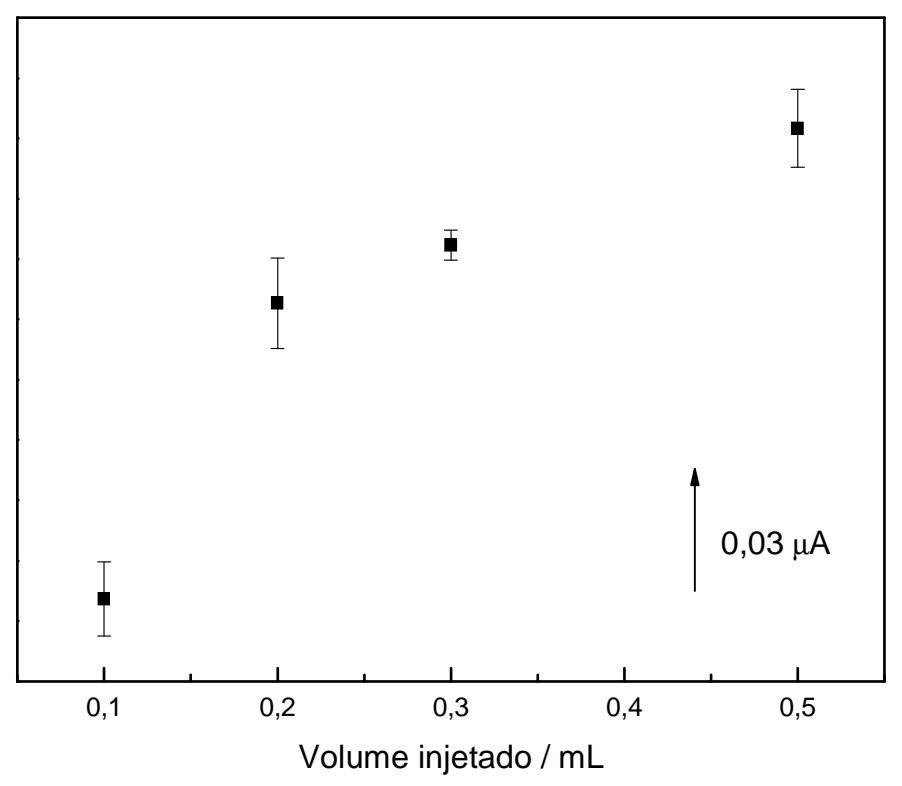

Figura 9.9.: Otimização da alça de amostragem a ser empregada no sistema em fluxo. 
Tendo sido escolhida alça de $300 \mu \mathrm{L}$, procedeu-se estudo de vazões, por meio de variações na velocidade de rotação da bomba peristática empregada. Foram avaliadas vazões de 1,4, 2,2, 2,8 e 3,6 mL min ${ }^{-1}$. Melhores perfis de sinais e relação freqüência analítica/consumo de reagente foram encontradas em vazão igual a 2,8 $\mathrm{mL} \mathrm{min}^{-1}$.

Parâmetros otimizados foram fixados: alça de $300 \mu \mathrm{L}$, vazão de $2,8 \mathrm{~mL}$ $\mathrm{min}^{-1}$, carregador em tampão acetato $\mathrm{pH} 3,3$. Tendo sido definido o sistema, realizou-se estudo visando a definição da região linear a ser explorada. Padrões de diferentes concentrações foram empregados, atingindo-se como resultados uma região linear entre $1,0 \times 10^{-5}$ e $1,0 \times 10^{-4} \mathrm{~mol} \mathrm{~L}^{-1}$ (Figuras 9.10. e 9.11.), com limite de detecção de $3 \times 10^{-6} \mathrm{~mol} \mathrm{~L}^{-1}$.

O sistema proposto forneceu curva analítica igual a:

$$
I_{p a}=0,0935[\mathrm{Fr}] A \mathrm{~mol} L^{-1}+2,1 \times 10^{-6} A,(r=0,997, n=5)
$$

A freqüência analítica atingida foi de 160 medidas por hora, com consumo de reagentes próximo a $180 \mathrm{~mL}$.

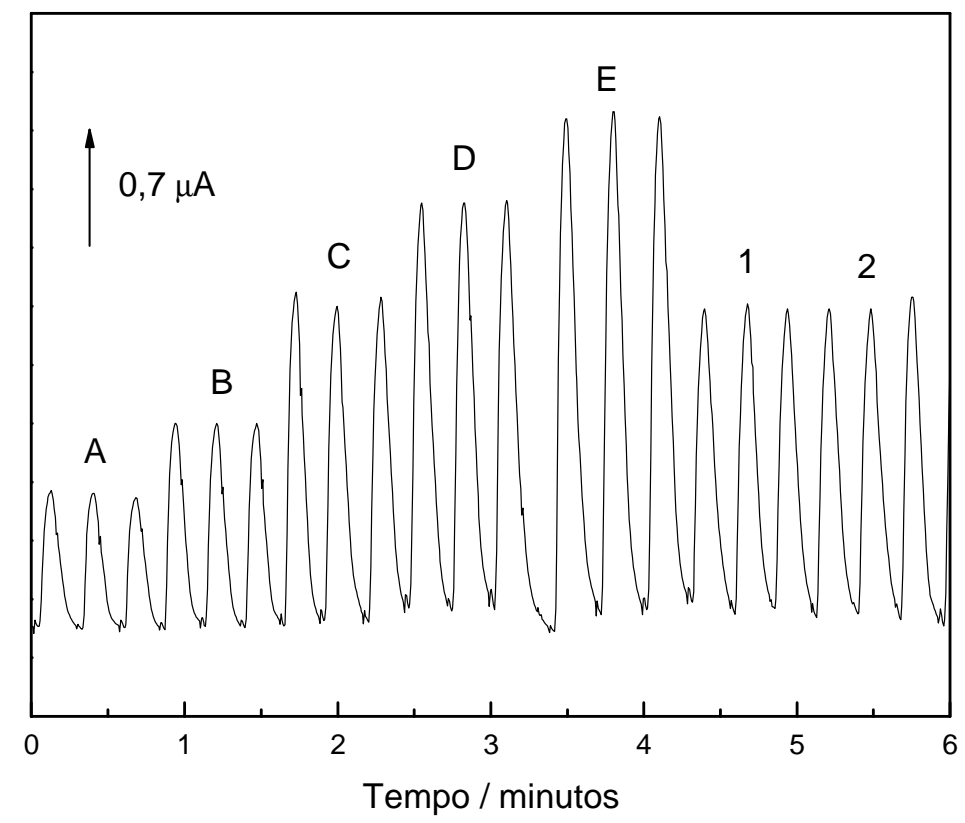

Figura 9.10.: Sinais transientes para curva analítica $\left(A=10^{-5}, B=2,5 \times 10^{-5}\right.$, $C=5,0 \times 10^{-5}, D=7,5 \times 10^{-5}$ e $E=10^{-4}, \mathrm{~mol} \mathrm{~L}^{-1}$ ) e exemplos de amostras reais ( 1 = Pharlab, 2 = Teuto $)$. 


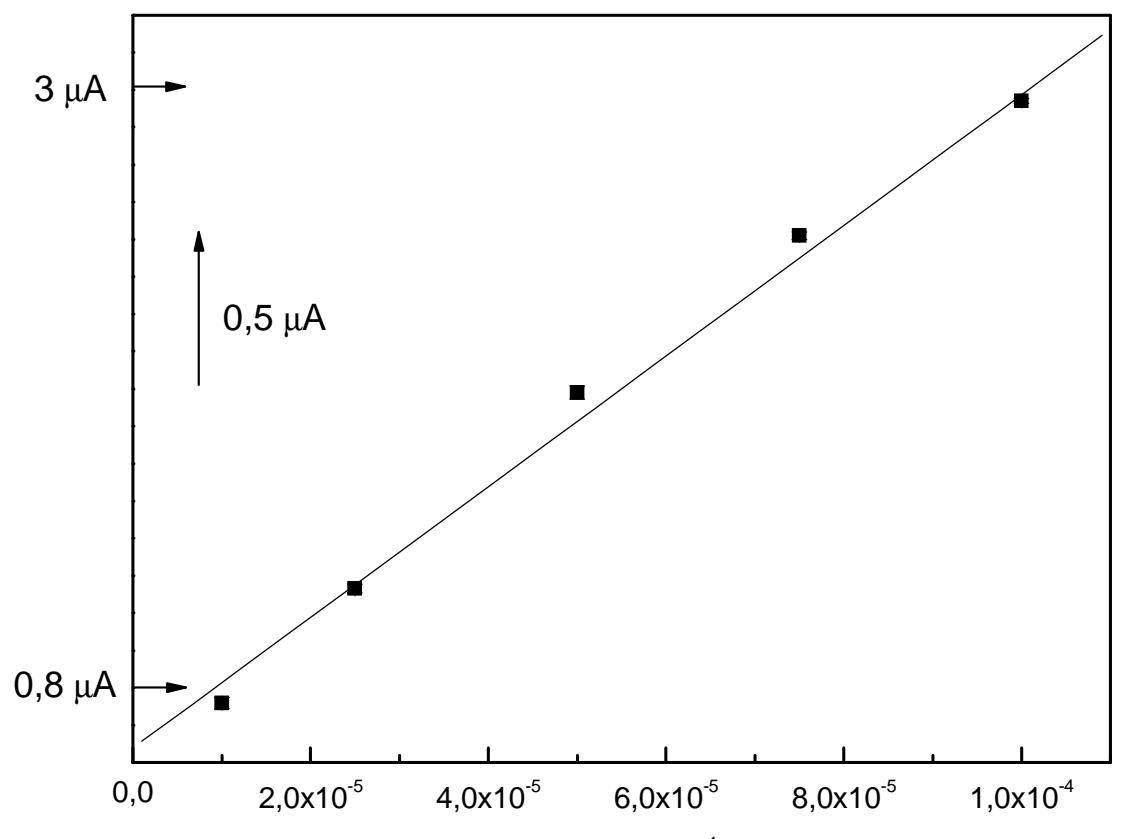

$[\mathrm{Fr}] / \mathrm{mol} \mathrm{L}^{-1}$

Figura 9.11.: Curva de calibração obtida a partir do registro de sinais anterior.

Ensaios de adição e recuperação empregando amostra comercial de Pharlab ${ }^{\circledR}$ forneceram resultados entre 102 e $104 \%$.

\subsection{Resultados obtidos}

Embora o conceito e vantagens do uso de compósitos como materiais de eletrodo tenham sido descritos anos atrás, suas reais aplicações têm sido pouco exploradas, considerando-se seu potencial, principalmente nas análises de rotina.

No presente trabalho objetivamos apresentar um modo, fácil, barato e robusto de emprego de compósitos na análise de fármacos por técnicas eletroanalíticas.

Compósito a base de resina poliuretana e pó de grafite foi empregado no preparo de eletrodos sólidos para quantificação voltamétrica de furosemida em amostras comerciais, demonstrando a viabilidade do método. Experimentos utilizando espectroscopia de impedância eletroquímica sugerem a não ocorrência de adsorção do analito na superfície do eletrodo, o que dispensa renovação periódica da mesma, tornando o procedimento mais rápido. 
Tabela 9.3.: Resultados obtidos pelas diferentes técnicas para comprimidos contendo $40 \mathrm{mg}$ de analito, segundo valor rotulado

\begin{tabular}{cccccc}
\hline & CV $^{\mathbf{a}}$ & DPV $^{\mathbf{a}}$ & SWV $^{\mathbf{a}}$ & FIA amp & $\begin{array}{c}\text { Método } \\
\text { Oficial }^{\mathbf{b}}\end{array}$ \\
\hline Furosix $^{\circledR}$ & $41 \pm 1$ & $40 \pm 2$ & $41,6 \pm 0,3$ & $41,0 \pm 0,4$ & 42,4 \\
Neosemid $^{\circledR}$ & $42 \pm 1$ & $42,1 \pm 0,3$ & $38,8 \pm 0,3$ & $41,3 \pm 0,5$ & 43,3 \\
Pharlab $^{\circledR}$ & $40 \pm 2$ & $41 \pm 2$ & $40,4 \pm 0,4$ & $41,0 \pm 0,4$ & 39,5 \\
Teuto $^{\circledR}$ & $41,9 \pm 0,4$ & $38,1 \pm 0,6$ & $41,5 \pm 0,4$ & $41,3 \pm 0,3$ & 41,8 \\
\hline${ }^{\text {aresultados médios, } \mathrm{n}=3 ; \text { mg por comprimido; }}$ \\
${ }^{\text {bmg por comprimido. }}$
\end{tabular}

Obs.: $\mathrm{CV}=$ voltametria cíclica, $\mathrm{DPV}=$ voltametria de pulso diferencial, $\mathrm{SWV}=$ voltametria de onda quadrada, FIA amp = análise por injeção em fluxo empregando amperometria, UV-vis = método Oficial por espectrofotometria UVvis. 


\section{CAPITULO 10: CONSIDERAÇÕES FINAIS E COMPARAÇÕES}

A presente tese teve por objetivo desenvolver e aplicar novos procedimentos analíticos para determinação do diurético de alça furosemida, amplamente empregado no controle da hipertensão arterial e de fácil aquisição no mercado brasileiro.

Foram descritos procedimentos empregando desde química clássica, como titulometria; a métodos instrumentais modernos, com considerável sensibilidade, como os métodos óticos (espectrofotometria UV-vis, espectroscopia de fluorescência) e métodos eletroanalíticos (voltametrias cíclica, de pulso diferencial e de onda quadrada, espectroscopia de impedância eletroquímica).

Visando facilitar a aplicação dos métodos desenvolvidos, bem como minimizar consumo de reagentes e geração de resíduos, e elevar a freqüência analítica, os mesmos foram adaptados a sistemas de análise em fluxo (FIA).

Testes estatísticos como teste $Q$, teste $t$ de Student e teste $t$ de Student pareado demonstraram a aplicabilidade dos procedimentos desenvolvidos à análise de diversas amostras, como formulações comerciais (comprimidos e soluções injetáveis) e materiais biológicos sintéticos (urina sintética).

Os procedimentos desenvolvidos e apresentados podem ser divididos entre estáticos e dinâmicos, visando facilitar as comparações. A seguir se resumem os resultados obtidos neste trabalho.

1- ) Estáticos:

a-) Titrimetria: foram realizados estudos explorando a reação de hidrólise ácida da furosemida e posterior óxido-redução entre os produtos de tal hidrólise e 
$\mathrm{KMnO}_{4}$, em meio aquoso ácido. Como meio para dissolução do fármaco foram empregadas, em situações diferentes, soluções de acetona:água (1:1, v/v), e solução aquosa de SDS 3\%. Em ambas as situações as titulações foram realizadas a $10^{\circ} \mathrm{C}$, adicionando-se alíquotas da amostra sobre volume constante de solução de $\mathrm{KMnO}_{4}$ preparada conforme descrito anteriormente; o ponto final correspondia ao descoramento completo do titulado (mudança de violeta para incolor), o que dificultava sua detecção visual. Tal procedimento abriu opções para uso de detecção espectrofotométrica e sua adaptação a sistemas em fluxo.

b-) Espectrofotometria na região visível: outro procedimento estático descrito foi o uso da reação de complexação entre o analito e íons $\mathrm{Fe}^{+3}$, em meio ácido; empregando um detector espectrofotométrico. Nesta reação a força iônica do meio se apresenta fundamental e a ordem de adição de reagentes é determinante, tornando o processo lento e tedioso quando comparado aos demais.

Da mesma maneira que a titrimetria, este procedimento serviu de ponto de partida para seu emprego em análise por injeção em fluxo.

c-) Determinações eletroanalíticas: empregando eletrodo compósito poliuretana-grafite foram realizados experimentos eletroanalíticos; por meio de voltametria cíclica foram obtidas informações que serviram de suporte para a realização de demais experimentos empregando voltametria de pulso diferencial e de onda quadrada, bem como de espectroscopia de impedância eletroquímica e amperométrica em fluxo. 


\section{2-) Dinâmicos:}

a-) Espectrofotometria com sistema em fluxo empregando $\mathrm{KMnO}_{4}$ como reagente redox: neste sistema explorou-se a capacidade do analito em gerar, por hidrólise ácida, produtos que, reagindo com o $\mathrm{KMnO}_{4}$, descoram o meio, de violeta para incolor, o que pode ser monitorado em $550 \mathrm{~nm}$. Tal sistema necessitou ser termostatizado em 50 graus para melhor desempenho, consumindo 2,2 $\mathrm{mL}$ de reagentes por minuto. Desta forma foi alcançada uma freqüência analítica de 40 medidas por hora.

Tal sistema, embora não apresente tanta vantagem em relação à velocidade, quando comparado aos demais sistemas em fluxo, solucionou o problema da detecção visual, observado durante experimentos de titrimetria, representando uma alternativa viável e de fácil aplicação.

b-) Espectrofotometria com sistema em fluxo empregando complexação com íons $\mathrm{Fe}^{+3}$ : a reação de complexação do analito com íons férricos em meio etanólico apresentou-se útil nos sistemas em fluxo, embora parâmetros como sensibilidade tenham ficado comprometidos, quando comparados com 0 sistema estático. Nesta situação, empregando apenas etanol P. A. como solvente, e avaliando-se intervalo entre $10^{-4}$ e $10^{-2} \mathrm{~mol} \mathrm{~L}^{-1}$, foi possível realizar 95 medidas por hora, consumindo $1 \mathrm{~mL}$ de reagentes por minuto e $250 \mu \mathrm{L}$ de amostra por medida.

O descarte gerado por este sistema pôde ser reaproveitado, por meio de destilação do etanol empregado, o que o tornou menos dispendioso. 
c-) Espectroscopia de fluorescência em fluxo: empregando espectroscopia de fluorescência foram desenvolvidos dois sistemas, o primeiro explorando as características intrínsecas do analito quando excitado, em $\mathrm{pH}$ adequado; o segundo, visando aumentar a sensibilidade e melhorar desempenho analítico, utilizou ambientes micelares, estudando o uso de SDS e CTAB, em suas respectivas concentrações micelares críticas.

Sem o uso de tensoativos, o sistema em fluxo otimizado possibilitou 90 medidas por hora, consumindo $3 \mathrm{~mL}$ de solução por minuto, foram necessários $400 \mu \mathrm{L}$ de amostra para cada medida. Após introdução de fluxo confluente de tensoativos, a freqüência analítica se reduz para 60 medidas por hora, tanto para SDS quanto para CTAB. Neste caso o consumo de amostra, bem como o limites de detecção e quantificação se mantêm os mesmos, porém, observouse maior consumo de soluções (216 mL por hora) e elevação do coeficiente angular nas curvas de calibração.

d-) Amperometria em fluxo: experimentos utilizando voltametria cíclica e espectroscopia de impedância eletroquímica forneceram informações que possibilitaram o uso dos eletrodos compósitos como detectores de sistema em fluxo, sem necessidade de renovação de superfície eletroativa.

Este procedimento apresentou consumo de $2,8 \mathrm{~mL}$ de solução por minuto de análise, consumindo $300 \mu \mathrm{L}$ de amostra por medida, com relação à velocidade, foram atingidas 160 medidas por hora.

Tais resultados são reunidos de forma simplificada na Tabela 10.1 . 
Tabela 10.1.: Comparação entre resultados obtidos pelos diversos procedimentos instrumentais desenvolvidos

\begin{tabular}{|c|c|c|c|c|c|c|c|}
\hline Procedimento & Técnica & $\begin{array}{l}\text { Reações } \\
\text { e/ou } \\
\text { ambientes }\end{array}$ & $\begin{array}{c}\text { Região } \\
\text { linear } / \\
\mu \mathrm{M}\end{array}$ & $\begin{array}{l}\text { LD / } \\
\mu \mathrm{M}\end{array}$ & $\underset{\mu \mathrm{M}}{\mathrm{LQ} /}$ & Sensibilidade & $\begin{array}{c}\text { Freqüência } \\
\text { analítica / } \\
\mathbf{h}^{-1}\end{array}$ \\
\hline Estático & UV-Vis & $\begin{array}{l}\text { complexação } \\
\text { íons férricos }\end{array}$ & 2 a 6 & 600 & 2000 & 139,3 & - \\
\hline Estático & $\begin{array}{l}\text { Voltametria } \\
\text { Cíclica* }^{*}\end{array}$ & $\begin{array}{l}\text { tampão } \\
\text { acetato } \\
\mathrm{pH} \mathrm{3,3}\end{array}$ & 8 a 21 & 2,7 & 8 & 0,305 & - \\
\hline Estático & $\begin{array}{l}\text { Voltametria } \\
\text { de pulso } \\
\text { diferencial }^{*}\end{array}$ & $\begin{array}{l}\text { tampão } \\
\text { acetato } \\
\text { pH 3,3 }\end{array}$ & $\begin{array}{c}0,75 \mathrm{a} \\
6,5\end{array}$ & 0,15 & 0,45 & 0,36 & - \\
\hline Estático & $\begin{array}{l}\text { Voltametria } \\
\text { de onda } \\
\text { quadrada* }\end{array}$ & $\begin{array}{l}\text { tampão } \\
\text { acetato } \\
\mathrm{pH} 3,3\end{array}$ & 3 a 9 & 0,96 & 3 & 0,2 & - \\
\hline $\begin{array}{l}\text { Injeção em } \\
\text { fluxo }\end{array}$ & UV-Vis & $\begin{array}{l}\text { óxido- } \\
\text { redução } \\
\mathrm{KMnO}_{4}\end{array}$ & $\begin{array}{c}100 \mathrm{a} \\
600\end{array}$ & 30 & 100 & 587,5 & 40 \\
\hline $\begin{array}{l}\text { Injeção em } \\
\text { fluxo }\end{array}$ & UV-Vis & $\begin{array}{l}\text { complexação } \\
\text { íons férricos }\end{array}$ & $\begin{array}{l}100 \mathrm{a} \\
10000\end{array}$ & 33 & 100 & 22,6 & 95 \\
\hline $\begin{array}{l}\text { Injeção em } \\
\text { fluxo }\end{array}$ & Amperometria & $\begin{array}{l}\text { tampão } \\
\text { acetato } \\
\mathrm{pH} 3,3\end{array}$ & $\begin{array}{l}10 a \\
100\end{array}$ & 3 & 10 & 0,1805 & 160 \\
\hline $\begin{array}{l}\text { Injeção em } \\
\text { fluxo }\end{array}$ & Fluorimétrico & $\begin{array}{c}\text { tampão } \\
\text { fosfato } \\
\mathrm{pH} 3,2\end{array}$ & $\begin{array}{c}0,1 \mathrm{a} \\
10\end{array}$ & 0,03 & 0,1 & $10^{8}$ & 90 \\
\hline $\begin{array}{l}\text { Injeção em } \\
\text { fluxo }\end{array}$ & Fluorimétrico & $\begin{array}{l}\text { meio micelar } \\
\text { SDS em CL }\end{array}$ & $\begin{array}{c}0,1 \mathrm{a} \\
10\end{array}$ & 0,03 & 0,1 & $3,0 \times 10^{8}$ & 60 \\
\hline $\begin{array}{l}\text { Injeção em } \\
\text { fluxo }\end{array}$ & Fluorimétrico & $\begin{array}{l}\text { meio micelar } \\
\text { CTAB em CL }\end{array}$ & $\begin{array}{c}0,1 a \\
10\end{array}$ & 0,03 & 0,1 & $3,0 \times 10^{8}$ & 60 \\
\hline
\end{tabular}

Os resultados apresentam pontos positivos e limitações de cada método e procedimento, mostrando a necessidade de se avaliar com critério a amostra antes de se escolher a ferramenta analítica a ser utilizada; dentre os parâmetros a se considerar podemos destacar a velocidade de análise e limites de detecção e quantificação necessários, a quantidade de amostra, bem como os reagentes e instrumentos disponíveis. 
A análise térmica mostrou que a furosemida se decompõe com perda de um mol de $\mathrm{NH}_{3}$ para cada dois moles do analito, após a fusão. Também foram determinados os parâmetros da cinética de decomposição como Ea e log A. 


\section{CAPITULO 11: REFERÊNCIAS BIBLIOGRÁFICAS}

[1]RIERA, A. R. P. Hipertensão arterial: conceitos práticos e terapêutica. São Paulo: Atheneu, 2000. 462p.

[2]VLASE, H.L.; PANAGOPOULOS, G.; MICHELIS, M.F. Effectiveness of Furosemide in Uncontrolled Hypertension in the Elderly: Role of Rennin Profiling. American Journal of Hypertension, v. 16, p.187-193, 2003.

[3]NOBRE, F.; LIMA, N. K. C. Hipertensão arterial: conceito, classificação e critérios diagnósticos. In: MANUAL de cardiologia SOCESP. São Paulo: Atheneu, 2000. p. 303.

[4]MANO, R. Manual de hipertensão arterial. [S.I.: s. n.], 2002. p. 30.

[5]HIPERTENSION. Disponível em:<Http://www.tuotromedico.com/temas/hipertension.htm> Acesso em: 21 dez. 2002.

[6]KAPLAN, N. M. Systemic hypertension: mechanisms and diagnosis. In: HEART disease. BRANWALD, E.; ZIPES, D.P.; LIBBY, P. (Eds.). 6. ed. Filadelphia: Saunders College Publishing, 2001. p. 941.

[7]LATUFO, P. A.; LOLIO, C. A. Epidemiologia da hipertensão arterial no Brasil. In: SOCESP Cardiologia. São Paulo: Atheneu, 1996. p. 327.

[8]FUROSEMIDE. Disponível em:

$<$ Http://www.rxlist.com/cgi/generic/furos.htm>. Acesso em: 21 dez. 2003. 
[9]SOUZA, F. S. Guia Farmacoterapêutico da rede ambulatorial municipal de Alfenas 1998/1999. 2 ed. Alfenas: Prefeitura Municipal, 1998. p. 30.

[10]RANG, H. P.; DALE, M. M.; RITTER, J. M. Farmacologia. 4 ed. Rio de Janeiro: Guanabara Koogan, 2001. 703p.

[11]NÉFRON, Disponível em: <Http://biocarampangue.tripod.com/1Nefron.jpg >. Acesso em: 21 dez. 2003.

[12]THE MERCK Index: an encyclopedia of chemicals, drugs and biologicals. 13. ed. Whitehouse Station: Merck, 2001. p. 1741.

[13]EADES, S.K.; CHRISTENSEN, M. L. The clinical pharmacology of loop diuretics in the pediatric patient. Pediatric Nephrology, v. 12, p. 603-616, 1998.

[14]EL-SAHARTY, Y. S. Simultaneous high-performance liquid chromatographic assay of furosemide and propranolol $\mathrm{HCl}$ and its application in a pharmacokinetic study. Journal of Pharmaceutical and Biomedical Analysis, v. 33, p. 699-709, 2003.

[15]GUZMÁN, A.; AGÜÍ, L.; PEDRERO,M.; YÁÑEZ-SEDEÑO, P.; PINGARRÓN, J.M. Flow injection and HPLC determination of furosemide using pulse amperometric detection at microelectrodes. Journal of Pharmaceutical and Biomedical analysis, v. 33, p. 923-933, 2003.

[16]CARDA-BROCH, S.; ESTEVE-ROMERO,J.; GARCIA-ALVAREZ-COQUE, M.C.Furosemide assay in pharmaceuticals by Micellar liquid chromatography: study of the stability of the drug. Journal of Pharmaceutical and Biomedical Analysis, v. 23, n. 5, p. 803-817, 2000. 
[17]CARDA-BROCH, S.; ESTEVE-ROMERO, J. S.; GARCIA-ALVAREZCOQUE, M. C. Chromatographic determination of diuretics in urine samples using hybrid micellar mobile phases with fluorimetric detection. Analytica Chimica Acta, v. 375, n. 1-2, p. 143-154, 1998.

[18]TAKASHI, M.; BENET, L. Z.; LIN, E. T. High-performance liquid chromatographic determination and identification of acyl migration and photodegradation products of furosemide 1-acyl glucuronide. Journal of Chromatography B: Biomedical Sciences and Applications, v. 718, n. 1, p. 153-162, 1998.

[19]ABOU-AUDA, H. S.; AL-YAMANI, M. J.; MORAD, A. M.; BAWAZIR, S. A.; KHAN, S.Z.; AL-KHAMIS, K.I. High-performance liquid chromatographic determination of furosemide in plasma and urine and its use in bioavailability studies. Journal of Chromatography B: Biomedical Sciences and Applications, v. 710, n. 1-2, p. 121-128, 1998.

[20]JANKOWSKI, A.; SKOREK-JANKOWSKA, A.; LAMPARCZYK, H. Determination and pharmacokinetics of a furosemide-amiloride drug combination. Journal of Chromatography B: Biomedical Sciences and Applications, v. 693, n. 2, p. 383-391, 1997.

[21]BARROSO, M. B.; JIMENEZ, R. M.; ALONSO, R. M.; ORTIZ, E. Determination of piretanide and furosemide in pharmaceuticals and human urine by high-performance liquid chromatography with amperometric detection. Journal of Chromatography B: Biomedical Sciences and Applications, v. 675, n. 2, p. 303-312, 1996.

[22]BONET-DOMINGO, E.; TORRES-LAPASIO, J. R.; MEDINA-HERNANDEZ, M.J.; GARCIA-ALVAREZ-COQUE, M. C. Chromatographic monitoring of diuretics in urine samples using a sodium dodecyl sulphate-propanol micellar eluent. Analytica Chimica Acta, v. 287, n. 3, p. 201-210, 1994. 
[23]AGATONOVIC-KUSTRIN, S.; ZIVANOVIC, L.; RADULOVIC, D.; PECANAC, D. Spectrophotometric determination of furosemide and its palladium (II) complex. Journal of Pharmaceuticals and Biomedical Analysis, v. 8, p. 983-986, 1990.

[24]GARCIA, M. S.; SÁNCHEZ-PEDREÑO, C.; ALBERO, M. I.; RÓDENAS, V. Flow-injection spectrophotometric determination of furosemide or sulphatiazole in pharmaceuticals. Journal of Pharmaceutical and Biomedical Analysis, v. 15 , p. $453-459,1997$.

[25]TORAL, M. I.; POPE, S.; QUINTANILLA, S.; RICHTER, P. Simultaneous determination of amiloride and furosemide in pharmaceutical formulations by first digital derivate spectrophotometry. International Journal of Pharmaceutics, v. 249, p. 117-126, 2002.

[26]KULICHENKO, S. A.; SHEVCHENKO, G. M. Triton X-100-stabilized "oil-inwater" emulsions a suitable media for alkalimetric determination of hydrophobic organic acids. Analytical and Bioanalytical Chemistry, v. 375, p. 255-258, 2003.

[27]KULICHENKO, S. A.; FESENKO, S. A. Titrimetric determination of furosemide using aqueous-micellar solutions of surfactants. Journal of Analytical Chemistry, v. 57, p. 231-234, 2002.

[28]BARROSO, M. B.; ALONSO, R. M.; JIMÉNES, R. M. Eletrochemical determination of the loop diuretics piretane and furosemide in pharmaceutical formulations and urine. Analytica Chimica Acta, v. 305, p. 332-339, 1995. 
[29]DIAS, I. L. T.; OLIVEIRA-NETO, G.; VENDRAMINI, D. C.; SOMMER, C.; MARTINS, J. L. S.; KUBOTA, L. T. A poly (vinyl chloride)membrane electrode for the determination of diuretic furosemide. Analytical Letters, v. 37, n. 1, p. 35-46, 2004.

[30]RAO, Y.; ZHANG,X.; LUO, G.; BAEYENS, W. R. G. Chemiluminescence flow-injection of furosemide based on a rhodamine $6 \mathrm{G}$ sensitized cerium(IV) method. Analytica Chimica Acta, v. 396, p. 273-277, 1999.

[31]BELTYUKOVA, S.V.; TSELIK, E. I.; EGOROVA, A. V. Use of sensitized luminescence of lanthanides in analysis of drugs. Journal of Pharmaceutical and Biomedical Analysis, v. 18, p. 261-266, 1998.

[32]IOANNON, P. C.; RUSAKOVA, N. V.; ANDRIKOPOULOU, D. A.; GLYNOU, K.M.; TZOMPANAKI, M. Spectrofluorimetric determination of anthranilic acid derivatives based on terbium sensitized fluorescence. The Analyst, v. 123, p. 2839-2843, 1998.

[33]GEORGES, N. A. Investigation of the luminescent properties of terbiumantrhanilate complexes and application to the determination of anthranilic acid derivatives in aqueous solutions. Analytica Chimica Acta, v. 476, p. 149-157, 2003.

[34]PHARMACOPEIA of the United States of America. Rockville: United States Pharmacopeial Convention, 1985. v. 21.

[35] PHARMACOPEIA of the United States of America. Rockville: United States Pharmacopeial Convention, 2003. v. 27. 
[36]SHIN, S. C.; KIM, J. Physicochemical characterization of solid dispersion of furosemide with TGPS. International Journal of Pharmaceutics, v. 251, p. $79-84,2003$.

[37]SHIN, S.C.; OH, I. J.; LEE, Y. B.; CHOI, H. K.; CHOI, J. S. Enhaced dissolution of furosemide by coprecipitation or cogrindinh with crospovidone. International Journal of Pharmaceutics, v. 175, p. 17-24, 1998.

[38]SPAMER, E.; MÜLLER, D. G.; WESSELS, P. L.; VENTER, J. O. Characterization of the complexes of furosemide with 2 -hydroxypropyl- $\beta$ cyclodextrin and sulfobutyl ether-7- $\beta$-cyclodextrin. European Journal of Pharamaceutical Sciences, v. 16, p. 247-253, 2002.

[39]KARSA, D. R.; STEPHENSON, R. A. Excipients and delivery systems for pharmaceutical formulations. Manchester: The Royal Society of Chemistry, 1995. 192p.

[40]RUBINSTEIN, M. H. Pharmaceutical technology: controlled drug release. Chichester: Ellis Horwood, 1987. v. 1.

[41]ALVAREZ, L.; CONCHEIRO, A.; GÓMEZ-AMOZA, J. L.; SOUTO, C.; MARTÍNEZ-PACHECO, R. Powdered celullose as excipient for extrusionspheronization pellets of a cohesive hydrophobic drug. European Journal of Pharmaceutics and Biopharmaceutics, v. 55, p. 291-295, 2003.

[42]LIU, X.; SUN, Q.; WANG, H.; ZHANG, L.; WANG, J.Y. Microspheres of corn protein, zein, for an ivermectin drug delivery system. Biomaterials, v. 26, p. 109-115, 2005. 
[43]SÄKKINEN, M.; TUONONEN, T.; JÜRJENSON, H.; VESKI, P.; MARVOLA, M. Evaluation of microcrystalline chitosans for gastro-retentive drug delivery. European Journal of Pharmaceutical Sciences, v. 19, p. 345-353, 2003.

[44]TERRA, J.; ROSSI, A. V. Sobre o desenvolvimento da análise volumétrica e algumas aplicações atuais. Química Nova, v. 28, p. 166-171, 2005.

[45]BACCAN, N.; ANDRADE, J. C.; GODINHO, O. E. S.; BARONE, J. S. Química Analítica Quantitativa Elementar. São Paulo: Editora Edgard Blücher, 2000. 192p.

[46]CRUZ, J. E.; MANESS, D. D.; YAKATAN, G. J. Kinetics and mechanism of hydrolysis of furosemide. International Journal of Pharmaceutics, v. 2, p. 275-281, 1979.

[47]MANIASSO, N. Ambientes micelares em química analítica. Química Nova, v. 24, n. 1, p. 87-93, 2001.

[48]SHIHAB, F. A.; EBIAN, A. R.; MUSTAFA, R. M. Effect of polyethylene glycol, sodium laury sulfate and polysorbate- 80 on the solubility of furosemide. International Journal of Pharmaceutics, v. 4, n. 1, p. 13-20, 1979.

[49]ZIVANOVIC, L.; AGATONOVIC, S.; RADULOVIC, D. Spectrophotometric determination of furosemide as its $\mathrm{Fe}$ (III) complex in pharmaceutical preparations. Mikrochimica Acta, v. 1, p. 49-54, 1990.

[50]MOORE, D. E. Photochemistry of diuretic drugs in solution. In: PHOTOCHEMISTRY and photostability. London: Royal Society of Chemistry,1998. p. 100-115. 
[51]FIORI, J.; BALLARDINI, R.; ANDRISANO, V.; CAVRINI, V. Photostability studies on the furosemide-triamterene drug association. II farmaco, v. 58, p. 867-873, 2003.

[52]SOMMER, L. Analytical absorption spectrophotometry in the visible and ultraviolet : the principles. Amsterdam: Elsevier, 1989. 311p. (Studies in Analytical Chemistry, 8)

[53]HANSEN, E. H.; RUZICKA, J. The principles of flow injection analysis as demonstred by three lab exercises. Journal of Chemical Education, v. 56, p. 677-680, 1979.

[54]SEMAAN, F. S. Análises por injeção em fluxo. Revista da Universidade de Alfenas, v. 2, p. 237-238, 1999.

[55]SKOOG, D. A.; WEST, D. M.; HOOLER, F.J. Fundamentals of analytical chemistry. 7. ed. Philadelphia: Saunders College, 1991. 870p.

[56]CHRISTIAN, G. D. Analytical chemistry. 5 ed. New York: John Wiley. 1994. 812p.

[57]LAUBE, N.; MOHR, B.; HESSE, A. Laser-probe-based investigation of the evolution of particle size distributions of calcium oxalate particles formed in artificial urines. Journal of Crystal Growth, v. 233, p. 367-374, 2001.

[58]BEYERS, H.; MALAN, S. F.; Van der Watt, J. G.; Villiers, M. M. Structuresolubility relationship and thermal decomposition of furosemide. Drug Development and Industrial Pharmacy, v. 26, n. 10, p. 1077-1083, 2000. 
[59] GUINESI, L. S.; CAVALHEIRO, E.T.G. Use of DSC curves to determine the acetylation degree of chitin/chitosan samples. Termochimica Acta, v. 444, n. 2, p. 128-133, 2006.

[60] NESMERAK, K.; NEMCOVÁ. Determination of critical micelle concentration by electrochemical means. Analytical Letters, v. 39, p. 1023-1040, 2006.

[61] SHAW, D. J. Introdução à química dos colóides e de superfícies. São Paulo: Edgard Blucher, 1975. 185p.

[62] ZILMAN, A.; SAFRAN, S. A.; STTMANN, T.; STREY, R. Temperature dependence of the thermodynamics and kinetics of micellar solutions.

Langmuir, v. 20, p. 2199-2207, 2004.

[63] TOMINAGA, T. T.; SOARES, D.; DAL-SANTOS, M. A.; SILVA, J.C.Z.; BORGES, C.P.F. Spectroscopic studies of cationic meso-tetrakis(4-N-methylpyridiniumyl) porphyrin (TMPyP) in the presence of ionic micelles of CTAB, SDS and HTS. Exact Soil Science, v. 10, n. 2, p. 7-14, 2004.

[64] DIAS, I. L. T., OLIVEIRA-NETO, G.; MARTINS, J. L. S. Metodologias analíticas para a determinação da furosemida. Lecta, v. 1, p. 19-36, 2004.

[65] RUÍZ-RANGEL, M. J., BERTHOD, A., CARDA-BROCH, S.; GARCIAÁLVAREZ-COQUE, M. C. Analytical techniques for furosemide determination. Separation \& Purification Reviews, v. 35, p. 39-58, 2006.

[66] ADAMS, R. N. Carbon paste electrodes.Analytical Chemistry, v. 30, p. 1576, 1958.

[67] TALLMAN, D. E.; PETERSEN, S. L. Composite electrodes for electroanalysis - principles and applications. Electroanalysis, v. 2, p. 499-510, 1990. 
[68] MENDES, R. K.,CLARO-NETO, S.; CAVALHEIRO, E. T. G. Evaluation of a new rigid carbon-polyurethane polyurethane composite as an electrode material. Talanta, v. 57, p. 909-917, 2002.

[69] MENDES, R. K., CERVINI, P.; CAVALHEIRO, E. T. G. The use of graphitepolyurethane polyurethane composite electrode for the determination of hydroquinone in photographic developers. Talanta, v. 68, p. 708-712, 2006.

[70] CERVINI, P., RAMOS, L. A.; CAVALHEIRO, E. T. G. Determination of atenolol at a graphite-polyurethane composite electrode. Talanta, v. 72, p. 206-209, 2007. 


\section{Anexo 1: Produção Bibliográfica}

\section{Os resultados obtidos no desenvolvimento da presente tese foram}

publicados em periódicos nacionais e internacionais, e em eventos especializados, de abrangência nacional e internacional, como demonstrado a seguir:

SEMAAN, F. S.; PINTO, E. M.; CAVALHEIRO, E. T. G.; BRETT, C. M. A. Graphitepolyurethane composite as electrode material for analysis of furosemida. To be submitted, 2007.

SEMAAN, F. S.; NOGUEIRA, P. A.; CAVALHEIRO, E. T. G. Flow-based fluorimetric determination of furosemide in pharmaceutical formulations and biological samples: use of micelar media to improve sensitivity. Submitted, 2007.

SEMAAN, F. S. ; CAVALHEIRO, E. T. G. Spectrophotometric Determination of Furosemide Based on Its Complexation with Fe(III) in Ethanolic Medium Using a Flow Injection Procedure. Analytical Letters, v. 39, p. 2557-2567, 2006.

SEMAAN, F. S. ; SANTOS NETO, A. J. ; LANÇAS, F. M. ; CAVALHEIRO, E. T. G. Rapid HPLC-DAD determination of furosemide in tablets using a short home-made column. Analytical Letters, v. 38, n. 10, p. 1651-1658, 2005.

SEMAAN, F. S. ; SOUSA, R. A. ; CAVALHEIRO, E. T. G. Flow Injection spectrophotometric determination of furosemide in pharmaceuticals by the bleaching of a permanganate carrier solution. Journal of flow injection analysis, Japão, v. 22, n. 1, p. 34-37, 2005.

SOUSA, R. A. ; SEMAAN, F. S. ; BAIO, J. A. F. ; CAVALHEIRO, E. T. G. Fast determination of minoxidil by photometric flow titration. Eclética Química, Araraquara-SP, v. 30 (3), p. 79-84, 2005.

SEMAAN, F. S.; NOGUEIRA, P. A.; SOUSA, R. A.; CAVALHEIRO, E. T. G. Determinação fluorimétrica de furosemida empregando ambientes micelares e análise em fluxo. In: 30 a Reunião Anual da Sociedade Brasileira de Química, 2007, Águas de Lindóia.

SOUSA, R. A.; SEMAAN, F. S.; CAVALHEIRO, E. T. G. Determinação por FIA de minoxidil em formulações farmacêuticas usando $\mathrm{KMnO}_{4}$ como reagente redox. . In: 30ạ Reunião Anual da Sociedade Brasileira de Química, 2007, Águas de Lindóia.

SEMAAN, F. S. ; CAVALHEIRO, E. T. G. ; BRETT, C. M. A. Graphite-Castor oil polyurethane composite electrodes for the analysis of furosemide. In: 6 Encontro da Divisão de Química Analítica - Sociedade Portuguesa de Química SPQ Analítica '07, 2007, Lisboa.

SEMAAN, F. S. ; SOUSA, R. A. ; GUINESI, L. S. ; CAVALHEIRO, E. T. G. Determinação de parâmetros cinéticos de furosemida e minoxidil por procedimento não-isotérmico. In: V Congresso Brasileiro de Análise Térmica e Calorimetria, 2006, Poços de Caldas.

SOUSA, R. A. ; SEMAAN, F. S. ; CAVALHEIRO, E. T. G. Determinação simultânea de minoxidil e furosemida em amostras comerciais e material biológico sintético. In: II Simpósio Brasileiro de Cromatografia e Técnicas Afins, 2006, São Pedro. 
SEMAAN, F. S. ; SOUSA, R. A. ; CAVALHEIRO, E. T. G. Estudo cromatográfico das reações de hidrólise ácida e oxidação do fármaco furosemida. In: II Simpósio Brasileiro de Cromatografia e Técnicas Afins, 2006, São Pedro.

SEMAAN, F. S. ; NOGUEIRA, P. A. ; CAVALHEIRO, E. T. G. Determinação fluorimétrica de furosemida empregando sistema por injeção em fluxo. In: 14 Simpósio Internacional de Iniciação Científica, 2006, São Paulo.

SEMAAN, F. S. ; SOUSA, R. A. ; CAVALHEIRO, E. T. G. Determinação volumétrica de furosemida em comprimidos por meio de sua reação com $\mathrm{KMnO}_{4}$. In: $28^{\circ}$ Reunião Anual da Sociedade Brasileira de Química, 2005, Poços de Caldas.

SOUSA, R. A. ; SEMAAN, F. S. ; BAIO, J. A. F. ; CAVALHEIRO, E. T. G. Determinação rápida de minoxidil usando titulação volumétrica e titulação espectrofotométrica. In: $28^{\circ}$ reunião anual da Sociedade Brasileira de Química, 2005, Poços de Caldas.

SEMAAN, F. S. ; SOUSA, R. A. ; CAVALHEIRO, E. T. G. Flow Injection spectrophotometric determination of furosemide in pharmaceuticals by the bleaching of a permanganate carrier solution. In: 5th International Congress of Pharmaceutical Sciences, 2005, Ribeirão Preto.

MOUAD, A. M. ; AL-ASFOUR, S. V. ; COUTINHO, C. B. ; SEMAAN, F. S. ; CHIERICE, G. O. Determinação de fosfato iônico na fosfoetanolamina pelo método espectrofométrico do azul de molibdênio: uma comprovação da formação de agregado em solução. In: 15 Encontro Regional de Química da Secretaria Regional Araraquara-Ribeirão Preto e São Carlos- SBQ-ARPSC, 2005, Ribeirão Preto. 